RESEARCH ARTICLE

Open Access

Open Peer-Review

\section{Wood technology: a Glossary and Code for the analysis of archaeological wood from stone tool cultures}

\author{
Annemieke Milks*1,2, Jens Lehmann ${ }^{1}$, Utz

\section{Böhner ${ }^{3}$, Dirk Leder ${ }^{1}$, Tim Koddenberg ${ }^{4}$, Michael} \\ Sietz ${ }^{5}$, Matthias Vogel ${ }^{5}$, Thomas Terberger ${ }^{1,6}$
}

Posted

2022-05-16

Cite as

Milks, A., Lehmann, J., Böhner,

U., Leder, D., Koddenberg, T.,

Sietz, M., Vogel, M. and

Terberger, T. (2022) Wood

technology: a Glossary and

Code for analysis of

archaeological wood from

stone tool cultures. OSF

Preprints, $x 8 \mathrm{~m} 4 \mathrm{j}$, ver. 7 peer-

reviewed and recommended

by Peer community in

Archaeology. https://doi.org/1 $\underline{0.31219 / o s f . i o / x 8 m 4 j}$

Correspondence

a.g.milks@reading.ac.uk

Recommender

Ruth Blasco

Reviewers

Paloma Vidal-Matutano, Eva Martellotta, Oriol López-Bultó, Laura Caruso Fermé

\author{
${ }^{1}$ Department of Hunter-Gatherer Archaeology, Niedersächsisches Landesamt für Denkmalpflege \\ (Lower Saxony State Office for Cultural Heritage). \\ 2 Department of Archaeology, University of Reading. \\ ${ }^{3}$ Inventory and Heritage Atlas, Niedersächsisches Landesamt für Denkmalpflege (Lower Saxony \\ State Office for Cultural Heritage). \\ ${ }^{4}$ Wood Biology and Wood Products, Faculty of Forest Sciences and Forest Ecology, University of \\ Göttingen. \\ ${ }^{5}$ Archaeological Conservation Department, Niedersächsisches Landesamt für Denkmalpflege (Lower \\ Saxony State Office for Cultural Heritage). \\ ${ }^{6}$ Department of Prehistoric Archaeology, University of Göttingen. \\ *Corresponding author
}

This article has been peer-reviewed and recommended by Peer Community in Archaeology https://doi.org/10.24072/pci.archaeo.100015

\section{ABSTRACT}

The analysis of wood technologies created by stone tool-using cultures remains underdeveloped relative to the study of lithic and bone technologies. In recent years archaeologists have begun to approach wood assemblages systematically, developing macro- and micro-analyses of natural and anthropogenic traces often with the assistance of experimental reference samples. The present a lack of established nomenclature hinders intra-site comparisons. Creating this glossary helps will help advance understanding of the use of wood for technological purposes in different times and places. Clear definitions of terms are useful to avoid confusion in ongoing and future evaluations of the biography of wood artefacts. This glossary and associated code is a first step towards a synthesis and standardisation of analytical terms for early wood technologies, focusing on archaeological assemblages from cultures that used stone tools. References and further reading support the selection of terms, and also provide a bibliography of the field of wood technology. This glossary is organised within a chaîne opératoire framework, and is complemented by a developing appendix of images. As a referenced synthesis, it relies on the collective expertise of the authors alongside that of the many cited researchers who have published in the fields of wood science and prehistoric archaeological wood artefacts.

Keywords: prehistoric wood, nomenclature, chaîne opératoire, Palaeolithic, Mesolithic, Neolithic 


\section{Introduction}

In recent decades it has become increasingly evident that wood was a key resource not just in later prehistory, but likely throughout human evolution (e.g. see reviews in Gürbüz \& Lycett 2021; Milks 2021). Chimpanzees, our closest extant relatives, use wood expediently to make proto-cultural wooden tools for subsistence (e.g. Boesch et al. 2009; Luncz et al. 2012; Pruetz et al. 2015) while residues on stone tools suggest that hominins may have worked wood using stone tools from as early as 1.7 million years ago (Dominguez-Rodrigo et al. 2001). Archaeological wooden artefacts from contexts connected to stone tool-using cultures are known from sites in Africa, Australia, Eurasia, and the Americas from the Lower Palaeolithic onwards. They include shaped objects without a clear function, as well as those interpreted as digging sticks, weapons, fire drills, tool handles, tools used in the production of cave art, hearth structures, poison applicators, figurative sculpture, dwelling structures, and much more (e.g. Aranguren et al. 2018; Bamforth 2017; Carbonell \& Castro-Curel 1992; Caruso Fermé et al. 2015; Caruso Fermé et al. 2021a; d'Errico et al. 2012; Jolie et al. 2011; Latorre et al. 2013; López-Bultó \& Piqué Huerta 2018; Lozovskaya and Lozovski 2013; Nadel et al. 2006; Oakley et al. 1977; Piqué et al. 2015; Rios-Garaizar et al. 2018; Schoch et al. 2015; Terberger et al. 2021; Thieme 2000; Vidal-Matutano et al. 2021a; Warren 1911). Yet, in comparison with stone and bone tool technologies, analysis of wooden tools from archaeological sites attributed to stone tool-using cultures remains underdeveloped. The discipline lacks established nomenclature and protocols, and there is a relative dearth of comparative data.

Archaeological sites that are submerged or are in frozen or waterlogged contexts, and which maintain a high level of humidity are most likely to lead to the preservation of wood (e.g. Alix et al. 2012; Aranguren et al. 2018; Bosch et al. 2006; Caruso Fermé et al. 2021b; Clark 2001; Facorellis et al. 2014; Fagan et al. 1966; Nadel et al. 2006; Panagopoulou et al. 2018; Thieme 1997). However, these conditions can also result in greater possibility for taphonomic and post-excavation alterations to the overall morphology and surface traces which in many cases can be permanent (see e.g. Allington-Jones 2015; Rios-Garaizar et al. 2018). In contrast, wood from dry archaeological contexts without significant changes to temperature and humidity can result in better surface preservation, particularly in absence of restoration treatments (e.g. Caruso Fermé \& Civalero 2014; Caruso Fermé \& Aschero 2020; Caruso Fermé et al., 2021a; Gilbert et al. 2008; Latorre et al. 2013; Vidal-Matutano et al. 2021a). In comparison with experimental studies on the manufacture and/or use of wood tools (e.g. Caruso-Fermé et al. 2021a; López-Bultó et al. 2012; Fluck 2015; Milks et al. 2019; Rich et al. 2016), those aimed at understanding the effects of post-depositional environments is underdeveloped (but see Dillehay 1997).

In this glossary, we aim to initiate a synthesis and standardisation of analytical terms for early wood technologies made by societies who used stone tools. It is important to note that human groups with stone tool behaviours encompass significant variability depending, e.g. on site and artefact function embedded in behavioural patterns of different Homo species, subsistence strategies, social structures, mobility patterns, and environments. Thus, although the use of stone tools may be a broadly unifying feature - particularly in terms of a technological analysis - there will inevitably be significant variability in terms of wood selection, products (e.g. small tools versus large dwelling structures), use, discard, and depositional environments.

This glossary and code relies upon the ongoing research and experience of the authors, alongside that of researchers who have systematically analysed, described and imaged wood technologies and traces from stone tool-using cultures. While this glossary of terms forms the foundation for our ongoing analysis and documentation of the wet and conserved woods from the Pleistocene site of Schöningen (Germany), we hope it may also provide a means for 
collaboration and communication with those currently working on wood from other Pleistocene and Holocene sites.

\section{Organisation}

We have organised the glossary into categories including general terms and natural traces, followed by blocks according to a chaîne opératoire framework (Figure 1). General terms are those that may fall into either no phases (e.g. separating natural wood from anthropogenic wood in an assemblage) or multiple phases (e.g. debarking that could occur anthropogenically or naturally) of a chaîne opératoire framework. Natural traces are alterations to wood caused by natural agents (e.g. insects, beaver, fungi) that can affect both unmodified and modified wood prior to, during or after anthropogenic engagement. Phases are as follows: Phase 0 (raw material), Phase 1 (manufacture), Phase 2 (use) with the additional sections of Phase 3 (taphonomy) and Phase 4 (excavation and post-excavation) (following e.g. Geneste 2010; Soressi \& Geneste 2011; Sørensen 2006; Tafelmaier et al. 2020, p.40). An asterisk ${ }^{*}$ ) within a definition or in a figure caption highlights words that are defined elsewhere in the glossary.

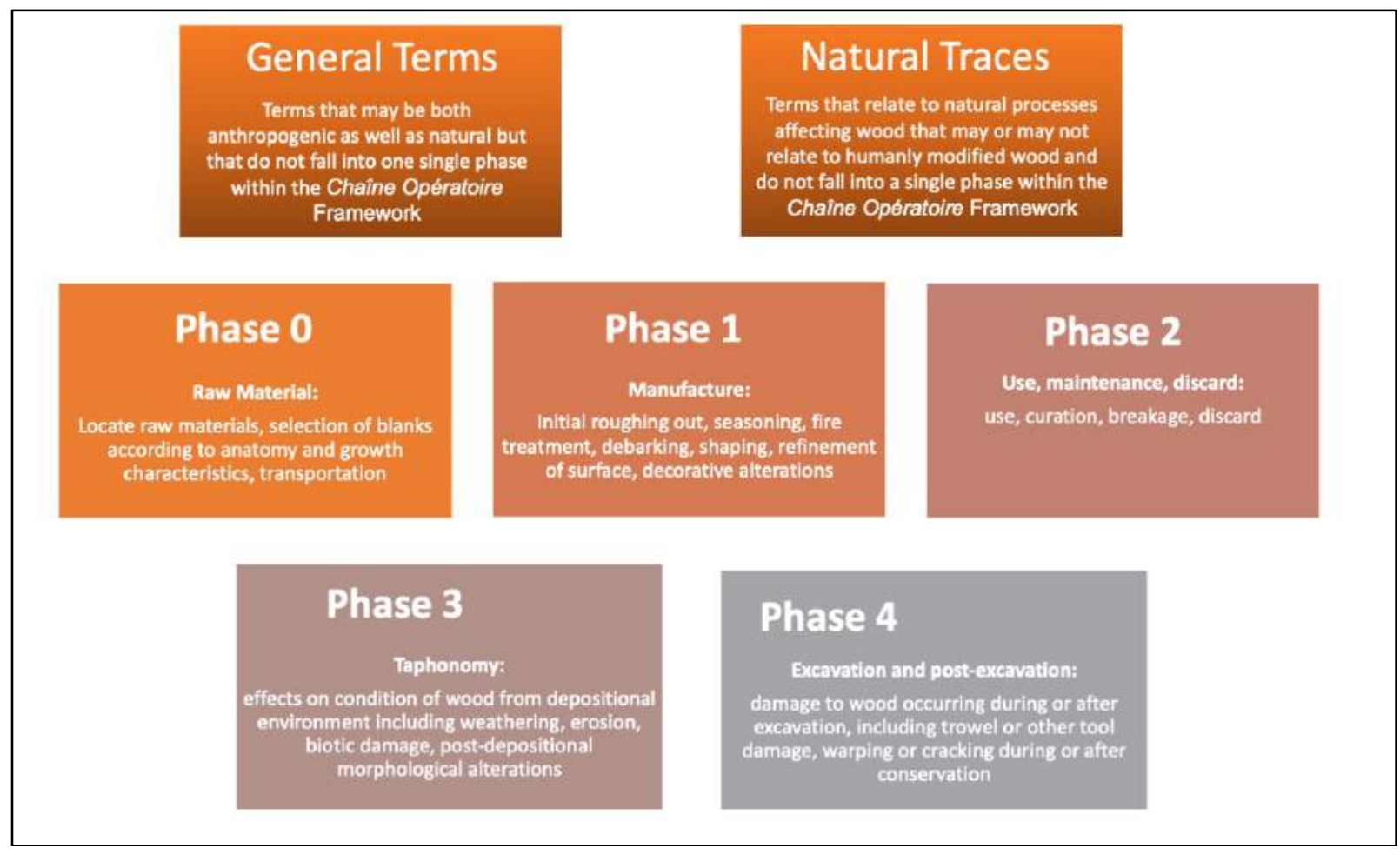

Figure 1. Schematic diagram of the organisation of the glossary with brief explanations.

\section{Terms and Code}

We provide English terms, an associated code, and definitions, often based on or modified from publications with special acknowledgements provided for these definitions. We also provide terms and definitions in German. In cases where terms overlap, or different terms are used in the literature for the same phenomenon, we have attempted to reconcile these differences by selecting a single term and placing alternative terms in brackets. We do not intend that these terms be used rigidly, and especially not so in a grammatical sense, but rather the terms help provide a referenced framework. References, where applicable and available, encompass sources for definitions, further reading, and examples where that term is used in archaeological publications. We have also created some new terms for features we 
have observed in our ongoing analyses of the Schöningen wood artefacts but have not yet seen referenced elsewhere, and thus a small selection of terms lack published citations.

\section{Future Versions}

It is our intention that the glossary remains for the time being as a preprint. In this way the glossary can develop over the coming years as researchers continue to make suggestions to improve the definitions and citations. The preprint server facilitates edits to the work as a new version while preserving older versions. We welcome collaborative and constructive comments from our peers, whether they be those who are analysing wood, or those whose work with other technologies can help expand this research agenda. Researchers who wish to make a substantial new contribution such as a new translation, or the provision of images, are welcome to join the current co-authors in a new preprint version. 


\section{GENERAL TERMS}

\begin{tabular}{|c|c|c|c|c|c|}
\hline Code & English Term & English Description & German Term & German Description & $\begin{array}{l}\text { References and } \\
\text { further reading }\end{array}$ \\
\hline BS & Break Surface & $\begin{array}{l}\text { A surface that is broken or } \\
\text { cracked naturally or } \\
\text { anthropogenically; always } \\
\text { qualified with the } \\
\text { orientation, e.g. transverse, } \\
\text { radial or tangential break } \\
\text { surface. In some instances, } \\
\text { this may result in a surface } \\
\text { fragment*. }\end{array}$ & Bruchfläche & $\begin{array}{l}\text { Fläche, die ausgebrochen } \\
\text { oder gerissen ist, natürlich } \\
\text { oder anthropogen; immer } \\
\text { auf die Ausrichtung } \\
\text { bezogen, z.B. quer, radial } \\
\text { oder tangential } \\
\text { verlaufend. In manchen } \\
\text { Fällen ist ein } \\
\text { Oberflächenfragment }{ }^{*} \text { das } \\
\text { Ergebnis. }\end{array}$ & \\
\hline Cha & Charring & $\begin{array}{l}\text { Partial burning, with the } \\
\text { surface blackened (natural } \\
\text { or anthropogenic). }\end{array}$ & Verkohlung & $\begin{array}{l}\text { Teilweise verbrannt, mit } \\
\text { geschwärzter Oberfläche } \\
\text { (natürlich oder } \\
\text { anthropogen). }\end{array}$ & $\begin{array}{l}\text { Aranguren et al. 2018; } \\
\text { Dillehay 1997, pp. 126, } \\
\text { 144; Fagan \& van } \\
\text { Noten 1971, p.107; } \\
\text { Fluck 2015; Martín- } \\
\text { Seijo 2020; Revedin et } \\
\text { al. 2019; Vidal- } \\
\text { Matutano et al. 2021a; } \\
\text { Vidal-Matutano et al. } \\
\text { 2021b } \\
\text { Use (fire } \\
\text { management): Roberts } \\
\text { et al. } 2022\end{array}$ \\
\hline
\end{tabular}




\begin{tabular}{|c|c|c|c|c|c|}
\hline $\mathrm{Cr}$ & $\begin{array}{l}\text { Crack } \\
\text { (e.g. longitudinal, } \\
\text { transverse, shear) }\end{array}$ & $\begin{array}{l}\text { Narrow, linear break where } \\
\text { the surface has split without } \\
\text { breaking entirely. }\end{array}$ & $\begin{array}{l}\text { Riss } \\
\text { (z.B. längs, quer, schräg) }\end{array}$ & $\begin{array}{l}\text { Schmaler, linearer Bruch } \\
\text { in einer Oberfläche, der } \\
\text { das Material nicht } \\
\text { vollständig durchtrennt. }\end{array}$ & \begin{tabular}{|l|} 
Richter 2015, pp.199- \\
214
\end{tabular} \\
\hline CS & $\begin{array}{l}\text { Cross-Section } \\
\text { (Transverse Plane/ } \\
\text { Cross Cut) }\end{array}$ & $\begin{array}{l}\text { Cut section perpendicular } \\
\text { to the grain or trunk } \\
\text { (transversal plane of } \\
\text { section). Section shows } \\
\text { annual growth rings*, radial } \\
\text { wood rays and also } \\
\text { characteristics from pith* to } \\
\text { bark* }^{*}\left(\text { heartwood }^{*} \text { and }\right. \\
\text { sapwood }\end{array}$ & Querschnitt & $\begin{array}{l}\text { Schnittfläche senkrecht } \\
\text { zum Faserverlauf bzw. } \\
\text { Stamm/Ast. Der Schnitt } \\
\text { zeigt Jahresringe**, radiale } \\
\text { Holzstrahlen und } \\
\text { Merkmale von der } \\
\text { Markröhre* bis zur Rinde* } \\
\text { (Kern*- und Splintholz*). }\end{array}$ & $\begin{array}{l}\text { Hoadley 1990, p. 12; } \\
\text { Piqué et al. 2015; Alix } \\
\text { et al. 2011; Caruso } \\
\text { Fermé et al. 2021b; } \\
\text { Caruso Fermé et al. } \\
2015\end{array}$ \\
\hline DS & Debarked Surface & $\begin{array}{l}\text { A wood surface where the } \\
\text { bark* has been removed }^{*} \text { naturally or } \\
\text { anthropogenically. }\end{array}$ & Entrindete Oberfläche & $\begin{array}{l}\text { Eine Holzoberfläche, bei } \\
\text { der die Rinde* (natürlich } \\
\text { oder anthropogen) } \\
\text { entfernt worden ist. }\end{array}$ & $\begin{array}{l}\text { Bamforth 2017; Rios- } \\
\text { Garaizar et al. 2018; } \\
\text { Aranguren et al. 2018; } \\
\text { Caruso Fermé et al. } \\
\text { 2015; Caruso Fermé et } \\
\text { al. 2021a; Pournou } \\
\text { 2020, p.428 }\end{array}$ \\
\hline $\mathbf{D i}$ & Discolouration & $\begin{array}{l}\text { A difference in colour of the } \\
\text { wood due to natural or } \\
\text { anthropogenic factors such } \\
\text { as residues*, fire, sediment } \\
\text { staining, mineralisation*. }\end{array}$ & Verfärbung & $\begin{array}{l}\text { Farbunterschiede des } \\
\text { Holzes aufgrund } \\
\text { natürlicher oder } \\
\text { anthropogener Faktoren } \\
\text { wie Reststoffe*, Feuer, } \\
\text { Sedimentverschmutzung, } \\
\text { Mineralisation*. }\end{array}$ & $\begin{array}{l}\text { Caruso Fermé et al. } \\
2014\end{array}$ \\
\hline DC & Drying crack & $\begin{array}{l}\text { Crack* in the wood as a } \\
\text { result of shrinking*. }\end{array}$ & $\begin{array}{l}\text { Trocknungsriss oder } \\
\text { Trockenriss }\end{array}$ & $\begin{array}{l}\text { Riss* im Holz durch } \\
\text { Schwindung*. }\end{array}$ & $\begin{array}{l}\text { Richter 2015, p. 200; } \\
\text { Nadel et al. } 2006\end{array}$ \\
\hline
\end{tabular}




\begin{tabular}{|c|c|c|c|c|c|}
\hline FD & Fibre Deformation & $\begin{array}{l}\text { The deformation (bending } \\
\text { or crushing) of fibres* } \\
\text { (single or bundles) that can } \\
\text { occur naturally or } \\
\text { anthropogenically during } \\
\text { manufacture, use, or the } \\
\text { taphonomic phase. Can be } \\
\text { classed according to } \\
\text { morphology, orientation, } \\
\text { and density. Fraying is a } \\
\text { type of fibre deformation. }\end{array}$ & Faserverformung & $\begin{array}{l}\text { Verformung (Biegen oder } \\
\text { Quetschen) von Fasern* } \\
\text { (einzeln oder in Bündeln), } \\
\text { die während der } \\
\text { Herstellung, des } \\
\text { Gebrauchs oder in der } \\
\text { taphonomischen Phase } \\
\text { auftreten kann. Sie kann } \\
\text { nach Morphologie, } \\
\text { Orientierung und Dichte } \\
\text { klassifiziert werden. } \\
\text { Ausfransen ist eine Form } \\
\text { der Faserverformung. }\end{array}$ & $\begin{array}{l}\text { Definition modified } \\
\text { after Vidal-Matutano et } \\
\text { al. 2021a } \\
\text { See also Aranguren et } \\
\text { al. 2018; Rios-Garaizar } \\
\text { et al. } 2018\end{array}$ \\
\hline FI & Flaking & $\begin{array}{l}\text { A small localised area of } \\
\text { surface damage* where a } \\
\text { thin layer of surface } \\
\text { material is lost naturally or } \\
\text { anthropogenically, e.g. due } \\
\text { to use, weathering", or } \\
\text { mineralization*. Often } \\
\text { associated with cracks*. }\end{array}$ & Abplatzung & $\begin{array}{l}\text { Kleine, lokale } \\
\text { Oberflächenbeschädigung } \\
\text { *, natürlich oder } \\
\text { anthropogen, bei der sich } \\
\text { Material abgelöst hat, z.B. } \\
\text { durch Gebrauch, } \\
\text { Verwitterung* oder } \\
\text { Mineralisierung*. }\end{array}$ & $\begin{array}{l}\text { Bone taphonomy: } \\
\text { Fernandez-Jalvo \& } \\
\text { Andrews 2016, p.210 }\end{array}$ \\
\hline No & Notch & $\begin{array}{l}\text { A naturally or } \\
\text { anthropogenically formed } \\
\text { V-shaped or U-shaped } \\
\text { indentation or incision. } \\
\text { Notches are usually } \\
\text { intentionally shaped during } \\
\text { manufacture, but can also } \\
\text { occur during use (e.g. from } \\
\text { percussion) or post- } \\
\text { depositionally. }\end{array}$ & Kerbe & $\begin{array}{l}\text { Eine natürlich oder } \\
\text { anthropogen geformte V- } \\
\text { oder U-förmige Vertiefung } \\
\text { oder Einkerbung. Kerben } \\
\text { werden normalerweise } \\
\text { während der Herstellung } \\
\text { absichtlich geformt, } \\
\text { können aber auch } \\
\text { während des Gebrauchs } \\
\text { (z. B. durch Schlag) oder } \\
\text { nach der Ablagerung } \\
\text { auftreten. }\end{array}$ & $\begin{array}{l}\text { Manufacture: } \\
\text { Aranguren et al. 2018; } \\
\text { Bailey et al. 2020, p. } \\
\text { 58; Bamforth 2017; } \\
\text { López-Bultó et al. } \\
\text { 2012, p. 61; Vidal- } \\
\text { Matutano et al. 2021a; } \\
\text { Dillehay 1997, p. 146; } \\
\text { Nadel et al. 2006; } \\
\text { Piqué et al. 2015; Alix } \\
\text { et al. 2011; Fagan \& } \\
\text { van Noten 1971, p.113 } \\
\text { Usewear: Martellotta et } \\
\text { al. } 2021\end{array}$ \\
\hline
\end{tabular}




\begin{tabular}{|c|c|c|c|c|c|}
\hline Per & Perforation & $\begin{array}{l}\text { Damage of variable size, } \\
\text { form and depth in the form } \\
\text { of a hole that passes } \\
\text { completely through the } \\
\text { object, i.e. with an entry } \\
\text { and exit. Can be natural } \\
\text { (e.g. root damage*) or } \\
\text { anthropogenic (e.g. } \\
\text { drilling). See also } \\
\text { Puncture*. } \\
\text { Note: Not to be confused } \\
\text { with 'perforation plates' in } \\
\text { plant vessels }\end{array}$ & Perforation & $\begin{array}{l}\text { Beschädigung } \\
\text { unterschiedlicher Größe, } \\
\text { Form und Tiefe in Form } \\
\text { eines Lochs, das das } \\
\text { Objekt vollständig } \\
\text { durchdringt, d. h. mit Ein- } \\
\text { und Ausgang. Kann } \\
\text { natürlich (z. B. } \\
\text { Wurzelschäden*) oder } \\
\text { anthropogen (z. B. } \\
\text { Bohren) sein. Siehe auch } \\
\text { Loch*. } \\
\text { Hinweis: Nicht zu } \\
\text { verwechseln mit } \\
\text { „Durchbrechungen“ in } \\
\text { Pflanzengefäßen. }\end{array}$ & $\begin{array}{l}\text { Definition modified } \\
\text { from zooarchaeological } \\
\text { literature: e.g. Duches } \\
\text { et al. 2016; } \\
\text { Gaudzinski- } \\
\text { Windheuser 2016; } \\
\text { Terberger et al. } 2021\end{array}$ \\
\hline $\mathbf{P}$ & $\begin{array}{l}\text { Pitting } \\
\text { (Pecking) }\end{array}$ & $\begin{array}{l}\text { Small, localised damage on } \\
\text { the wood surface in the } \\
\text { form of an indented mark or } \\
\text { groups of indented marks } \\
\text { (compacted or } \\
\text { compressed) without the } \\
\text { removal of material (natural } \\
\text { or anthropogenic). }\end{array}$ & Druckstelle & $\begin{array}{l}\text { Kleiner, örtlich begrenzter } \\
\text { Schaden an der } \\
\text { Holzoberfläche in Form } \\
\text { einer eingedrückten Stelle } \\
\text { oder in Gruppen von } \\
\text { Eindrücken (verdichtet } \\
\text { oder komprimiert) ohne } \\
\text { Materialabtrag (natürlich } \\
\text { oder anthropogen). }\end{array}$ & $\begin{array}{l}\text { Vidal-Matutano et al. } \\
\text { 2021a; Nugent } 2006\end{array}$ \\
\hline $\mathrm{Pu}$ & Puncture & $\begin{array}{l}\text { Damage of variable size, } \\
\text { form and depth in the form } \\
\text { of a hole in the wood } \\
\text { surface that does not fully } \\
\text { perforate* through the } \\
\text { entire object. Can be } \\
\text { natural (e.g. root damage* } \\
\text { or anthropogenic (e.g. } \\
\text { drilling). }\end{array}$ & Loch & $\begin{array}{l}\text { Beschädigung } \\
\text { unterschiedlicher Größe, } \\
\text { Form und Tiefe in Form } \\
\text { eines Lochs in der } \\
\text { Holzoberfläche, das nicht } \\
\text { das gesamte Objekt } \\
\text { vollständig perforiert*. } \\
\text { Kann natürlich (z. B. } \\
\text { Wurzelschaden*) oder } \\
\text { anthropogen (z. B. } \\
\text { Bohren) sein. }\end{array}$ & $\begin{array}{l}\text { Definition modified } \\
\text { from zooarchaeological } \\
\text { literature: e.g. Duches } \\
\text { et al. 2016; } \\
\text { Gaudzinski- } \\
\text { Windheuser } 2016\end{array}$ \\
\hline
\end{tabular}




\begin{tabular}{|c|c|c|c|c|c|}
\hline $\operatorname{Re}$ & $\begin{array}{l}\text { Residue } \\
\begin{array}{r}\text { Residue } \\
\text { Analysis }\end{array}\end{array}$ & $\begin{array}{l}\text { Remains of a substance } \\
\text { deposited on the surface of } \\
\text { wood (natural or } \\
\text { anthropogenic), often } \\
\text { characterised by colour or } \\
\text { texture (e.g. blood, } \\
\text { fat/grease, peat, } \\
\text { adhesives). }\end{array}$ & Reststoff/ Residuum & $\begin{array}{l}\text { Reste einer Substanz auf } \\
\text { der Holzoberfläche } \\
\text { (natürlichen oder } \\
\text { anthropogenen } \\
\text { Ursprungs), oft durch } \\
\text { Farbveränderung sichtbar } \\
\text { (z.B. Blut, Fett/Schmiere, } \\
\text { Torf, Klebstoffe). }\end{array}$ & $\begin{array}{l}\text { Caruso Fermé et al. } \\
\text { 2014; Caruso Fermé et } \\
\text { al. 2015; d'Errico et al. } \\
\text { 2012; Nugent 2006; } \\
\text { Terberger et al. } 2021\end{array}$ \\
\hline Rou & Rounded & $\begin{array}{l}\text { A feature where an edge or } \\
\text { multiple edges are rounded } \\
\text { naturally or } \\
\text { anthropogenically including } \\
\text { deliberate shaping, use or } \\
\text { taphonomic factors. }\end{array}$ & Verrundung & $\begin{array}{l}\text { Merkmal, bei dem eine } \\
\text { oder mehrere Kanten } \\
\text { durch natürliche oder } \\
\text { absichtliche Formgebung, } \\
\text { Gebrauch oder } \\
\text { taphonomische Prozesse } \\
\text { abgerundet sind. }\end{array}$ & $\begin{array}{l}\text { Caruso-Fermé et al. } \\
\text { 2014; Clark 2001, } \\
\text { p.486; Fagan \& van } \\
\text { Noten 1971, p.113; } \\
\text { Martellotta et al. } 2021\end{array}$ \\
\hline SD & Surface Damage & $\begin{array}{l}\text { General term for a wood } \\
\text { surface that is damaged } \\
\text { naturally or } \\
\text { anthropogenically (from } \\
\text { use). There are different } \\
\text { sub-types of surface } \\
\text { damage including torn } \\
\text { surface }^{*} \text {, flaking*, pitting } \\
\text { trampling mark }^{*} \text {, } \\
\text { weathered }^{*}, \text { excavation }^{*} \\
\text { damage }^{*} \text { etc. }\end{array}$ & Oberflächenbeschädigung & $\begin{array}{l}\text { Allgemeiner Begriff für } \\
\text { eine Holzoberfläche, die } \\
\text { auf natürliche Weise oder } \\
\text { durch anthropogene } \\
\text { Einflüsse (Gebrauch) } \\
\text { beschädigt worden ist. } \\
\text { Es gibt verschiedene } \\
\text { Formen der } \\
\text { Oberflächenbeschädigung } \\
\text { wie Ausriss*, Abplatzung*, }^{*} \text { Druckstelle*, Trittspur*, } \\
\text { Verwittert*, } \\
\text { Grabungsbeschädigung*, } \\
\text { etc. }\end{array}$ & \\
\hline SF & Surface Fragment & $\begin{array}{l}\text { A piece of wood broken off } \\
\text { from the surface, which can } \\
\text { be natural or anthropogenic } \\
\text { (from use), but is not a } \\
\text { woodworking fragment; see } \\
\text { Phase } 1 \text { for terms relevant }\end{array}$ & Oberflächenfragment & $\begin{array}{l}\text { Ein aus der Oberfläche } \\
\text { herausgebrochenes } \\
\text { Holzstück (natürlich oder } \\
\text { anthropogen durch } \\
\text { Gebrauch entstanden), } \\
\text { das kein }\end{array}$ & \\
\hline
\end{tabular}




\begin{tabular}{|c|c|c|c|c|c|}
\hline & & $\begin{array}{l}\text { to woodworking including } \\
\text { woodworking chip* and } \\
\text { shaving*. }\end{array}$ & & $\begin{array}{l}\text { Holzbearbeitungsfragmen } \\
\mathrm{t} \text { ist; für die } \\
\text { Holzbearbeitung relevante } \\
\text { Begriffe siehe Phase 1, } \\
\left(\text { Span }(\text { Hobel- })^{*} \text { und Span }\right. \\
\left.(\text { Grob- })^{\star}\right) .\end{array}$ & \\
\hline TS & Transverse Surface & $\begin{array}{l}\text { A surface that is oriented } \\
\text { transversely, across the } \\
\text { grain of a piece of wood, } \\
\text { and perpendicular to the } \\
\text { trunk or branch (created } \\
\text { naturally or } \\
\text { anthropogenically). }\end{array}$ & $\begin{array}{l}\text { Transversalfläche } \\
\text { (Hirnholzfläche) }\end{array}$ & $\begin{array}{l}\text { Fläche, die quer zur } \\
\text { Maserung (Faserverlauf) } \\
\text { des Holzes und senkrecht } \\
\text { zum Stamm oder Ast } \\
\text { ausgerichtet ist (natürlich } \\
\text { oder anthropogen). }\end{array}$ & \\
\hline TaS & $\begin{array}{l}\text { Tangential Section } \\
\text { (Tangential Plane) }\end{array}$ & $\begin{array}{l}\text { Cut section (tangential } \\
\text { plane of section) that is } \\
\text { perpendicular to the wood } \\
\text { rays and parallel to the } \\
\text { grain. }\end{array}$ & Tangentialschnitt & $\begin{array}{l}\text { Schnittfläche parallel zum } \\
\text { Faserverlauf bzw. zur } \\
\text { Stammachse, und } \\
\text { senkrecht zu den } \\
\text { Holzstrahlen. }\end{array}$ & $\begin{array}{l}\text { Hoadley 1990, p. 12; } \\
\text { Piqué et al. 2015; Alix } \\
\text { et al. 2011; Caruso } \\
\text { Fermé et al. 2015; } \\
\text { Caruso Fermé et al. } \\
\text { 2021b; }\end{array}$ \\
\hline RS & $\begin{array}{l}\text { Radial Section } \\
\text { (Radial Plane) }\end{array}$ & $\begin{array}{l}\text { Cut section (radial plane of } \\
\text { section) parallel to the grain } \\
\text { or trunk axis and parallel to } \\
\text { the wood rays. }\end{array}$ & Radialschnitt & $\begin{array}{l}\text { Schnittfläche parallel zur } \\
\text { Stammachse bzw. zum } \\
\text { Faserverlauf und parallel } \\
\text { zu den Holzstrahlen. }\end{array}$ & $\begin{array}{l}\text { Hoadley 1990, p.12; } \\
\text { Piqué et al. 2015; Alix } \\
\text { et al. 2011; Caruso } \\
\text { Fermé et al. 2015; } \\
\text { Caruso Fermé et al. } \\
\text { 2021b }\end{array}$ \\
\hline ARS & Annual Ring Surface & $\begin{array}{l}\text { Exposed or eroded surface } \\
\text { with recognisable annual } \\
\text { rings* (natural or } \\
\text { anthropogenic). }\end{array}$ & Jahresringfläche & $\begin{array}{l}\text { Abgetragene Oberfläche } \\
\text { mit erkennbaren } \\
\text { Jahresringen* (natürlich } \\
\text { oder anthropogen). }\end{array}$ & \\
\hline TAR & $\begin{array}{l}\text { Tangential Annual } \\
\text { Rings }\end{array}$ & $\begin{array}{l}\text { Annual rings that become } \\
\text { visible when a tangential } \\
\text { surface is exposed } \\
\text { (naturally or }\end{array}$ & $\begin{array}{l}\text { Tangential verlaufende } \\
\text { Jahresringe }\end{array}$ & $\begin{array}{l}\text { Bogenförmig verlaufende } \\
\text { Jahresringe innerhalb } \\
\text { einer tangential } \\
\text { abgetragenen Fläche }\end{array}$ & $\begin{array}{l}\text { Wilson \& White1986, } \\
\text { p.183 }\end{array}$ \\
\hline
\end{tabular}




\begin{tabular}{|c|c|c|c|c|c|}
\hline & & $\begin{array}{l}\text { anthropogenically), } \\
\text { characterised by a layered, } \\
\text { arched appearance. }\end{array}$ & & $\begin{array}{l}\text { (natürlich oder } \\
\text { anthropogen). }\end{array}$ & \\
\hline RAR & Radial Annual Rings & $\begin{array}{l}\text { Annual rings that become } \\
\text { visible when a radial } \\
\text { surface is exposed } \\
\text { (naturally or } \\
\text { anthropogenically), } \\
\text { characterised by a parallel } \\
\text { and straight appearance. }\end{array}$ & $\begin{array}{l}\text { Radial verlaufende } \\
\text { Jahresringe }\end{array}$ & $\begin{array}{l}\text { Gerade und parallel } \\
\text { verlaufende Jahresringe } \\
\text { innerhalb einer radial } \\
\text { abgetragenen Fläche } \\
\text { (natürlich oder } \\
\text { anthropogen). }\end{array}$ & $\begin{array}{l}\text { Wilson \& White 1986, } \\
\text { p.183 }\end{array}$ \\
\hline Shr & Shrinking & $\begin{array}{l}\text { Dimensional change in the } \\
\text { wood due to the release of } \\
\text { water from the cell walls } \\
\text { and cell lumina through the } \\
\text { drying process. Shrinkage } \\
\text { can occur in different } \\
\text { directions (e.g. radial } \\
\text { shrinkage), and can result } \\
\text { in drying cracks (radial, } \\
\text { tangential and longitudinal). }\end{array}$ & Schwinden & $\begin{array}{l}\text { Dimensionsveränderung } \\
\text { des Holzes durch Abgabe } \\
\text { von Wasser aus den } \\
\text { Zellwänden und Zellumen } \\
\text { während des } \\
\text { Trocknungsprozesses. } \\
\text { Die Schrumpfung kann in } \\
\text { verschiedene Richtungen } \\
\text { erfolgen (z.B. radiale } \\
\text { Schrumpfung) und zu } \\
\text { Trocknungsrissen* führen } \\
\text { (radial, tangential und } \\
\text { longitudinal). }\end{array}$ & $\begin{array}{l}\text { Stamm 1935; Florian } \\
\text { 1990, p.11-12. } \\
\text { Allington-Jones 2015; } \\
\text { Taylor et al. 2018; } \\
\text { Rios-Garaizar et al. } \\
\text { 2018; Dillehay 1997; } \\
\text { Puhar et al. 2018; Alix } \\
\text { et al. 2011 }\end{array}$ \\
\hline Sp & Splinter & $\begin{array}{l}\text { A wood fragment that is } \\
\text { normally longer than it is } \\
\text { wide. Splinters can be } \\
\text { small or large and can } \\
\text { occur naturally e.g. when } \\
\text { tree trunks snap off the end } \\
\text { grain or laterally from } \\
\text { lightning strikes, or } \\
\text { anthropogenically during } \\
\text { manufacture, or from use. }\end{array}$ & Splitter & $\begin{array}{l}\text { Ein Holzfragment, das in } \\
\text { der Regel länger als breit } \\
\text { ist. Splitter können klein } \\
\text { oder groß sein und auf } \\
\text { natürliche Weise } \\
\text { entstehen, z. B. wenn } \\
\text { Baumstämme am } \\
\text { Hirnholz oder seitlich } \\
\text { durch Blitzeinschläge } \\
\text { umbrechenDiese können } \\
\text { sich auch bei der } \\
\text { Herstellung oder während }\end{array}$ & $\begin{array}{l}\text { Aranguren et al. 2018; } \\
\text { Nugent 2006, p. 94; } \\
\text { Oakley et al. 1977; } \\
\text { Fagan \& van Noten } \\
\text { 1971, p.111; Fagan et } \\
\text { al. } 1966\end{array}$ \\
\hline
\end{tabular}




\begin{tabular}{|c|c|c|c|c|c|}
\hline & & & & $\begin{array}{l}\text { des Gebrauchs eines } \\
\text { Artefakts abspalten. }\end{array}$ & \\
\hline SpN & $\begin{array}{l}\text { Splinter Negative } \\
\text { (Splinter Scar) }\end{array}$ & $\begin{array}{l}\text { Surface damage* where a } \\
\text { splinter has been removed } \\
\text { (naturally or } \\
\text { anthropogenically). }\end{array}$ & Splitternegativ & $\begin{array}{l}\text { Oberflächenbeschädigung } \\
\text { *, bei der ein Splitter* } \\
\text { entfernt wurde (natürlich } \\
\text { oder anthropogen). }\end{array}$ & \\
\hline St & Step & $\begin{array}{l}\text { An abrupt change in height } \\
\text { on the surface (natural or } \\
\text { anthropogenic). }\end{array}$ & Stufe & $\begin{array}{l}\text { Eine abrupte } \\
\text { Veränderung der Höhe an } \\
\text { der Oberfläche (natürlich } \\
\text { oder anthropogen). }\end{array}$ & \\
\hline Str & $\begin{array}{l}\text { Striation } \\
\text { (striae) }\end{array}$ & $\begin{array}{l}\text { Linear marks - grooves } \\
\text { and/or ridges. These can } \\
\text { be natural or } \\
\text { anthropogenic, and can be } \\
\text { produced by tool edges, } \\
\text { abrading with a tool, } \\
\text { additives, use, or } \\
\text { taphonomic factors. They } \\
\text { can be described by } \\
\text { delineation (e.g. straight or } \\
\text { sinuous), cross-sectional } \\
\text { profile (V-shaped, U- } \\
\text { shaped, irregular or } \\
\text { indeterminate), depth, } \\
\text { length (short, medium or } \\
\text { long), orientation (parallel, } \\
\text { transversal, oblique or } \\
\text { multidirectional with respect } \\
\text { to the major axis) and } \\
\text { density (isolated, grouped, } \\
\text { superimposed, etc.). }\end{array}$ & Striae & $\begin{array}{l}\text { Lineare Spuren - Rillen } \\
\text { und/oder Grate. Diese } \\
\text { können natürlichen oder } \\
\text { anthropogen Ursprungs } \\
\text { sein und durch } \\
\text { Werkzeugkanten, } \\
\text { abschleifen mit einem } \\
\text { Werkzeug, Poliermittel, } \\
\text { den Gebrauch oder } \\
\text { taphonomische Faktoren } \\
\text { entstehen. Sie können } \\
\text { durch den Verlauf (z.B. } \\
\text { gerade oder gewunden), } \\
\text { das Querschnittsprofil (V- } \\
\text { förmig, U-förmig, } \\
\text { unregelmäßig oder } \\
\text { unbestimmt), die Tiefe, } \\
\text { die Länge (kurz, mittel } \\
\text { oder lang), die } \\
\text { Ausrichtung (parallel, } \\
\text { quer, schräg oder } \\
\text { multidirektional in Bezug } \\
\text { auf die Hauptachse) und } \\
\text { die Dichte (isoliert, } \\
\text { gruppiert, }\end{array}$ & $\begin{array}{l}\text { Definition modified } \\
\text { after Vidal-Matutano et } \\
\text { al. 2021a } \\
\text { See also: Aranguren et } \\
\text { al. 2018; } \\
\text { Bamford \& Henderson } \\
\text { 2003; Oakley et al. } \\
\text { 1977; Caruso Fermé } \\
\text { 2012; Martellotta et al. } \\
\text { 2021 }\end{array}$ \\
\hline
\end{tabular}




\begin{tabular}{|c|c|c|c|c|c|}
\hline & & & & $\begin{array}{l}\text { übereinanderliegend), } \\
\text { beschrieben werden. }\end{array}$ & \\
\hline TA & Traceological Analysis & $\begin{array}{l}\text { The study of marks that } \\
\text { arise naturally or } \\
\text { anthropogenically, during } \\
\text { the manufacturing, use, } \\
\text { and taphonomic processes. }\end{array}$ & Spurenanalyse & $\begin{array}{l}\text { Das Studium der Spuren, } \\
\text { die durch Herstellungs- } \\
\text { Gebrauchs- und } \\
\text { taphonomische Prozesse } \\
\text { entstanden sind. }\end{array}$ & $\begin{array}{l}\text { López-Bultó et al. } \\
\text { 2012; López-Bultó et } \\
\text { al. 2020; Martellotta et } \\
\text { al. 2021; Vidal- } \\
\text { Matutano et al. 2021a; }\end{array}$ \\
\hline UW & $\begin{array}{l}\text { Use-Wear } \\
\qquad \begin{array}{l}\text { Use-Wear } \\
\text { Analysis }\end{array}\end{array}$ & $\begin{array}{l}\text { Any trace that can be } \\
\text { specifically attributed to use } \\
\text { of a wood fragment or tool } \\
\text { (e.g. polish, fractures, } \\
\text { retouch traces, rounding). }\end{array}$ & $\begin{array}{l}\text { Gebrauchsspuren } \\
\text { - } \begin{array}{l}\text { Gebrauchsspurena } \\
\text { nalyse }\end{array}\end{array}$ & $\begin{array}{l}\text { Jede Spur, die spezifisch } \\
\text { der Verwendung } \\
\text { zugeschrieben werden } \\
\text { kann (z.B. Politur, Brüche, } \\
\text { Gebrauchsretuschen, } \\
\text { Verrundungen). }\end{array}$ & $\begin{array}{l}\text { Caruso Fermé et al. } \\
\text { 2014; Caruso Fermé et } \\
\text { al. 2015; Caruso } \\
\text { Fermé et al. 2021a; } \\
\text { Dillehay 1997; } \\
\text { Martellotta et al. 2021; } \\
\text { Nugent 2006; Vidal- } \\
\text { Matutano et al. 2021a }\end{array}$ \\
\hline Wa & $\begin{array}{l}\text { Warped } \\
\text { (Bent/deformed) }\end{array}$ & $\begin{array}{l}\text { Wood that is bent or twisted } \\
\text { out of shape as a result of } \\
\text { the effects of temperature } \\
\text { or moisture changes. } \\
\text { Warping can be intentional } \\
\text { (anthropogenic), natural } \\
\text { (e.g. heat from bushfires or } \\
\text { variation in moisture), or } \\
\text { can occur during or after } \\
\text { conservation. }\end{array}$ & $\begin{array}{l}\text { Verzogen } \\
\text { (Verbogen/verformt) }\end{array}$ & $\begin{array}{l}\text { Holz, das aufgrund von } \\
\text { Temperatur- oder } \\
\text { Feuchtigkeitsschwankung } \\
\text { en verbogen oder } \\
\text { verdreht ist. Das } \\
\text { Verziehen kann } \\
\text { beabsichtigt } \\
\text { (anthropogen), natürlich } \\
\text { (z. B. Hitze von Feuern } \\
\text { oder } \\
\text { Feuchtigkeitsschwankung } \\
\text { en) oder während oder } \\
\text { nach der Konservierung } \\
\text { auftreten. }\end{array}$ & $\begin{array}{l}\text { Allington-Jones 2015; } \\
\text { Dillehay 1997; } \\
\text { see also Rios-Garaizar } \\
\text { et al. 2018; Puhar et al. } \\
\text { 2015; Clark 2001, } \\
\text { p.486; Alix et al. } 2011\end{array}$ \\
\hline
\end{tabular}




\begin{tabular}{|c|c|c|c|c|c|}
\hline \multicolumn{6}{|c|}{ Natural Traces } \\
\hline Code & English Term & English Description & German Term & German Description & $\begin{array}{l}\text { References and } \\
\text { further reading }\end{array}$ \\
\hline BD & Bacterial Decay & $\begin{array}{l}\text { Decomposition of wood as } \\
\text { a result of bacteria. The } \\
\text { appearance of break } \\
\text { surfaces* are affected, } \\
\text { which are neat. Unlike } \\
\text { wood decay caused by } \\
\text { fungi (rot*), bacterial decay } \\
\text { can also occur with a lack } \\
\text { of oxygen, but the rate of } \\
\text { wood decomposition in this } \\
\text { case is very slow. The } \\
\text { degree of decay is } \\
\text { classifiable (see Macchioni } \\
\text { et al. 2013). }\end{array}$ & Bakterieller Holzabbau & $\begin{array}{l}\text { Holzabbau durch } \\
\text { Bakterien. Von } \\
\text { bakteriellem Abbau } \\
\text { betroffene Hölzer brechen } \\
\text { glatt. Im Gegensatz zu } \\
\text { Holzfäule durch Pilze } \\
\text { (Fäulnis*) kann } \\
\text { bakterieller Abbau auch } \\
\text { bei Sauerstoffmangel } \\
\text { auftreten, allerdings } \\
\text { verläuft er sehr langsam. } \\
\text { Der Abbaugrad ist } \\
\text { klassifizierbar (vgl. } \\
\text { Macchioni et al. 2013). }\end{array}$ & $\begin{array}{l}\text { Definition adapted from } \\
\text { Aranguren et al. } 2018 \\
\text { See also: Macchioni et } \\
\text { al. 2013; Blanchette et } \\
\text { al. 1990 }\end{array}$ \\
\hline BT & Beaver Traces & $\begin{array}{l}\text { Gnaw marks by beaver } \\
\text { teeth. } \\
\text { Figure } 3\end{array}$ & Biberfraßspuren & $\begin{array}{l}\text { Nagespuren von } \\
\text { Biberzähnen. }\end{array}$ & $\begin{array}{l}\text { Coles 2003; Bigga et } \\
\text { al. } 2015\end{array}$ \\
\hline FPI & Faecal Pellets, Insects & $\begin{array}{l}\text { Faecal matter resulting } \\
\text { from the activity of } \\
\text { xylophagus insects*. Frass } \\
\text { is fine faecal matter mixed } \\
\text { with wood fragments. }\end{array}$ & Insektenkot & $\begin{array}{l}\text { Fäkalien, die aus der } \\
\text { Aktivität von Xylophagen } \\
\text { Insekten* resultieren. } \\
\text { Frass sind feine Fäkalien, } \\
\text { die mit Holzfragmenten } \\
\text { vermischt sind. }\end{array}$ & $\begin{array}{l}\text { Abdel-Azeem et al. } \\
\text { 2019; } \\
\text { Marguerie \& Hunot } \\
\text { 2007; Martín-Seijo } \\
\text { 2020; Pournou 2020; } \\
\text { Toriti et al. 2014; Toriti } \\
\text { et al. 2021 }\end{array}$ \\
\hline FTI & Feeding Traces, Insects & $\begin{array}{l}\text { Feeding tunnels and bore } \\
\text { holes in the wood caused } \\
\text { by xylophagus insects*. }\end{array}$ & Insektenfraßspuren & $\begin{array}{l}\text { Fraßgänge und } \\
\text { Bohrlöcher von } \\
\text { Xylophagen Insekten* im } \\
\text { Holz. }\end{array}$ & $\begin{array}{l}\text { Abdal-Azeem et al. } \\
\text { 2019; Clausen 2010; } \\
\text { Pournou 2020; Vidal- } \\
\text { Matutano et al. 2021a; }\end{array}$ \\
\hline
\end{tabular}




\begin{tabular}{|c|c|c|c|c|c|}
\hline & & Figure 4 & & & $\begin{array}{l}\text { Vidal-Matutano et al. } \\
2021 \mathrm{~b} ; \text { Vidal-Matutano } \\
\text { et al. } 2022\end{array}$ \\
\hline Ful & Fungal Infestation & $\begin{array}{l}\text { Infestation of wood by } \\
\text { fungi. There are two } \\
\text { groups: } \\
\text { wood-destroying fungi }\left(\text { rot }^{*}\right) \\
\text { and wood discolouring } \\
\text { fungi (moulds, blue stain). } \\
\text { The degree of decay is } \\
\text { classifiable (e.g. see } \\
\text { Blanchette 2000). }\end{array}$ & Pilzbefall & $\begin{array}{l}\text { Befall von Holz durch } \\
\text { Pilze. Zwei Gruppen: } \\
\text { Holzabbauende Pilze } \\
{\left.\text { (Fäule }{ }^{\star}\right) \text { und }}^{\text {holzverfärbende Pilze }} \\
\text { (Schimmelpilze, Bläue). } \\
\text { Der Zerfallsgrad ist } \\
\text { klassifizierbar (e.g. see } \\
\text { Blanchette 2000). }\end{array}$ & $\begin{array}{l}\text { Clausen, 2010; Richter } \\
\text { 2015, p. 31; Blanchette } \\
\text { 2000; Dillehay 1997, p. } \\
\text { 140; Vidal-Matutano et } \\
\text { al. 2021a; Moskal-del } \\
\text { Hoyo et al. } 2010\end{array}$ \\
\hline Ro & Rot & $\begin{array}{l}\text { Wood degradation caused } \\
\text { by wood-destroying fungi. } \\
\text { There are three groups: } \\
\text { brown rot, white rot and soft } \\
\text { rot. }\end{array}$ & Fäule & $\begin{array}{l}\text { Holzabbau durch } \\
\text { holzzerstörende Pilze, } \\
\text { Drei Gruppen: Braunfäule, } \\
\text { Weißfäule und } \\
\text { Moderfäule. }\end{array}$ & $\begin{array}{l}\text { Forest Products } \\
\text { Laboratory 2010, } \\
\text { Glossary; Blanchette et } \\
\text { al. } 1990 \\
\text { Blanchette 2000; } \\
\text { Macchioni et al. } 2013\end{array}$ \\
\hline $\mathbf{X I}$ & Xylophagus Insects & $\begin{array}{l}\text { Insect species that feed } \\
\text { entirely or almost entirely } \\
\text { on wood, leaving feeding } \\
\text { traces*, and faecal pellets*. }\end{array}$ & Xylophage Insekten & $\begin{array}{l}\text { Insektenarten, die sich } \\
\text { ausschließlich oder fast } \\
\text { ausschließlich von Holz } \\
\text { ernähren und } \\
\text { Fraßspuren* und Kot* } \\
\text { hinterlassen. }\end{array}$ & $\begin{array}{l}\text { Pournou 2020; Solé et } \\
\text { al. 2013; Toriti et al. } \\
\text { 2014; Uzquiano et al. } \\
\text { 2015; Vidal-Matutano } \\
\text { et al. 2021a; Vidal- } \\
\text { Matutano et al. 2021b }\end{array}$ \\
\hline
\end{tabular}




\section{PHASE 0 \\ RAW MATERIALS}

\begin{tabular}{|c|c|c|c|c|c|}
\hline Code & English Term & English Description & German Term & German Description & $\begin{array}{l}\text { References and } \\
\text { further reading }\end{array}$ \\
\hline AGR & $\begin{array}{l}\text { Annual Growth Ring } \\
\text { (tree ring) }\end{array}$ & $\begin{array}{l}\text { Concentric band of wood } \\
\text { tissue that shows annual } \\
\text { tree growth in the growth } \\
\text { period for one year, as } \\
\text { viewed on the cross-section } \\
\text { of a trunk }{ }^{*} \text { and branch*. } \\
\text { Growth rings are } \\
\text { characteristic for trees of } \\
\text { temperate zones and often } \\
\text { consists of earlywood* and } \\
\text { latewood*. It is formed by } \\
\text { the cambium*. Growth rings } \\
\text { are used to estimate the } \\
\text { age and growth } \\
\text { characteristics of the tree, } \\
\text { as well as in } \\
\text { dendrochronology. }\end{array}$ & Jahresring & $\begin{array}{l}\text { Jährliche, konzentrische } \\
\text { Zuwachsschicht eines } \\
\text { Baumes, welche im } \\
\text { Querschnitt von Stamm* } \\
\text { und Ast* erkennbar ist. } \\
\text { Sie werden vom } \\
\text { Kambium* gebildet. Durch } \\
\text { die Jahresringfolge } \\
\text { können Alter und } \\
\text { Wuchsmerkmale eines } \\
\text { Baumes bestimmt } \\
\text { werden. Sie werden auch } \\
\text { für die Dendrochronologie } \\
\text { genutzt. }\end{array}$ & $\begin{array}{l}\text { Richter 2015, p. 94; } \\
\text { Lohmann, 2010, pp. } \\
\text { 647-648; Eaton \& Hale } \\
\text { 1993, p. 7; Rios- } \\
\text { Garaizar et al. 2018; } \\
\text { Schoch et al. 2015; } \\
\text { Bamforth et al. 2018; } \\
\text { Alix et al. } 2011\end{array}$ \\
\hline $\mathrm{Ba}$ & Bark & $\begin{array}{l}\text { Collective term for the outer } \\
\text { layer of trunks* and } \\
\text { branches* of trees. In } \\
\text { general, the bark consists } \\
\text { of the outer bark* and the } \\
\text { inner bark* (bast). }\end{array}$ & Rinde & $\begin{array}{l}\text { Sammelbegriff für das } \\
\text { äußere Abschlussgewebe } \\
\text { an Stämmen*und Ästen* } \\
\text { von Bäumen. Allgemein } \\
\text { besteht die Rinde aus der } \\
\text { Borke* und dem Bast*. }^{*} \text {. }\end{array}$ & $\begin{array}{l}\text { Lohmann 2010, pp. } \\
\text { 996-997 }\end{array}$ \\
\hline $\mathrm{Br}$ & Branch (Limb) & $\begin{array}{l}\text { A part of a tree that grows } \\
\text { laterally from the trunk }{ }^{*} \text { or } \\
\text { from another branch. A } \\
\text { distinction is made between }\end{array}$ & Ast & $\begin{array}{l}\text { Teil eines Baumes, der } \\
\text { seitlich aus dem Stamm* } \\
\text { oder aus einem anderen } \\
\text { Ast* herauswächst. Es }^{*}\end{array}$ & $\begin{array}{l}\text { Richter 2015, p. 65; } \\
\text { Richter 2019, p. } 101\end{array}$ \\
\hline
\end{tabular}




\begin{tabular}{|c|c|c|c|c|c|}
\hline & & $\begin{array}{l}\text { green limbs* and dead } \\
\text { limbs*. }\end{array}$ & & $\begin{array}{l}\text { wird zwischen Grün-* und } \\
\text { Totästen* unterschieden. }\end{array}$ & \\
\hline BC & Branch Collar & $\begin{array}{l}\text { The thickening at the base } \\
\text { of a branch between a } \\
\text { branch* and trunk*, formed } \\
\text { of cambium*. }\end{array}$ & Astring / Astkragen & $\begin{array}{l}\text { Verdickung am Astansatz } \\
\text { zwischen Ast* und } \\
\text { Stamm }^{\star} \text {, die vom } \\
\text { Kambium }^{*} \text { gebildet wird. }\end{array}$ & $\begin{array}{l}\text { Richter 2015, pp. } 65 \text {, } \\
68-69 \text {; Richter 2019, } \\
\text { pp. 101, 118; } \\
\text { Lohmann 2010, p. } 66\end{array}$ \\
\hline BF & Branch Fork & $\begin{array}{l}\text { Location where a branch* } \\
\text { splits in two directions. }\end{array}$ & Astgabel & $\begin{array}{l}\text { Bereich in dem sich ein } \\
\text { Ast }^{*} \text { in zwei Richtungen } \\
\text { aufteilt. }\end{array}$ & Richter 2015, p. 46 \\
\hline Wh & Branch Whorl & $\begin{array}{l}\text { The arrangement of three } \\
\text { or more branches }{ }^{*} \text { at the } \\
\text { same height around the } \\
\text { trunk* of conifer trees. } \\
\text { These branches appear } \\
\text { star-shaped in cross- } \\
\text { section. The term whorl is } \\
\text { only used for conifers. }\end{array}$ & Astquirl & $\begin{array}{l}\text { Anordnung von drei oder } \\
\text { mehr Ästen* auf gleicher } \\
\text { Höhe, die um den Umfang } \\
\text { eines Stammes* verteilt } \\
\text { sind. Diese Äste sind im } \\
\text { Stammquerschnitt } \\
\text { sternförmig angeordnet. } \\
\text { Die Bezeichnung } \\
\text { "Astquirl" wird nur für } \\
\text { Nadelbäume verwendet. }\end{array}$ & $\begin{array}{l}\text { Richter 2015, pp. 69, } \\
\text { 85; Richter 2019, pp. } \\
\text { 110, 118, 133; } \\
\text { see also: Bigga et al. } \\
2015\end{array}$ \\
\hline CT & Callus Tissue & $\begin{array}{l}\text { Tissue that forms in } \\
\text { response to damage/wound } \\
\text { on a living tree, as a means } \\
\text { of providing a protective } \\
\text { external barrier. The wound } \\
\text { is overgrown by the callus } \\
\text { tissue. }\end{array}$ & $\begin{array}{l}\text { Wundgewebe I } \\
\text { Kallusgewebe } \\
\text { (Überwallung) }\end{array}$ & $\begin{array}{l}\text { Gewebe, das sich als } \\
\text { Reaktion auf Schäden an } \\
\text { einem lebenden Baum } \\
\text { bildet, um eine äußere } \\
\text { Schutzbarriere } \\
\text { aufzubauen. Die Wunde } \\
\text { wird durch sogenanntes } \\
\text { Kallusgewebe } \\
\text { überwachsen bzw. } \\
\text { überwallt. }\end{array}$ & Richter 2015, p.66 \\
\hline $\mathbf{C a}$ & Cambium & $\begin{array}{l}\text { A thin layer of biologically } \\
\text { active vascular tissue } \\
\text { between bark }^{*} \text { and wood } \\
\text { that annually produce wood }\end{array}$ & Kambium & $\begin{array}{l}\text { Eine dünne Schicht aus } \\
\text { teilungsfähigem Gewebe } \\
\text { zwischen der Rinde* und } \\
\text { dem Holz, das jährlich }\end{array}$ & $\begin{array}{l}\text { Lohmann 2010, pp. } \\
654-655 ; \text { Taylor et al. } \\
2018\end{array}$ \\
\hline
\end{tabular}




\begin{tabular}{|c|c|c|c|c|c|}
\hline & & $\begin{array}{l}\text { cells inwards and bark } \\
\text { cells outwards. }\end{array}$ & & $\begin{array}{l}\text { Holzzellen nach innen } \\
\text { und Rindenzellen (Bast*) } \\
\text { nach außen produziert. }\end{array}$ & \\
\hline CW & Compression Wood & $\begin{array}{l}\text { Reaction wood }{ }^{*} \text { formed } \\
\text { only by conifers on the side } \\
\text { subject to pressure (e.g., } \\
\text { underside of branches). It } \\
\text { has thicker wood cells, } \\
\text { leading to eccentricity }{ }^{*} \text {. } \\
\text { Compression wood zones } \\
\text { often appear reddish due to } \\
\text { more lignin. } \\
\text { Figure } 5\end{array}$ & Druckholz & $\begin{array}{l}\text { Reaktionsholz*, das nur } \\
\text { von Nadelbäumen auf der } \\
\text { druckbeanspruchten Seite } \\
\text { (z. B. Unterseite von } \\
\text { Ästen) gebildet wird. Es } \\
\text { hat dickere Holzzellen, } \\
\text { welches die } \\
\text { charakteristische, } \\
\text { Exzentrizität* hervorruft. } \\
\text { Druckholzzonen } \\
\text { erscheinen oft rötlich } \\
\text { aufgrund des erhöhten } \\
\text { Ligninanteils. }\end{array}$ & $\begin{array}{l}\text { See Reaction Wood for } \\
\text { technical references } \\
\text { Archaeological } \\
\text { examples: Friedman } \\
\text { 1975, pp121-123 }\end{array}$ \\
\hline $\mathrm{DL}$ & Dead Limb & $\begin{array}{l}\text { Deceased branch*, no } \\
\text { longer connected to the } \\
\text { stem tissue. }\end{array}$ & Totast & $\begin{array}{l}\text { Abgestorbener Seitentrieb } \\
\left(\text { Ast }{ }^{\star}\right), \text { der nicht mehr mit } \\
\text { dem Gewebe des } \\
\text { Baumschaftes } \\
\text { verwachsen ist. }\end{array}$ & $\begin{array}{l}\text { Richter 2015, pp. 65, } \\
\text { 83-84; Richter 2019, } \\
\text { pp. 101-102 }\end{array}$ \\
\hline EW & Earlywood & $\begin{array}{l}\text { Part of the annual growth } \\
\text { ring* that is formed early in } \\
\text { the growing season. It is } \\
\text { often more porous, less } \\
\text { dense, and lighter coloured } \\
\text { than latewood*. The } \\
\text { function is the transport of } \\
\text { water in a living tree. }\end{array}$ & Frühholz & $\begin{array}{l}\text { Bereich in einem } \\
\text { Jahresring*, der zu } \\
\text { Beginn der } \\
\text { Vegetationsperiode } \\
\text { entsteht. Das Frühholz ist } \\
\text { heller, poröser und hat } \\
\text { eine geringere Dichte als } \\
\text { das Spätholz. In einem } \\
\text { lebenden Baum hat es } \\
\text { die Aufgabe Wasser zu } \\
\text { transportieren. }\end{array}$ & $\begin{array}{l}\text { Wagenführ 1999, pp. } \\
\text { 24-27; Lohmann 2010, } \\
\text { p. } 424 \\
\text { López-Bultó \& Piqué } \\
\text { 2018; Vidal-Matutano } \\
\text { et al. } 2022\end{array}$ \\
\hline$E$ & Eccentricity & $\begin{array}{l}\text { The location of the pith* is } \\
\text { off-center in cross-section }\end{array}$ & Exzentrizität & $\begin{array}{l}\text { Die Markröhre* liegt im } \\
\text { Querschnitt von }\end{array}$ & Richter 2015, p.52 \\
\hline
\end{tabular}




\begin{tabular}{|c|c|c|c|c|c|}
\hline & & $\begin{array}{l}\text { of trunks* or branches*. } \\
\text { Eccentricity can be caused } \\
\text { by the formation of reaction } \\
\text { wood*. }^{*}\end{array}$ & & $\begin{array}{l}\text { Stämmen* oder Ästen* } \\
\text { eutlich außerhalb der } \\
\text { geometrischen Mitte. } \\
\text { Exzentrizität kann durch } \\
\text { Bildung von } \\
\text { Reaktionsholz* } \\
\text { hervorgerufen werden. }\end{array}$ & \\
\hline $\mathbf{F i}$ & Fibre & $\begin{array}{l}\text { A wood cell comparatively } \\
\text { long ( } \leq 40 \text { to } 300 \mathrm{~mm},) \\
\text { narrow, tapering, and } \\
\text { closed at both ends. }\end{array}$ & Faser & $\begin{array}{l}\text { Eine vergleichsweise } \\
\text { lange Holzzelle ( } \leq 40 \text { bis } \\
300 \mathrm{~mm} \text { ), schmal, spitz } \\
\text { zulaufend und an beiden } \\
\text { Enden geschlossen. }\end{array}$ & $\begin{array}{l}\text { Forest Products } \\
\text { Laboratory 2010, } \\
\text { Glossary }\end{array}$ \\
\hline GL & Green Limb & $\begin{array}{l}\text { Living side shoots with a } \\
\text { continuous connection to } \\
\text { the stem's cell tissue } \\
\text { (sound branch*) or partially } \\
\text { isolated (dying branch*). }\end{array}$ & Grünast & $\begin{array}{l}\text { Lebender Seitentrieb, der } \\
\text { mit dem Gewebe des } \\
\text { Baumschaftes } \\
\text { verwachsen (gesund) } \\
\text { oder nur noch teilweise } \\
\text { verwachsen ist } \\
\text { (absterbend). }\end{array}$ & $\begin{array}{l}\text { Richter, } 2015 \text { p. } 65-66 ; \\
\text { Richter 2019, pp. 101- } \\
102\end{array}$ \\
\hline HW & Heartwood & $\begin{array}{l}\text { The inner core of a trunk*, } \\
\text { composed of non-living } \\
\text { cells and without } \\
\text { physiological function. In } \\
\text { some tree species (e.g., } \\
\text { oak, pine, larch) it is clearly } \\
\text { darker (coloured } \\
\text { heartwood) than the } \\
\text { sapwood*. } \\
\text { Figure } 2\end{array}$ & Kernholz & $\begin{array}{l}\text { Innerer Kern eines } \\
\text { Stammes*, der aus } \\
\text { abgestorbenen Zellen } \\
\text { besteht und keine } \\
\text { Wasserleitungsfunktion } \\
\text { mehr besitzt. Er ist bei } \\
\text { einigen Baumarten (z. B. } \\
\text { Eiche, Kiefer, Lärche) } \\
\text { deutlich dunkler } \\
\text { (Farbkern) als das } \\
\text { Splintholz*. }\end{array}$ & $\begin{array}{l}\text { Richter 2015, pp. 13- } \\
\text { 14, 58-59; Taylor et al. } \\
\text { 2018; Lohmann 2010, } \\
\text { p. } 542\end{array}$ \\
\hline
\end{tabular}




\begin{tabular}{|c|c|c|c|c|c|}
\hline IB & $\begin{array}{l}\text { Inner Bark } \\
\text { (bast) }\end{array}$ & $\begin{array}{l}\text { The inner bark is in } \\
\text { between the cambium* and } \\
\text { the outer bark*. The } \\
\text { primary function of the bast } \\
\text { is transport of assimilates } \\
\text { and nutrients. Bast cells } \\
\text { live for only a short period } \\
\text { of time, eventually } \\
\text { becoming part of outer } \\
\text { bark*. }^{*} \\
\text { Figure } 6\end{array}$ & Bast & $\begin{array}{l}\text { Der Bast befindet sich } \\
\text { zwischen dem Kambium* } \\
\text { und der Borke*. Die } \\
\text { Hauptfunktion des Bastes } \\
\text { ist der Transport von } \\
\text { Assimilaten und } \\
\text { Nährstoffen. Bastzellen } \\
\text { leben nur kurze Zeit und } \\
\text { werden schließlich Teil } \\
\text { der Borke*. }\end{array}$ & $\begin{array}{l}\text { Rios-Garaizar et al. } \\
\text { 2018; Schoch et al. } \\
\text { 2018; Fletcher et al. } \\
2018\end{array}$ \\
\hline Kn & Knot & $\begin{array}{l}\text { On archaeological woods, } \\
\text { due to their bad } \\
\text { preservation or intensive } \\
\text { processing, it is often no } \\
\text { longer possible to reliably } \\
\text { assess the respective } \\
\text { branch type (e.g. green } \\
\text { limb*, dead limb*). "Knot" is } \\
\text { therefore used as a generic } \\
\text { term for all branch } \\
\text { fragments enclosed in } \\
\text { wood (see also limb scar*). } \\
\text { A more detailed } \\
\text { assessment can sometimes } \\
\text { be made, e.g. sound knot, } \\
\text { black knot, splay knot. }\end{array}$ & $\begin{array}{l}\text { Ast } \\
\text { (überwallt/ überwachsen) }\end{array}$ & $\begin{array}{l}\text { Der Begriff „Ast“ wird wird } \\
\text { im Deutschen auch als } \\
\text { Oberbegriff für die } \\
\text { Beschreibung aller im } \\
\text { Holz überwallten bzw. } \\
\text { überwachsenen Astreste } \\
\text { verwendet (vgl. Glossar } \\
\text { Branch*/Ast*). }\end{array}$ & $\begin{array}{l}\text { Richter 2015, pp. 78- } \\
\text { 84; Richter 2019, pp. } \\
\text { 121-123; } \\
\text { Alix et al. 2011; Rios- } \\
\text { Garaizar et al. 2018; } \\
\text { Schoch et al. 2015; } \\
\text { Revedin et al. 2019; } \\
\text { Hayden 1979a, p. } 26\end{array}$ \\
\hline $\mathbf{K H}$ & Knot Hole & $\begin{array}{l}\text { Hole in the wood of trunks* } \\
\text { or branches caused by } \\
\text { failed branch that has not } \\
\text { grown together. }\end{array}$ & Astloch & $\begin{array}{l}\text { Loch im Holz von } \\
\text { Stämmen* oder Ästen*, } \\
\text { verursacht durch } \\
\text { ausgefallenen, nicht } \\
\text { verwachsenen Ast. }\end{array}$ & Richter 2015, p. 78 \\
\hline LW & Latewood & $\begin{array}{l}\text { Part of the annual growth } \\
\text { ring* that is formed later in } \\
\text { the growing season. It is }\end{array}$ & Spätholz & $\begin{array}{l}\text { Bereich eines } \\
\text { Jahresrings*, der sich } \\
\text { während der }\end{array}$ & $\begin{array}{l}\text { Wagenführ 1999, pp. } \\
\text { 24-27; Lohmann 2010, } \\
\text { p. } 424\end{array}$ \\
\hline
\end{tabular}




\begin{tabular}{|c|c|c|c|c|c|}
\hline & & $\begin{array}{l}\text { denser and darker coloured } \\
\text { than earlywood, especially } \\
\text { with conifers. The function } \\
\text { is the mechanical support } \\
\text { of the tree. }\end{array}$ & & $\begin{array}{l}\text { Vegetationsperiode spät } \\
\text { ausbildet. Spätholz ist } \\
\text { dunkler und dichter als } \\
\text { das Frühholz, vor allem } \\
\text { bei Nadelhölzern. Es } \\
\text { unterstützt die } \\
\text { Standsicherheit eines } \\
\text { Baumes. }\end{array}$ & $\begin{array}{l}\text { López-Bultó \& Piqué } \\
\text { Huerta 2018; Vidal- } \\
\text { Matutano et al. } 2022\end{array}$ \\
\hline LS & Limb Scar & $\begin{array}{l}\text { A callused stub of a branch } \\
\text { or twig left behind on the } \\
\text { trunk* or branch*. Limb } \\
\text { scars are identified by } \\
\text { changes to bark in the area } \\
\text { of the scar, and consist of a } \\
\text { branch collar* and a bark } \\
\text { ridge. A limb scar is an } \\
\text { indication that a knot* } \\
\text { relates to a dead limb*. On } \\
\text { some tree species, they } \\
\text { can also indicate the } \\
\text { direction of growth. }\end{array}$ & Astnarbe & $\begin{array}{l}\text { Überwallter Stumpf eines } \\
\text { Astes oder Zweiges, der } \\
\text { am Stamm* oder Ast* } \\
\text { zurückbleibt. Astnarben } \\
\text { sind an Veränderungen } \\
\text { der Rinde im Bereich der } \\
\text { Narbe zu erkennen und } \\
\text { bestehen aus einem } \\
\text { Astsiegel (Astkragen*) } \\
\text { und einer } \\
\text { Rindenquetschfalte. Eine } \\
\text { Astnarbe ist ein Indikator } \\
\text { dafür, dass ein } \\
\text { überwallter Ast* mit einem } \\
\text { Totast* in Verbindung } \\
\text { steht. Bei manchen } \\
\text { Baumarten können } \\
\text { Astnarben auch die } \\
\text { Wuchsrichtung anzeigen. }\end{array}$ & $\begin{array}{l}\text { Richter 2015, pp. 66, } \\
\text { 83-88, 92; Richter } \\
\text { 2019, pp. 125-126, } \\
\text { 130, 133-136 }\end{array}$ \\
\hline OB & Outer Bark & $\begin{array}{l}\text { The outermost (dead) layer } \\
\text { of the tree. Its primary } \\
\text { function is to protect the } \\
\text { tree from biological and } \\
\text { physical environmental } \\
\text { influences (e.g., insects, } \\
\text { fire, desiccation }{ }^{*} \text {. } \\
\text { Figure } 6\end{array}$ & Borke & $\begin{array}{l}\text { Abgestorbene } \\
\text { Außenschicht des } \\
\text { Baumes. Ihre Funktion ist } \\
\text { der Schutz des Baumes } \\
\text { vor biologischen und } \\
\text { physikalischen } \\
\text { Umwelteinflüssen (z. B. } \\
\text { Insekten, Feuer, } \\
\text { Austrocknung*). }\end{array}$ & $\begin{array}{l}\text { Rios-Garaizar et al. } \\
2018 \text {; Fletcher et al. } \\
2018\end{array}$ \\
\hline
\end{tabular}




\begin{tabular}{|c|c|c|c|c|c|}
\hline $\mathbf{P i}$ & Pith & $\begin{array}{l}\text { Cylindrical tissue of thin- } \\
\text { walled, parenchymatic cells } \\
\text { located within the first } \\
\text { annual growth ring*. In the } \\
\text { cross-section* of branches } \\
\text { and trunks, the pith is } \\
\text { usually located in centre. It } \\
\text { differs in colour and } \\
\text { structure (softer) from the } \\
\text { surrounding heartwood*. } \\
\text { Figure } 6\end{array}$ & Markröhre & $\begin{array}{l}\text { Zylindrisches Gewebe } \\
\text { von dünnwandigen, } \\
\text { parenchymatischen Zellen } \\
\text { innerhalb des ersten } \\
\text { Jahresrings*. Im } \\
\text { Querschnitt* von Ast und } \\
\text { Stamm liegt diese i.d.R. } \\
\text { zentral. Sie unterscheidet } \\
\text { sich in Farbe und Struktur } \\
\text { (weicher) vom } \\
\text { umgebenden Kernholz*. }\end{array}$ & $\begin{array}{l}\text { e.g., Lohmann 2010, } \\
\text { pp. 787-788; Schoch et } \\
\text { al. 2015; Bamforth } \\
\text { 2017; Gaspari et al. } \\
\text { 2011; Bamforth et al. } \\
2018\end{array}$ \\
\hline RW & Reaction Wood & $\begin{array}{l}\text { Wood produced by the tree } \\
\text { as a response to } \\
\text { compensate for external } \\
\text { loading. It can occur on } \\
\text { branches (due to gravity) } \\
\text { and trunks (due to gravity } \\
\text { and/or environmental } \\
\text { conditions). This results in } \\
\text { a region of increased } \\
\text { growth with wider annual } \\
\text { rings* so the cross-section* } \\
\text { is often asymmetric, or } \\
\text { elliptical (see eccentricity*). } \\
\text { Reaction wood differs } \\
\text { chemically and } \\
\text { anatomically from normal } \\
\text { wood. A distinction is made } \\
\text { between compression } \\
\text { wood* for conifers and } \\
\text { tension wood* for } \\
\text { deciduous trees. } \\
\text { Figure } 5\end{array}$ & Reaktionsholz (allgemein) & $\begin{array}{l}\text { Holz, das ein Baum als } \\
\text { Reaktion auf externe } \\
\text { Belastungen bildet, um } \\
\text { diese wieder } \\
\text { auszugleichen. } \\
\text { Es kann sowohl an Ästen } \\
\text { (aufgrund der } \\
\text { Schwerkraft) als auch an } \\
\text { Stämmen (aufgrund der } \\
\text { Schwerkraft und/oder der } \\
\text { Umweltbedingungen) } \\
\text { auftreten. } \\
\text { Hierdurch bildet sich ein } \\
\text { Bereich verstärkten } \\
\text { Wachstums mit breiteren } \\
\text { Jahresringen* aus, } \\
\text { wodurch der Querschnitt* } \\
\text { oft asymmetrisch oder } \\
\text { elliptisch wird (siehe } \\
\text { Exzentrizität*). } \\
\text { Reaktionsholz } \\
\text { unterscheidet sich } \\
\text { chemisch und anatomisch } \\
\text { von Normalholz. Es wird } \\
\text { zwischen Druckholz* bei } \\
\text { Nadelbäumen und }\end{array}$ & $\begin{array}{l}\text { Richter 2015. pp. 52, } \\
\text { 56; Donaldson \& Singh } \\
\text { 2016; Lohmann 2010, } \\
\text { pp. 980-981; Barnett \& } \\
\text { Saranpää 2014; Ruelle } \\
2014\end{array}$ \\
\hline
\end{tabular}




\begin{tabular}{|c|c|c|c|c|c|}
\hline & & & & $\begin{array}{l}\text { Zugholz* bei Laubbäumen } \\
\text { unterschieden. }\end{array}$ & \\
\hline Roo & Root & $\begin{array}{l}\text { Part of the tree that } \\
\text { connects the vegetation } \\
\text { organs with water and } \\
\text { nutrients in the soil, and } \\
\text { anchors the tree. }\end{array}$ & Wurzel & $\begin{array}{l}\text { Teil des Baumes, der die } \\
\text { Vegetationsorgane mit } \\
\text { Wasser und Nährstoffen } \\
\text { im Boden verbindet und } \\
\text { den Baum verankert. }\end{array}$ & \\
\hline SW & Sapwood & $\begin{array}{l}\text { Physiologically active wood } \\
\text { tissue with partially living } \\
\text { cells directly below the } \\
\text { cambium* in the trunk of a } \\
\text { tree. It conducts water from } \\
\text { the root* to the crown for } \\
\text { photosynthesis. In some } \\
\text { tree species the sapwood is } \\
\text { lighter coloured than the } \\
\text { heartwood* (e.g., oak, } \\
\text { pine). } \\
\text { Figure } 2\end{array}$ & Splintholz & $\begin{array}{l}\text { Physiologisch aktives } \\
\text { Holzgewebe mit teilweise } \\
\text { lebenden Zellen im } \\
\text { Stamm eines Baumes, } \\
\text { unmittelbar unter dem } \\
\text { Kambium*. } \\
\text { Es transportiert Wasser } \\
\text { von der Wurzel* zur } \\
\text { Krone für die } \\
\text { Photosynthese. } \\
\text { Bei einigen Baumarten ist } \\
\text { das Splintholz heller als } \\
\text { das Kernholz* (z.B. Eiche, } \\
\text { Kiefer). }\end{array}$ & $\begin{array}{l}\text { Richter } 2015, \text { p. } 52 ; \\
\text { Taylor et al. } 2018\end{array}$ \\
\hline $\mathrm{Se}$ & Seam & $\begin{array}{l}\text { An axially oriented channel- } \\
\text { like depression that can be } \\
\text { formed underneath the } \\
\text { basis of branches. Such } \\
\text { seams can help indicate } \\
\text { the original direction of } \\
\text { growth as well assist in } \\
\text { determining that a fragment } \\
\text { originates from a trunk*. }\end{array}$ & Hohlkehle & $\begin{array}{l}\text { In Faserrichtung } \\
\text { verlaufende rinnenartige } \\
\text { Vertiefung am Stamm, } \\
\text { welche unter Astansätzen } \\
\text { entstehen kann. Solche } \\
\text { Vertiefungen können } \\
\text { helfen, die ursprüngliche } \\
\text { Wuchsrichtung zu } \\
\text { erkennen und zu } \\
\text { bestimmen, ob ein } \\
\text { Fragment von einem } \\
\text { Stamm* stammt. }\end{array}$ & $\begin{array}{l}\text { Richter 2015, pp. 13- } \\
\text { 14, 58-59; Lohmann } \\
2010 \text {, p. } 542\end{array}$ \\
\hline
\end{tabular}




\begin{tabular}{|c|c|c|c|c|c|}
\hline TW & Tension Wood & $\begin{array}{l}\text { Reaction wood* formed } \\
\text { only by deciduous trees on } \\
\text { the side subject to tensile } \\
\text { stress (e.g., top of } \\
\text { branches). Localised wood } \\
\text { increments lead to } \\
\text { eccentricity*. The colour is } \\
\text { often shiny white due to } \\
\text { more cellulose. }\end{array}$ & Zugholz & $\begin{array}{l}\text { Reaktionsholz*, das nur } \\
\text { von Laubbäumen auf der } \\
\text { zugbeanspruchten Seite } \\
\text { (z. B. Oberseite von } \\
\text { Ästen) gebildet wird. } \\
\text { Lokaler Holzzuwachs } \\
\text { führt zur Exzentrizität*. } \\
\text { Die Farbe erscheint oft } \\
\text { schimmernd weiß } \\
\text { aufgrund des erhöhten } \\
\text { Cellulosegehalts. }\end{array}$ & $\begin{array}{l}\text { See Reaction Wood for } \\
\text { technical references }\end{array}$ \\
\hline $\mathrm{Tr}$ & Trunk & $\begin{array}{l}\text { The central main axis of a } \\
\text { tree located between the } \\
\text { root collar and the } \\
\text { branches }^{*} \text { (crown). }\end{array}$ & Stamm & $\begin{array}{l}\text { Zentrale Hauptachse } \\
\text { eines Baumes, die sich } \\
\text { zwischen dem Wurzelhals } \\
\text { und den Ästen* (Krone) } \\
\text { befindet. }\end{array}$ & \\
\hline Wo & Wood & $\begin{array}{l}\text { Wood is a porous and } \\
\text { fibrous structural tissue of } \\
\text { stems and roots of trees. It } \\
\text { is produced by the } \\
\text { cambium* inwards and is } \\
\text { characterized by lignified } \\
\text { (lignocellulosic) cells. The } \\
\text { main functions of wood are } \\
\text { the water transport from the } \\
\text { root to the } \\
\text { photosynthetically active } \\
\text { crown and the mechanical } \\
\text { support/stability of the tree. }\end{array}$ & Holz & $\begin{array}{l}\text { Holz ist ein poröses und } \\
\text { faseriges Strukturgewebe } \\
\text { der Stämme und Wurzeln } \\
\text { von Bäumen. Es wird } \\
\text { durch das Kambium* } \\
\text { nach innen gebildet und } \\
\text { ist durch verholzte } \\
\text { (lignocellulosehaltige) } \\
\text { Zellen gekennzeichnet. } \\
\text { Die Hauptfunktionen des } \\
\text { Holzes liegen im } \\
\text { Wassertransport von der } \\
\text { Wurzel zur } \\
\text { photosynthetisch aktiven } \\
\text { Krone und die } \\
\text { mechanische } \\
\text { Unterstützung/Stabilität } \\
\text { des Baumes. }\end{array}$ & \\
\hline
\end{tabular}




\begin{tabular}{|c|c|c|c|c|c|}
\hline \multicolumn{6}{|c|}{$\begin{array}{c}\text { PHASE } 1 \\
\text { MANUFACTURE }\end{array}$} \\
\hline Code & English Term & English Description & German Term & German Description & $\begin{array}{l}\text { References and } \\
\text { further reading }\end{array}$ \\
\hline AS & $\begin{array}{l}\text { Abraded Surface } \\
\text { (Polish, polished area) }\end{array}$ & $\begin{array}{l}\text { An area with marks, which } \\
\text { reflects a deliberate attempt } \\
\text { to regularise, smooth } \\
\text { and/or polish it. Abraded } \\
\text { surfaces are characterised } \\
\text { by an absence of other tool } \\
\text { marks*, or the presence of } \\
\text { scratches with different } \\
\text { directions and orientations, } \\
\text { and sometimes look } \\
\text { polished (or reflective). } \\
\text { Abrasion marks are created } \\
\text { by a tool surface, not a tool } \\
\text { edge. The material of } \\
\text { abrading tools can be } \\
\text { abiotic (e.g., coarse rock, } \\
\text { stone chips) or organic } \\
\text { (e.g. hide, sea sponge, or } \\
\text { plant material). The gesture } \\
\text { can be multidirectional, and } \\
\text { the resulting multi- } \\
\text { directionality of striations is } \\
\text { what distinguishes them } \\
\text { from scraping marks*. }\end{array}$ & Schliffläche & $\begin{array}{l}\text { Bereich mit Spuren, in } \\
\text { dem die Oberfläche } \\
\text { absichtlich geglättet } \\
\text { und/oder poliert worden } \\
\text { ist. Abrasionsflächen sind } \\
\text { durch das Fehlen anderer } \\
\text { Arbeitsspuren* oder die } \\
\text { Anwesenheit winziger } \\
\text { Kratzer unterschiedlicher } \\
\text { Richtung und Ausrichtung } \\
\text { gekennzeichnet und } \\
\text { sehen manchmal poliert } \\
\text { (oder reflektierend) aus. } \\
\text { Schleifspuren werden } \\
\text { durch eine } \\
\text { Werkzeugoberfläche } \\
\text { erzeugt, nicht durch eine } \\
\text { Werkzeugkante. Das } \\
\text { Material des } \\
\text { Schleifwerkzeugs kann } \\
\text { abiotisch (Grobgestein, } \\
\text { Absplisse) oder organisch } \\
\text { (z. B. Tierhaut, } \\
\text { Meeresschwamm oder } \\
\text { Pflanzenmaterial) sein. } \\
\text { Die Bearbeitungsrichtung }\end{array}$ & $\begin{array}{l}\text { Definition adapted after } \\
\text { Vidal-Matutano et al. } \\
\text { 2021a and } \\
\text { López-Bultó et al. } 2020 \\
\text { See also: Taylor et al. } \\
2018 \text { p. 379; Conard et } \\
\text { al. 2020; Aranguren et } \\
\text { al. 2018; Piqué et al. } \\
\text { 2015; Belitzky et al. } \\
\text { 1991; Caruso Fermé et } \\
\text { al. 2015; Revedin et al. } \\
\text { 2019 }\end{array}$ \\
\hline
\end{tabular}




\begin{tabular}{|c|c|c|c|c|c|}
\hline & & & & $\begin{array}{l}\text { kann multidirektional sein } \\
\text { und die daraus } \\
\text { resultierende } \\
\text { Multidirektionalität der } \\
\text { Striae* unterscheidet sie } \\
\text { von Schabspuren*. }\end{array}$ & \\
\hline BTM & Beaver Tool Marks & $\begin{array}{l}\text { Use of beaver mandibles } \\
\text { and/or teeth by humans in } \\
\text { woodworking activities }\end{array}$ & Biberwerkzeugspuren & $\begin{array}{l}\text { Verwendung von } \\
\text { Biberkiefern und/oder - } \\
\text { zähnen durch Menschen } \\
\text { bei der Holzbearbeitung. }\end{array}$ & $\begin{array}{l}\text { see Lozovskaya and } \\
\text { Lozovski } 2013 \text { for an } \\
\text { archaeological } \\
\text { example. }\end{array}$ \\
\hline $\mathrm{BeC}$ & Bevel Cut (Bevel) & $\begin{array}{l}\text { An artefact deliberately } \\
\text { worked into a bevelled } \\
\text { shape. }\end{array}$ & Schräganschnitt & $\begin{array}{l}\text { Ein Artefakt, das } \\
\text { absichtlich in eine } \\
\text { abgeschrägte Form } \\
\text { gebracht wurde. }\end{array}$ & $\begin{array}{l}\text { López-Bultó et al. } \\
\text { 2012; Vidal-Matutano } \\
\text { et al. 2021a; Caruso } \\
\text { Fermé et al 2021a; } \\
\text { Caruso Fermé \& } \\
\text { Aschero } 2020\end{array}$ \\
\hline CaM & Carving Mark & $\begin{array}{l}\text { Type of tool facet }{ }^{*} \text { created } \\
\text { by pushing or pulling the } \\
\text { wide edge of a tool blade in } \\
\text { one direction, usually at a } \\
\text { working angle of } \leq 45^{\circ} \text {. The } \\
\text { aim is to cut into and } \\
\text { remove material, producing } \\
\text { wood shavings*. (Also } \\
\text { sometimes called whittling). } \\
\text { This creates a wide, } \\
\text { shallow tool facet* with } \\
\text { more surface material } \\
\text { removed than scraping. }\end{array}$ & Schnitzfacette & $\begin{array}{l}\text { Arbeitsfacette*, die beim } \\
\text { Schnitzen/Spanabhub } \\
\text { durch Stoß oder Zug, der } \\
\text { breiten Schneide einer } \\
\text { Werkzeugklinge in eine } \\
\text { Richtung, normalerweise } \\
\text { in einem Arbeitswinkel } \\
\text { von } \leq 45^{\circ} \text {, entsteht. Das } \\
\text { Ziel ist, in das Material } \\
\text { hineinzuschneiden, um } \\
\text { einen Span* zu entfernen. } \\
\text { Hierdurch entsteht eine } \\
\text { breite, flache } \\
\text { Arbeitsfacette } \\
\text { mehr } \text { Oberflächen der } \\
\text { abgetragen wird als beim } \\
\text { Schaben. }\end{array}$ & $\begin{array}{l}\text { Callahan 1995; } \\
\text { Dillehay } 1995\end{array}$ \\
\hline
\end{tabular}




\begin{tabular}{|c|c|c|c|c|c|}
\hline ChaM & Chatter Marks & $\begin{array}{l}\text { A series of tool marks* } \\
\text { caused by a stone tool } \\
\text { edge skipping along the } \\
\text { surface while working in } \\
\text { one direction. These marks } \\
\text { are accidental and likely } \\
\text { occur because the angle, } \\
\text { pressure or tool edge is } \\
\text { imperfect. }\end{array}$ & $\begin{array}{l}\text { Schabwellen } \\
\text { (veraltet: Schrappspur) }\end{array}$ & $\begin{array}{l}\text { Eine Reihe von } \\
\text { Bearbeitungsspuren*, die } \\
\text { entstehen, wenn eine } \\
\text { steinerne Werkzeugkante } \\
\text { beim Arbeiten in eine } \\
\text { Richtung über die } \\
\text { Oberfläche springt. Diese } \\
\text { Spuren sind zufällig und } \\
\text { entstehen wahrscheinlich, } \\
\text { weil der Winkel, der Druck } \\
\text { oder die Werkzeugkante } \\
\text { nicht perfekt sind. }\end{array}$ & $\begin{array}{l}\text { English term used in } \\
\text { Oakley et al. 1977; } \\
\text { Martellotta et al. } 2021 \\
\text { German term } \\
\text { Schrappspur used in: } \\
\text { Jakob-Friesen 1956; } \\
\text { Thieme \& Veil 1985, } \\
\text { p.44 }\end{array}$ \\
\hline ChM & Chopping Mark & $\begin{array}{l}\text { A type of tool mark* created } \\
\text { by a percussive action of a } \\
\text { tool edge at different angles } \\
\text { to the wood surface, } \\
\text { resulting in woodworking } \\
\text { chips* or splinters* being } \\
\text { removed. Such marks are } \\
\text { relatively deep and U- } \\
\text { shaped or V-shaped, with } \\
\text { hinge or step endings } \\
\text { (following the Ho Ho } \\
\text { classification, Hayden } \\
\text { 1979b). }\end{array}$ & Hackspur & $\begin{array}{l}\text { Bearbeitungsspur*, die } \\
\text { durch Schlageinwirkung } \\
\text { einer in verschiedenen } \\
\text { Winkeln zur } \\
\text { Holzoberfläche geführten } \\
\text { Werkzeugschneide } \\
\text { entsteht, wodurch grobe } \\
\text { Späne* oder Splitter* } \\
\text { entfernt werden. Diese } \\
\text { Spuren sind relativ tief } \\
\text { und U- oder V-förmig } \\
\text { ausgebildet, sie enden als } \\
\text { Angelbruch oder Stufen } \\
\text { (vgl. Hayden 1979b). }\end{array}$ & $\begin{array}{l}\text { Definition modified } \\
\text { after Vidal-Matutano et } \\
\text { al. 2021a } \\
\text { Chopping gesture and } \\
\text { marks see also: } \\
\text { Dillehay 1997, p. 122; } \\
\text { Rios-Garaizar et al. } \\
\text { 2018; Fagan \& van } \\
\text { Noten 1971, p.109; } \\
\text { Martellotta et al. 2021; } \\
\text { Hayden 1979a, pp. 24- } \\
\text { 26; Bencomo Viala et } \\
\text { al. 2020; Claud et al. } \\
2015\end{array}$ \\
\hline CM & Cut Mark & $\begin{array}{l}\text { Type of tool mark }{ }^{*} \text { created } \\
\text { by pulling/pushing the } \\
\text { sharp edge of a tool in a } \\
\text { unidirectional motion. The } \\
\text { tool edge is usually } \leq 75^{\circ} \\
\text { and the angle of cutting is } \\
\text { often (but not always) } \\
\text { undertaken at close to a } 90 \\
{ }^{\circ} \text { angle to the surface being }\end{array}$ & Schnittspur & $\begin{array}{l}\text { Bearbeitungsspur*, die } \\
\text { durch Ziehen/Drücken } \\
\text { einer scharfen } \\
\text { Werkzeugschneide in } \\
\text { eine unidirektionaler } \\
\text { Bewegung erzeugt wird. } \\
\text { Der Winkel der } \\
\text { Werkzeugschneide } \\
\text { beträgt normalerweise } \\
\leq 75^{\circ} \text { und der } \\
\end{array}$ & $\begin{array}{l}\text { Definition modified } \\
\text { after Vidal-Matutano et } \\
\text { al. 2021a } \\
\text { See also: Aranguren et } \\
\text { al. 2018; Vidal- } \\
\text { Matutano et al. 2021a; } \\
\text { Bamford \& Henderson } \\
\text { 2003; Alix et al. 2011; } \\
\text { Caruso Fermé et al. } \\
\end{array}$ \\
\hline
\end{tabular}




\begin{tabular}{|c|c|c|c|c|c|}
\hline & & $\begin{array}{l}\text { cut. This results in a } \\
\text { straight cut through the } \\
\text { wood fibres, with either V- } \\
\text { shaped or irregular profiles } \\
\text { depending on the nature of } \\
\text { the tool edge. Cut marks } \\
\text { are variable in length and } \\
\text { direction in respect to the } \\
\text { grain of the wood (e.g. } \\
\text { longitudinally, obliquely, } \\
\text { transversally). }\end{array}$ & & $\begin{array}{l}\text { Schnittwinkel zur } \\
\text { schneidenden Oberfläche } \\
\text { beträgt oft (aber nicht } \\
\text { immer) nahezu } 90^{\circ} \text {. Dies } \\
\text { führt zu einem } \\
\text { geradlinigen Schnitt, der } \\
\text { die Holzfasern mit V- } \\
\text { förmigen oder } \\
\text { unregelmäßigen Profilen } \\
\text { durchtrennt, je nach } \\
\text { Beschaffenheit der } \\
\text { Werkzeugkante. } \\
\text { Schnittspuren sind in } \\
\text { Länge und Richtung, } \\
\text { bezogen auf die } \\
\text { Holzmaserung, variabel } \\
\text { (z.B. längs, schräg, quer). }\end{array}$ & $\begin{array}{l}\text { 2015; Fagan \& van } \\
\text { Noten 1971, p.109; } \\
\text { Fagan et al. 1966; } \\
\text { Revedin et al. } 2019 \\
\text { Cutting: Bencomo Viala } \\
\text { et al. } 2020\end{array}$ \\
\hline EM & $\begin{array}{l}\text { Entry Mark } \\
\text { (Entry Heel) }\end{array}$ & $\begin{array}{l}\text { The start of a single tool } \\
\text { mark* and/or tool facet*}^{*} \text {. } \\
\text { Entry marks are not always } \\
\text { distinguishable features of } \\
\text { tool facets }{ }^{*}, \text { e.g. if they are } \\
\text { shallow. }\end{array}$ & Startmarke & $\begin{array}{l}\text { Der Beginn einer } \\
\text { einzelnen } \\
\text { Bearbeitungsspur* } \\
\text { und/oder Arbeitsfacette*. } \\
\text { Startmarken sind nicht } \\
\text { immer erkennbare } \\
\text { Merkmale von } \\
\text { Arbeitsfacetten*, wenn } \\
\text { diese bspw. flach } \\
\text { beginnen. }\end{array}$ & $\begin{array}{l}\text { "Entry Heel": Sands } \\
1997\end{array}$ \\
\hline FT & $\begin{array}{l}\text { Fire Treatment } \\
\text { (Thermal Alteration) }\end{array}$ & $\begin{array}{l}\text { Traces of the use of fire } \\
\text { that can be attributed to } \\
\text { anthropogenic activity (see } \\
\text { also charring*). Fire and } \\
\text { heat treatment for } \\
\text { manufacturing can be used } \\
\text { to assist for a variety of } \\
\text { reasons such as removal of } \\
\text { material, straightening or }\end{array}$ & $\begin{array}{l}\text { Feuerbehandlung } \\
\text { (Thermische Veränderung) }\end{array}$ & $\begin{array}{l}\text { Spuren der Feuernutzung, } \\
\text { die auf anthropogene } \\
\text { Ursachen zurückgeführt } \\
\text { werden können (siehe } \\
\text { auch Verkohlung*). } \\
\text { Für die Herstellung kann } \\
\text { die Feuer- und } \\
\text { Wärmebehandlung aus } \\
\text { verschiedenen Gründen } \\
\text { eingesetzt werden, bspw. }\end{array}$ & $\begin{array}{l}\text { López-Bultó } \\
\text { et al. 2020; Aranguren } \\
\text { et al. 2018; Rios- } \\
\text { Garaizar et al. 2018; } \\
\text { Gaspari et al. 2011; } \\
\text { Clark 2001; Hayden } \\
\text { 1979a } \\
\text { Thermal alteration: } \\
\text { Caruso Fermé et al. }\end{array}$ \\
\hline
\end{tabular}




\begin{tabular}{|c|c|c|c|c|c|}
\hline & & $\begin{array}{l}\text { intentional warping }{ }^{*} \text {, or } \\
\text { hardening. }\end{array}$ & & $\begin{array}{l}\text { um Material abzutragen, } \\
\text { zum Richten oder } \\
\text { absichtlichen Verziehen* } \\
\text { oder um zu Härten. }\end{array}$ & $\begin{array}{l}\text { 2015; Vidal-Matutano } \\
\text { et al. } 2021 b\end{array}$ \\
\hline OP & Offset Point & $\begin{array}{l}\text { Deliberate shaping of a } \\
\text { point so that the pith* is not } \\
\text { central within a worked } \\
\text { point*. } \\
\text { Figure } 7\end{array}$ & Seitenständige Spitze & $\begin{array}{l}\text { Bewusste Formgebung } \\
\text { einer Spitze, so dass das } \\
\text { Mark* nicht zentral in } \\
\text { einer Spitze liegt. }\end{array}$ & $\begin{array}{l}\text { e.g. as described in } \\
\text { Schoch et al. } 2015\end{array}$ \\
\hline PC & Perimeter Cut & $\begin{array}{l}\text { Deliberate shaping of an } \\
\text { artefact by cutting or } \\
\text { chopping around the } \\
\text { perimeter creating a } \\
\text { cylindrical shape. }\end{array}$ & Umfangsschnitt & $\begin{array}{l}\text { Absichtliches Formen } \\
\text { eines Artefakts durch } \\
\text { Schneiden oder Hacken } \\
\text { um dessen Umfang } \\
\text { herum, wodurch eine } \\
\text { zylindrische Form } \\
\text { entsteht. }\end{array}$ & $\begin{array}{l}\text { Caruso Fermé et al. } \\
2021\end{array}$ \\
\hline PM & Planing / Drawing Mark & $\begin{array}{l}\text { A type of tool facet*. A } \\
\text { planing mark is defined as } \\
\text { a removal of variable length } \\
\text { and slightly concave relief } \\
\text { creating a flat surface by } \\
\text { pushing (wood planing) or } \\
\text { pulling (like using a } \\
\text { drawknife) the wide edge of } \\
\text { a tool, using one or both } \\
\text { hands over the surface at a } \\
\text { low working angle (ca. } 30^{\circ} \\
\text { ). Planing results in } \\
\text { upwardly curved thin wood } \\
\text { shavings*. Working with the } \\
\text { grain* typically leaves a } \\
\text { smooth surface or fine } \\
\text { striations*, while working } \\
\text { against the grain* results in } \\
\text { splintering*. The } \\
\text { morphology differs }\end{array}$ & Hobelspur & $\begin{array}{l}\text { Typ einer Arbeitsfacette*. } \\
\text { Eine Hobelspur ist } \\
\text { definiert als ein Abtrag } \\
\text { von variabler Länge mit } \\
\text { einem leicht konkaven } \\
\text { Relief, der eine ebene } \\
\text { Oberfläche durch Drücken } \\
\text { (Hobeln) oder Ziehen (wie } \\
\text { mit einem Ziehmesser) } \\
\text { der breiten Kante eines } \\
\text { Werkzeugs mithilfe einer } \\
\text { oder beider Hände über } \\
\text { die Oberfläche unter } \\
\text { einem flachen } \\
\text { Arbeitswinkel (ca. } 30^{\circ} \text { ) } \\
\text { erzeugt. Beim Hobeln } \\
\text { entstehen nach oben } \\
\text { gebogene dünne } \\
\text { Holzspäne*. Das Arbeiten } \\
\text { mit der Faser* hinterlässt }\end{array}$ & $\begin{array}{l}\text { Definition modified } \\
\text { after Vidao-Matutano et } \\
\text { al. 2021, Lozovskaya \& } \\
\text { Lozovski 2013, and } \\
\text { Callahan } 1995 \\
\text { See also: Dillehay } \\
\text { 1995, p.122; Caruso } \\
\text { Fermé et al. 2015; } \\
\text { Fagan \& van Noten } \\
\text { 1971, p.110 }\end{array}$ \\
\hline
\end{tabular}




\begin{tabular}{|c|c|c|c|c|c|}
\hline & & $\begin{array}{l}\text { depending on the tool type, } \\
\text { working edge and gestures. } \\
\text { Planing / drawing can lead } \\
\text { to the formation of surface } \\
\text { facets* and stop marks*. } \\
\text { Figure } 8\end{array}$ & & $\begin{array}{l}\text { normalerweise eine glatte } \\
\text { Oberfläche oder feine } \\
\text { Striae*, während das } \\
\text { Arbeiten gegen die } \\
\text { Faser* zu } \\
\text { Aussplitterungen führt } \\
\text { (siehe Splitter*). Die } \\
\text { Morphologie } \\
\text { unterscheidet sich je nach } \\
\text { Werkzeugtyp, } \\
\text { Arbeitskante und Gesten. } \\
\text { Hobeln kann zur Bildung } \\
\text { von } \\
\text { Oberflächenfacettierung } \\
\text { und Stoppmarken* führen. }\end{array}$ & \\
\hline Po & Point & $\begin{array}{l}\text { An artefact deliberately } \\
\text { worked into a pointed } \\
\text { shape (not indicative of } \\
\text { function). }\end{array}$ & Spitze & $\begin{array}{l}\text { Ein Artefakt,, das } \\
\text { absichtlich in eine spitze } \\
\text { Form gebracht wurde } \\
\text { (kein Hinweis auf eine } \\
\text { Funktion). }\end{array}$ & $\begin{array}{l}\text { Aranguren et al 2018; } \\
\text { Rios-Garaizar et al. } \\
\text { 2018; Conard et al. } \\
\text { 2020; Schoch et al. } \\
\text { 2015; Clark 2001, } \\
\text { p.481; Luebbers 1978, } \\
\text { p.130; Fagan et al. } \\
\text { 1966; Hayden 1979a, } \\
\text { p.76 }\end{array}$ \\
\hline RoW & Roundwood & $\begin{array}{l}\text { Blanks used for wooden } \\
\text { tools that consist of wood } \\
<150 \mathrm{~mm} \text { in diameter } \\
\text { (unprocessed or } \\
\text { processed). Larger blanks } \\
\text { are sometimes referred to } \\
\text { as 'timber'. }\end{array}$ & Rundholz & $\begin{array}{l}\text { Englischer Begriff für die } \\
\text { Grundform von } \\
\text { Holzwerkzeugen mit } \\
\text { einem Durchmesser von } \\
<150 \text { mm (bearbeitet oder } \\
\text { unbearbeitet). } \\
\text { Größere Hölzer werden } \\
\text { als Bauholz bezeichnet. }\end{array}$ & $\begin{array}{l}\text { Dillehay 1997, p. 120; } \\
\text { Coles et al. 1978; } \\
\text { Taylor et al. 2018; } \\
\text { O'Sullivan 2007; Rich } \\
\text { et al. } 2016\end{array}$ \\
\hline SaM & Sawing Mark & $\begin{array}{l}\text { A tool mark* resulting from } \\
\text { repeatedly moving the long, } \\
\text { sharp edge of a tool back } \\
\text { and forth over the same }\end{array}$ & Sägespur & $\begin{array}{l}\text { Eine Bearbeitungsspur*, } \\
\text { die durch wiederholtes } \\
\text { Hin- und Herbewegen der } \\
\text { langen, scharfen Kante }\end{array}$ & $\begin{array}{l}\text { Definition modified } \\
\text { after Vidal-Matutano et } \\
\text { al. 2021a }\end{array}$ \\
\hline
\end{tabular}




\begin{tabular}{|c|c|c|c|c|c|}
\hline & & $\begin{array}{l}\text { location. The tool's active } \\
\text { edge is usually sharp }\left(\leq 75^{\circ}\right) \\
\text { with a straight or convex } \\
\text { delineation. The blade edge } \\
\text { may be smooth or } \\
\text { denticulated. The tool edge } \\
\text { is in continuous contact at or } \\
\text { close to a } 90^{\circ} \text { angle to the } \\
\text { material. The gesture } \\
\text { results in linear striations } \\
\text { that vary in length and have } \\
\text { either V-shaped or irregular } \\
\text { profiles. } \\
\text { Note: further work is } \\
\text { required to better } \\
\text { understand the tool mark } \\
\text { traces and profiles that may } \\
\text { be left by unretouched } \\
\text { versus denticulated tool } \\
\text { edges and by unidirectional } \\
\text { 'cutting' and bidirectional } \\
\text { 'sawing'. }\end{array}$ & & $\begin{array}{l}\text { eines Werkzeugs an } \\
\text { gleicher Stelle entsteht. } \\
\text { Die aktive Kante des } \\
\text { Werkzeugs ist } \\
\text { normalerweise scharf } \\
\left(\leq 75^{\circ}\right) \text { mit einem geraden } \\
\text { oder konvexem Verlauf. } \\
\text { Die Klinge kann glatt oder } \\
\text { gezähnt sein. Die } \\
\text { Werkzeugschneide } \\
\text { befindet sich in ständigem } \\
\text { Kontakt zum Material in } \\
\text { einem Arbeitswinkel um } \\
\text { die } 90^{\circ} . \text { Die Bewegung } \\
\text { führt zu unterschiedlich } \\
\text { langen, geradlinigen } \\
\text { Rillen mit entweder V- } \\
\text { förmigen oder } \\
\text { unregelmäßigen Profilen. } \\
\text { Hinweis: Weitere } \\
\text { Experimente sind } \\
\text { erforderlich, um die } \\
\text { Werkzeugspuren und - } \\
\text { profile besser zu } \\
\text { verstehen, die von glatten } \\
\text { vs. gezähnten } \\
\text { Werkzeugkanten } \\
\text { hinterlassen werden } \\
\text { können. }\end{array}$ & $\begin{array}{l}\text { See also: Hayden } \\
\text { 1979a, pp.84-85 } \\
\text { Sawing: Bencomo } \\
\text { Viala et al. } 202\end{array}$ \\
\hline ScM & Scraping Mark & $\begin{array}{l}\text { A type of tool facet* } \\
\text { resulting from dragging or } \\
\text { pushing the wide edge of a } \\
\text { tool blade, usually at a } \\
\text { working angle of between } \\
45^{\circ} \text { and } 90^{\circ} \text {, across the } \\
\text { surface either uni- } \\
\text { directionally or multi- }\end{array}$ & Schabspur & $\begin{array}{l}\text { Typ einer Arbeitsfacette*, } \\
\text { die durch Ziehen oder } \\
\text { Drücken der breiten Kante } \\
\text { einer Werkzeugklinge, } \\
\text { normalerweise in einem } \\
\text { Arbeitswinkel zwischen } \\
45^{\circ} \text { und } 90^{\circ}, \text { über die } \\
\text { Oberfläche, entweder in } \\
\end{array}$ & $\begin{array}{l}\text { Definition modified } \\
\text { after Vidal-Matutano et } \\
\text { al. 2021a, Lozovskaya } \\
\text { \& Lozovski } 2013 \text { and } \\
\text { Callahan } 1995 \\
\text { See also: Aranguren et } \\
\text { al. 2018; Caruso }\end{array}$ \\
\hline
\end{tabular}




\begin{tabular}{|c|c|c|c|c|c|}
\hline & & $\begin{array}{l}\text { directionally. The purpose } \\
\text { is to regularise the surface } \\
\text { without removing significant } \\
\text { portions of the raw material. } \\
\text { Scraping results in multiple } \\
\text { parallel or intersecting } \\
\text { groups of linear striations* } \\
\text { or isolated curved grooves. } \\
\text { Figure } 9\end{array}$ & & $\begin{array}{l}\text { einer oder in mehreren } \\
\text { Richtungen, entsteht. Der } \\
\text { Zweck besteht darin, die } \\
\text { Oberfläche zu glätten, } \\
\text { ohne wesentliche Teile } \\
\text { des Rohmaterials zu } \\
\text { entfernen. Das Schaben } \\
\text { führt zu mehreren } \\
\text { parallelen oder sich } \\
\text { überschneidenden } \\
\text { Gruppen von linearen } \\
\text { Striae* oder isolierten } \\
\text { gekrümmten Rillen. }\end{array}$ & $\begin{array}{l}\text { Fermé et al. 2015; } \\
\text { Martellotta et al. 2021; } \\
\text { Hayden 1979a, p. 27; } \\
\text { Roberts et al. } 2022 \\
\text { Scraping: Bencomo } \\
\text { Viala et al. 2020; Claud } \\
\text { et al. } 2015\end{array}$ \\
\hline Sea & Seasoning & $\begin{array}{l}\text { The process of air-drying } \\
\text { wood. }\end{array}$ & Lufttrocknung & $\begin{array}{l}\text { Der Prozess der } \\
\text { Lufttrocknung von Holz. }\end{array}$ & $\begin{array}{l}\text { Stantzl-Tschegg et al. } \\
2011 \\
\text { Archaeological } \\
\text { references: Coles et al. } \\
\text { 1978, p. 29; Alix et al. } \\
\text { 2011; Rich et al. } 2016\end{array}$ \\
\hline ShF & Shaping Facet & $\begin{array}{l}\text { Small worked facets } \\
\text { typically measuring less } \\
\text { than a few } \mathrm{cm}^{2} \text {, usually with } \\
\text { a concave profile and oval } \\
\text { shape. They are formed by } \\
\text { the use of an adze to shape } \\
\text { the tool. } \\
\text { Figure } 10\end{array}$ & Formungsfacette & $\begin{array}{l}\text { Kleine bearbeitete } \\
\text { Facetten, typischerweise } \\
\text { weniger als ein paar } \mathrm{cm}^{2} \\
\text { groß, normalerweise mit } \\
\text { einem konkaven Profil } \\
\text { und einer ovalen Form. } \\
\text { Sie werden durch die } \\
\text { Verwendung eines } \\
\text { Dechsels erzeugt, um das } \\
\text { Werkzeug zu formen. }\end{array}$ & $\begin{array}{l}\text { Definition modified } \\
\text { after López-Bultó et al. } \\
2020 \\
\text { See also Lozovskaya \& } \\
\text { Lozovski } 2013\end{array}$ \\
\hline SiF & $\begin{array}{l}\text { Side Features } \\
\text { (bone: shoulders) }\end{array}$ & $\begin{array}{l}\text { The left and/or right sides } \\
\text { of a tool mark*. } \\
\text { Figure } 11\end{array}$ & $\begin{array}{l}\text { Seitenmarken } \\
\text { (Knochen: Schultern) }\end{array}$ & $\begin{array}{l}\text { Die linken und/oder } \\
\text { rechten Seiten von } \\
\text { Bearbeitungsspuren*. }\end{array}$ & $\begin{array}{l}\text { Wood: Sands } 1997 \\
\text { Bone: e.g. Bello et al. } \\
\text { 2009; Domínguez- } \\
\text { Rodrigo et al. } 2009\end{array}$ \\
\hline
\end{tabular}




\begin{tabular}{|c|c|c|c|c|c|}
\hline Sig & $\begin{array}{l}\text { Signature } \\
\qquad \begin{array}{l}\text { Signature } \\
\text { analysis }\end{array} \\
\text { (bone: } \text { micro-striations) }\end{array}$ & $\begin{array}{l}\text { A series of ridges or } \\
\text { grooves running down the } \\
\text { long axis of a tool facet }{ }^{*} \text {, } \\
\text { the pattern of which is } \\
\text { created by the tool edge. } \\
\text { This can sometimes be } \\
\text { connected to a unique tool } \\
\text { working edge. } \\
\text { Signature analysis refers to } \\
\text { techniques aimed at } \\
\text { recording and comparing } \\
\text { signatures. } \\
\text { Figure } 11\end{array}$ & $\begin{array}{l}\text { Signatur } \\
\qquad \quad \text { Signaturanalyse } \\
\text { (Knochen: Mikro-Striae) }\end{array}$ & $\begin{array}{l}\text { Eine Reihe von Rippen } \\
\text { oder Rillen, die entlang } \\
\text { der Längsachse einer } \\
\text { Arbeitsfacette* verlaufen, } \\
\text { deren Muster von der } \\
\text { Arbeitskante eines } \\
\text { einzelnen Werkzeugs } \\
\text { erzeugt wird. Dies kann } \\
\text { manchmal mit einer } \\
\text { unverwechselbaren } \\
\text { Werkzeugkante in } \\
\text { Verbindung gebracht } \\
\text { werden. Die } \\
\text { Signaturanalyse bezieht } \\
\text { sich auf Techniken, die } \\
\text { darauf abzielen, } \\
\text { Signaturen zu } \\
\text { dokumentieren und zu } \\
\text { vergleichen. }\end{array}$ & $\begin{array}{l}\text { Definition after Sands } \\
1997 \text { and López-Bultó } \\
\text { et al. } 2020 \\
\text { See also: Coles et al. } \\
1978 \\
\text { Bone: e.g. Bello \& } \\
\text { Galway-Witham } 2019\end{array}$ \\
\hline SpW & Split Wood & $\begin{array}{l}\text { Blanks used for wooden } \\
\text { tools that consist of a } \\
\text { fragment of a trunk } k^{*} \text { or } \\
\text { branch* that has been split } \\
\text { and is often characterised } \\
\text { by splitting marks*. }\end{array}$ & Spaltholz & $\begin{array}{l}\text { Grundformen, die für } \\
\text { Holzwerkzeuge, genutzt } \\
\text { werden, aus einem } \\
\text { Fragment eines } \\
\text { gespaltenen Stammes* } \\
\text { oder Astes* bestehen und } \\
\text { oft durch Spaltflächen* } \\
\text { gekennzeichnet sind. }\end{array}$ & $\begin{array}{l}\text { Dillehay 1997, p.120; } \\
\text { Rich et al. 2016; } \\
\text { López-Bulto et al. } \\
\text { 2020; Alix et al. 2011; } \\
\text { Fagan \& van Noten } \\
\text { 1971, p.111; López- } \\
\text { Bultó \& Piqué } 2018\end{array}$ \\
\hline SpM & $\begin{array}{l}\text { Splitting Mark } \\
\text { (Split Surface) }\end{array}$ & $\begin{array}{l}\text { Surface that results from } \\
\text { modification of the original } \\
\text { roundwood* by splitting. } \\
\text { Occurs due to splitting for } \\
\text { manufacture purposes. } \\
\text { Splitting can be undertaken } \\
\text { radially and tangentially in } \\
\text { various configurations. } \\
\text { Neolithic evidence for } \\
\text { splitting suggests it can be }\end{array}$ & Spaltfläche & $\begin{array}{l}\text { Durch Spaltprozesse } \\
\text { modifizierte Oberfläche } \\
\text { eines Rundholzes*. } \\
\text { Diese entsteht zu } \\
\text { Herstellungszwecken } \\
\text { durch Spaltung. } \\
\text { Die Spaltung kann in } \\
\text { unterschiedlichen } \\
\text { Konfigurationen, radial } \\
\text { und tangential, } \\
\end{array}$ & $\begin{array}{l}\text { Definition modified } \\
\text { after López-Bultó et al. } \\
\text { 2020; } \\
\text { See also: Coles et al. } \\
\text { 1978; Vidal-Matutano } \\
\text { et al. 2021a; Taylor et } \\
\text { al. 2018; Dillehay 1997, } \\
\text { p. 151; Bamforth } 2017\end{array}$ \\
\hline
\end{tabular}




\begin{tabular}{|c|c|c|c|c|c|}
\hline & & $\begin{array}{l}\text { executed with wooden or } \\
\text { antler wedges or chisels, } \\
\text { stone flakes, and stone or } \\
\text { wood hammers. } \\
\text { Converging spltting marks } \\
\text { that feather out can be } \\
\text { referred to as 'Split fading } \\
\text { out'. }\end{array}$ & & $\begin{array}{l}\text { durchgeführt werden. } \\
\text { Neolithische Belege für } \\
\text { die Spalttechnik deuten } \\
\text { darauf hin, dass sie mit } \\
\text { Holz- oder Geweihkeilen } \\
\text { oder Meißeln, } \\
\text { Steinsplittern und Stein- } \\
\text { oder Holzhämmern } \\
\text { ausgeführt werden kann. } \\
\text { Konvergierende } \\
\text { Spaltflächen, die } \\
\text { auslaufen, können als } \\
\text { „auslaufende Spatfläche“ } \\
\text { bezeichnet werden. }\end{array}$ & $\begin{array}{l}\text { Fading out: Bamforth } \\
2017 \\
\text { Use of stone wedges: } \\
\text { Hayden } 1979 a\end{array}$ \\
\hline SM & $\begin{array}{l}\text { Stop Mark } \\
\text { (Jam) }\end{array}$ & $\begin{array}{l}\text { The termination of a tool } \\
\text { mark*, usually in the form } \\
\text { of a step* that is } \\
\text { perpendicular to a tool } \\
\text { facet*, indicating the } \\
\text { direction of working. Stop } \\
\text { marks can be characterised } \\
\text { as ending in a feather, step } \\
\text { or hinge termination } \\
\text { (following the Ho Ho } \\
\text { Classification, Hayden } \\
\text { 1979b). } \\
\text { Figure } 11\end{array}$ & Stoppmarke & $\begin{array}{l}\text { Das Ende einer } \\
\text { Bearbeitungsspur, in der } \\
\text { Regel in Form einer Stufe, } \\
\text { senkrecht zur } \\
\text { Arbeitsfacette }{ }^{\star} \text {, die die } \\
\text { Arbeitsrichtung anzeigt. } \\
\text { Stoppmarken können in } \\
\text { Feder-, Stufen- oder } \\
\text { Angelbrüchen enden } \\
\text { (vergl. Hayden 1979b). }\end{array}$ & $\begin{array}{l}\text { Taylor et al. 2018, p. } \\
\text { 354; Bamforth, 2017, p. } \\
102 \\
\text { "Jam": Sands } 1997\end{array}$ \\
\hline SuF & Surface Facet & $\begin{array}{l}\text { A flat surface that is shaped } \\
\text { by repeated fine processing } \\
\text { of wood in the same place. } \\
\text { Adjacent facet surfaces are } \\
\text { separated from one another } \\
\text { by an edge. Surface } \\
\text { facetting can be created by } \\
\text { planing }^{*}, \text { scraping } \\
\text {, or }\end{array}$ & Oberflächenfacettierung & $\begin{array}{l}\text { Ebene Fläche, die durch } \\
\text { wiederholtes feines } \\
\text { Abarbeiten von Holz an } \\
\text { gleicher Stelle entsteht. } \\
\text { Benachbarte Facetten } \\
\text { sind durch einen Kante } \\
\text { voneinander getrennt. } \\
\text { Eine } \\
\text { Oberflächenfacettierung }\end{array}$ & \\
\hline
\end{tabular}




\begin{tabular}{|c|c|c|c|c|c|}
\hline & & $\begin{array}{l}\text { abrading* to regularise a } \\
\text { surface. }\end{array}$ & & $\begin{array}{l}\text { kann durch Hobeln*, } \\
\text { Schaben* oder Schleifen* } \\
\text { entstehen, um eine } \\
\text { Oberfläche zu ebnen. }\end{array}$ & \\
\hline TF & Tool Facet & 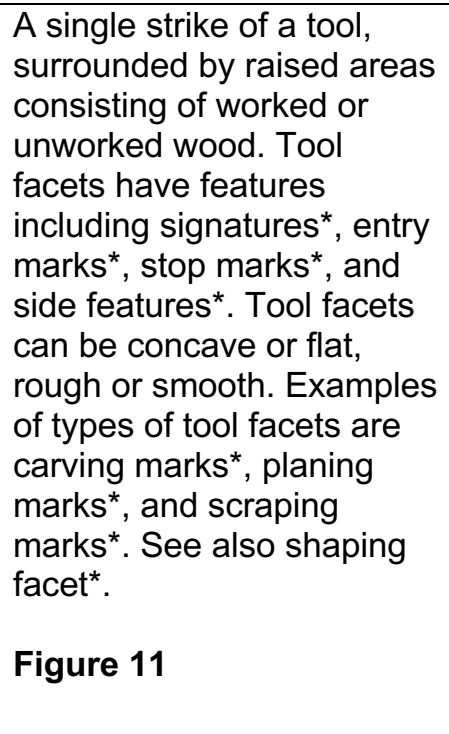 & Arbeitsfacette & $\begin{array}{l}\text { Eine einzelne Spur eines } \\
\text { Werkzeugs, umgeben von } \\
\text { bearbeitetem oder } \\
\text { unbearbeitetem Holz und } \\
\text { einer erhöhten Fläche. } \\
\text { Arbeitsfacetten besitzen } \\
\text { Merkmale wie } \\
\text { Signaturen*, } \\
\text { Startmarken*, } \\
\text { Stoppmarken*, und } \\
\text { Seitenmarken*. Sie } \\
\text { können konkav oder flach, } \\
\text { rau oder glatt sein. } \\
\text { Beispiele für } \\
\text { Arbeitsfacetten sind } \\
\text { Schnitzfacetten*, Hobel-* } \\
\text { und Schabspuren*. Siehe } \\
\text { auch Formungsfacette*. }\end{array}$ & $\begin{array}{l}\text { Definition modified } \\
\text { after Sands } 1997 \\
\text { See also: Taylor et al. } \\
\text { 2018, p. 396; Coles et } \\
\text { al. 1978, Plate 2; } \\
\text { Bamforth et al. 2018, p. } \\
352\end{array}$ \\
\hline TM & $\begin{array}{l}\text { Tool Mark } \\
\text { (Manufacturing Mark) }\end{array}$ & $\begin{array}{l}\text { A term for any mark(s) } \\
\text { made by tools on wood. }\end{array}$ & Bearbeitungsspur & $\begin{array}{l}\text { Oberbegriff für jegliche } \\
\text { durch Werkzeug } \\
\text { verursachte Spur(en) auf } \\
\text { Holz. }\end{array}$ & $\begin{array}{l}\text { López-Bultó et al. } \\
\text { 2020; López-Bulto \& } \\
\text { Piqué 2018; Vidal- } \\
\text { Matutano et al. 2021a; } \\
\text { Martellotta et al. 2021; } \\
\text { Schoch et al. 2015; } \\
\text { Belitzky et al. 1991 } \\
\text { (absence thereof); } \\
\text { Vidal-Matutano et al. } \\
\text { 2021b }\end{array}$ \\
\hline ToS & Torn Surface & $\begin{array}{l}\text { A woodworking term for } \\
\text { when wood fibres* are } \\
\text { deliberately torn away, e.g. } \\
\text { when green limbs* are torn }\end{array}$ & Ausriss & $\begin{array}{l}\text { Ein Begriff aus der } \\
\text { Holzbearbeitung für das } \\
\text { absichtliche Abreißen von } \\
\text { Holzfasern*, z.B. wenn }\end{array}$ & $\begin{array}{l}\text { Bamforth 2017; } \\
\text { Bamforth et al. } 2018\end{array}$ \\
\hline
\end{tabular}




\begin{tabular}{|c|c|c|c|c|c|}
\hline & & $\begin{array}{l}\text { off. Tears are sometimes } \\
\text { associated with chopping } \\
\text { marks* ('chop and tear'). } \\
\text { Figure } 12\end{array}$ & & $\begin{array}{l}\text { Grünäste* abgerissen } \\
\text { werden. Ausrisse können } \\
\text { zusammen mit } \\
\text { Hackspuren* auftreten } \\
\text { („,Hacken und ausreißen“). }\end{array}$ & \\
\hline WC & Wood Chip & $\begin{array}{l}\text { A type of woodworking } \\
\text { debris (debitage), in the } \\
\text { form of a small amorphous } \\
\text { wood fragment that is } \\
\text { removed from the surface } \\
\text { during manufacture (e.g. } \\
\text { the debitage from chopping } \\
\text { marks }{ }^{*} \text {. }\end{array}$ & Span (Grob-) & $\begin{array}{l}\text { Holzbearbeitungsabfall in } \\
\text { Form eines kleinen, } \\
\text { amorphen Holzfragments, } \\
\text { das bei der Herstellung } \\
\text { von der Oberfläche } \\
\text { entfernt wird (z.B. } \\
\text { Spaltabfall einer } \\
\text { Hackspur*). }\end{array}$ & $\begin{array}{l}\text { Rich et al. 2016; } \\
\text { Bamforth 2017; } \\
\text { Dillehay 1997, p. 152; } \\
\text { Clark 2001, p.482; } \\
\text { Fagan \& van Noten } \\
\text { 1971, p.107 }\end{array}$ \\
\hline WSh & Wood Shaving & $\begin{array}{l}\text { A type of woodworking } \\
\text { debris (debitage), in the } \\
\text { form of a thin curled strip } \\
\text { cut off of a surface during } \\
\text { carving }{ }^{*} \text { or planing*. } \\
\text { Figure } 13\end{array}$ & Span (Hobel-) & $\begin{array}{l}\text { Holzbearbeitungsabfall, in } \\
\text { Form eines dünnen, } \\
\text { gebogenen oder gerollten } \\
\text { Streifens, der beim } \\
\text { Schnitzen* oder Hobeln* } \\
\text { von einer Oberfläche } \\
\text { abgeschnitten wird. }\end{array}$ & Hayden 1979a, p. 27 \\
\hline AcG & $\begin{array}{l}\text { Working across the } \\
\text { Grain }\end{array}$ & $\begin{array}{l}\text { Cutting angle to the grain } \\
\text { direction in the workpiece } \\
>90^{\circ} \text {. } \\
\text { Depending on the wood } \\
\text { properties and the tool } \\
\text { sharpness characterised by } \\
\text { a worked surface with fine } \\
\text { broken fibres and tear-outs. }\end{array}$ & Arbeiten quer zur Faser & $\begin{array}{l}\text { Schnittwinkel zum } \\
\text { Faserverlauf } 90^{\circ} . \\
\text { Abhängig von den } \\
\text { Holzeigenschaften und } \\
\text { der Klingenschärfe kann } \\
\text { die bearbeitete } \\
\text { Oberfläche feine } \\
\text { Faserbrüche und Ausrisse } \\
\text { aufweisen. }\end{array}$ & Hayden 1979a, p.92 \\
\hline AG & $\begin{array}{l}\text { Working against the } \\
\text { Grain }\end{array}$ & $\begin{array}{l}\text { The cutting angle with } \\
\text { respect to the grain }\end{array}$ & Arbeiten gegen die Faser & $\begin{array}{l}\text { Schnittwinkel zum } \\
\text { Faserverlauf am }\end{array}$ & \\
\hline
\end{tabular}




\begin{tabular}{|c|c|c|c|c|}
\hline & & $\begin{array}{l}\text { direction of the workpiece is } \\
>90 \text { and }<180^{\circ} \text {. } \\
\text { Depending on the wood } \\
\text { properties and the tool } \\
\text { sharpness characterised by } \\
\text { a worked surface with fine } \\
\text { broken fibres and/or tear- } \\
\text { outs. } \\
\text { Figure } 14\end{array}$ & & $\begin{array}{l}\text { Werkstück }>90^{\circ} \text { und } \\
<180^{\circ} \text {. } \\
\text { Abhängig von den } \\
\text { Holzeigenschaften und } \\
\text { der Klingenschärfe kann } \\
\text { die bearbeitete } \\
\text { Oberfläche feine } \\
\text { Faserbrüche und/oder } \\
\text { Ausrisse aufweisen. }\end{array}$ \\
\hline WG & Working with the Grain & $\begin{array}{l}\text { The cutting angle with } \\
\text { respect to the grain } \\
\text { direction of the workpiece is } \\
<90^{\circ} \text {. Characterised by a } \\
\text { worked surface without fine } \\
\text { broken fibres. } \\
\text { Figure } 15\end{array}$ & Arbeiten mit der Faser & $\begin{array}{l}\text { Schnittwinkel zum } \\
\text { Faserverlauf am } \\
\text { Werkstück }<90^{\circ} \text {. } \\
\text { Bearbeitete Oberfläche } \\
\text { ohne Faserbrüche und } \\
\text { Ausrisse. }\end{array}$ \\
\hline
\end{tabular}




\section{PHASE 2 \\ USE, MAINTENANCE, DISCARD}

\begin{tabular}{|c|c|c|c|c|c|}
\hline Code & English Term & English Description & German Term & German Description & $\begin{array}{l}\text { References and } \\
\text { further reading }\end{array}$ \\
\hline BFr & Bevelled Fracture & $\begin{array}{l}\text { Oblique fracture that starts } \\
\text { on the side of a point*, } \\
\text { breaking off its distal } \\
\text { portion, resulting in a step-, } \\
\text { hinge- or bevel-shaped } \\
\text { proximal termination. } \\
\text { Figure } 16\end{array}$ & Schrägbruch & $\begin{array}{l}\text { Schrägfraktur, die an der } \\
\text { Seite einer Spitze* } \\
\text { beginnt, den distalen Teil } \\
\text { der Spitze abbricht und } \\
\text { ein stufen- oder } \\
\text { falzförmiges oder schräg } \\
\text { auslaufendes proximales } \\
\text { Ende aufweist. }\end{array}$ & $\begin{array}{l}\text { Term based on bone } \\
\text { projectile point } \\
\text { damage: Pétillon et al. } \\
\text { 2016; Stodiek 1993, } \\
\text { Plates } 112-113\end{array}$ \\
\hline Fu & $\begin{array}{l}\text { Furrow } \\
\text { (Gouging) }\end{array}$ & $\begin{array}{l}\text { Removal of material as a } \\
\text { result of dragging across a } \\
\text { bone or other hard surface } \\
\text { during use; characterised } \\
\text { by and differentiated from } \\
\text { tool marks* by irregular } \\
\text { edges. }\end{array}$ & Furche & $\begin{array}{l}\text { Material, das durch eine } \\
\text { Bewegung bei der } \\
\text { Berührung mit einer } \\
\text { Knochenoberfläche oder } \\
\text { einem anderen harten } \\
\text { Material abgetragen } \\
\text { worden ist; } \\
\text { gekennzeichnet durch } \\
\text { unregelmäßige Kanten. } \\
\text { Furchen gehören nicht zu } \\
\text { den Bearbeitungsspuren*. }\end{array}$ & $\begin{array}{l}\text { As seen from } \\
\text { experiments in Milks } \\
2018, \text { p. } 399\end{array}$ \\
\hline $\mathrm{ICr}$ & Impact Crack & $\begin{array}{l}\text { A surface crack* caused by } \\
\text { flexing and bending the } \\
\text { wood during a sudden high- } \\
\text { energy impact. }\end{array}$ & Aufprallriss & $\begin{array}{l}\text { Ein Oberflächenriss, der } \\
\text { durch Biegen und } \\
\text { Beugen des Holzes } \\
\text { während eines plötzlichen } \\
\text { Aufpralls mit hoher } \\
\text { Energie verursacht wird. }\end{array}$ & Roberts et al. 2022 \\
\hline IP & $\begin{array}{l}\text { Impact-induced } \\
\text { Peeling }\end{array}$ & $\begin{array}{l}\text { Small detachments of a thin } \\
\text { layer of wooden surface as }\end{array}$ & Aufprallabplatzung & $\begin{array}{l}\text { Kleine Ablösungen einer } \\
\text { dünnen Schicht der }\end{array}$ & $\begin{array}{l}\text { Eva Martellotta, pers. } \\
\text { comm. }\end{array}$ \\
\hline
\end{tabular}




\begin{tabular}{|c|c|c|c|c|c|}
\hline & & $\begin{array}{l}\text { a result of flexion or impact, } \\
\text { e.g. during use as a } \\
\text { retoucher. This type of use } \\
\text { wear from use as a } \\
\text { retoucher occurs when the } \\
\text { trajectory of the impact is } \\
\text { parallel to the lithic edge. }\end{array}$ & & $\begin{array}{l}\text { Holzoberfläche durch } \\
\text { Biegen oder Schlag, z.B. } \\
\text { beim Einsatz als } \\
\text { Retuscheur. Diese Art von } \\
\text { Gebrauchsspur durch den } \\
\text { Einsatz als Retuscheur } \\
\text { tritt auf, wenn die } \\
\text { Bewegungsbahn des } \\
\text { Aufpralls parallel zur } \\
\text { Steinkante verläuft. }\end{array}$ & \\
\hline LC & Longitudinal Crushing & $\begin{array}{l}\text { Damage in which the } \\
\text { original point* material has } \\
\text { been compressed* and } \\
\text { flattened, or bent, with or } \\
\text { without material being } \\
\text { removed. }\end{array}$ & $\begin{array}{l}\text { Stauchung in } \\
\text { Längsrichtung }\end{array}$ & $\begin{array}{l}\text { Schlagschaden, bei dem } \\
\text { das ursprüngliche } \\
\text { Material der Spitze* } \\
\text { zusammengedrückt und } \\
\text { abgeflacht oder verbogen } \\
\text { wurdeund auch Material } \\
\text { abgetragen werden kann. }\end{array}$ & $\begin{array}{l}\text { Term based on bone } \\
\text { projectile point } \\
\text { damage: Pétillon et al. } \\
2016\end{array}$ \\
\hline SB & Shaft Break & $\begin{array}{l}\text { A transverse break on the } \\
\text { shaft of a worked artefact, } \\
\text { which was likely broken } \\
\text { during use, characterised } \\
\text { by longer and uneven } \\
\text { break surfaces*, sometimes } \\
\text { with splinter negatives* } \\
\text { originating from the shaft } \\
\text { break. } \\
\text { Figure } 17\end{array}$ & Schaftbruch & $\begin{array}{l}\text { Ein Querbruch am Schaft } \\
\text { eines bearbeiteten } \\
\text { Artefakts, das } \\
\text { wahrscheinlich } \\
\text { während des Gebrauchs } \\
\text { zerbrach. Der Bruch wird } \\
\text { durch längere und } \\
\text { ungleichmäßige } \\
\text { Bruchflächen* } \\
\text { gekennzeichnet, } \\
\text { manchmal auch mit } \\
\text { Splitternegativen*, die } \\
\text { vom Schaftbruch } \\
\text { stammen. }\end{array}$ & $\begin{array}{l}\text { As seen from } \\
\text { experiments in Milks } \\
2018, \text { Appendix } 1\end{array}$ \\
\hline TSp & Tip Split & $\begin{array}{l}\text { Longitudinal breaking apart } \\
\text { of a point* without the } \\
\text { separation of the two } \\
\text { sections. It may originate } \\
\text { from the tip of the point }\end{array}$ & $\begin{array}{l}\text { Spitzenspaltung } \\
\text { (Aufspaltung) }\end{array}$ & $\begin{array}{l}\text { Längsbruch durch eine } \\
\text { Spitze*, ohne dass ein } \\
\text { Bruchstück abgetrennt } \\
\text { wird. } \\
\text { Er beginnt an der Spitze } \\
\text { selbst oder kann direkt }\end{array}$ & $\begin{array}{l}\text { Allington-Jones 2015; } \\
\text { Milks 2018, Appendix } 1\end{array}$ \\
\hline
\end{tabular}




\begin{tabular}{|c|c|c|c|c|c|}
\hline & & $\begin{array}{l}\text { itself, or just below the tip } \\
\text { along the shaft. } \\
\text { Figure } 18\end{array}$ & & $\begin{array}{l}\text { unterhalb der Spitze } \\
\text { entlang des Schaftes } \\
\text { auftreten. }\end{array}$ & \\
\hline UP & Use Polish & $\begin{array}{l}\text { Polish that develops during } \\
\text { use, particularly when } \\
\text { isolated on a specific part } \\
\text { of a wood artefact. Polish } \\
\text { can further characterised } \\
\text { by type (e.g. bright polish) } \\
\text { and direction (e.g. } \\
\text { 'longitudinal polish' and } \\
\text { 'horizontal polish'). }\end{array}$ & Gebrauchspolitur & $\begin{array}{l}\text { Politur, die auf den } \\
\text { Gebrauch zurückgeführt } \\
\text { werden kann, } \\
\text { insbesondere wenn sie an } \\
\text { einem bestimmten Teil } \\
\text { eines Holzgegenstandes } \\
\text { isoliert ist. Politur kann } \\
\text { weiter durch Art (z. B. } \\
\text { Glanzpolitur) und } \\
\text { Richtung (z. B. } \\
\text { "Längspolitur" und } \\
\text { "Horizontalpolitur") } \\
\text { charakterisiert werden. }\end{array}$ & $\begin{array}{l}\text { Taylor et al. } 2018 \text { p. } \\
\text { 369, p.375; Caruso } \\
\text { Fermé et al. 2014; } \\
\text { Caruso Fermé et al. } \\
\text { 2015; Nadel et al. } \\
\text { 2006; Martellotta et al. } \\
\text { 2021 }\end{array}$ \\
\hline WA & Wear Abrasion & $\begin{array}{l}\text { Surface abrasion that can } \\
\text { be attributed to use. }\end{array}$ & Abnutzungsabrieb & $\begin{array}{l}\text { Durch Nutzung } \\
\text { abgeriebene Oberfläche. }\end{array}$ & $\begin{array}{l}\text { López-Bultó et al. } \\
\text { 2012; López-Bultó et } \\
\text { al. 2020; Nugent 2006; } \\
\text { Caruso Fermé et al. } \\
\text { 2014; Caruso Fermé \& } \\
\text { Aschero } 2020\end{array}$ \\
\hline
\end{tabular}




\section{PHASE 3 \\ TAPHONOMY}

\begin{tabular}{|c|c|c|c|c|c|}
\hline Code & English Term & English Description & German Term & German Description & $\begin{array}{l}\text { References and } \\
\text { further reading }\end{array}$ \\
\hline Del & $\begin{array}{l}\text { Delaminated } \\
\text { (bone: exfoliation) }\end{array}$ & $\begin{array}{l}\text { Wood or bark that is falling } \\
\text { apart either along the rays } \\
\text { or the annual growth rings } \\
\text { often associated with } \\
\text { desiccation*. }\end{array}$ & Delamination (Aufblättern) & $\begin{array}{l}\text { Holz oder Rinde, die } \\
\text { entweder entlang der } \\
\text { Strahlen oder der } \\
\text { Jahresringe* } \\
\text { auseinanderfallen, oft } \\
\text { verbunden mit } \\
\text { Austrocknung*. }\end{array}$ & Fletcher et al. 2018 \\
\hline Des & Desiccation & $\begin{array}{l}\text { Drying out of wood in the } \\
\text { depositional environment. } \\
\text { Permanent desiccation can } \\
\text { lead to the preservation of } \\
\text { wood and can alter surface } \\
\text { modifications. }\end{array}$ & Austrocknung & $\begin{array}{l}\text { Das Austrocknen von } \\
\text { Holz in der } \\
\text { Ablagerungsumgebung. } \\
\text { Dauerhafte Austrocknung } \\
\text { kann zur Konservierung } \\
\text { führen; die Austrocknung } \\
\text { verändert die } \\
\text { Oberflächenmodifika- } \\
\text { tionen. }\end{array}$ & $\begin{array}{l}\text { Taylor et al. 2018; } \\
\text { Vidal-Matutano et al. } \\
\text { 2021a }\end{array}$ \\
\hline Fle & Flecked & $\begin{array}{l}\text { A surface marked or dotted } \\
\text { with small patches of } \\
\text { discolouration*. }\end{array}$ & Gefleckt & $\begin{array}{l}\text { Eine Oberfläche mit } \\
\text { Verfärbungen*in Form } \\
\text { kleiner, gesprenkelter } \\
\text { Flecken }\end{array}$ & \\
\hline RD & Root Damage & $\begin{array}{l}\text { Damage to wood (post- } \\
\text { depositional) caused by the } \\
\text { growth roots from plants } \\
\text { growing in the depositional } \\
\text { environment. }\end{array}$ & Wurzelschaden & $\begin{array}{l}\text { Schäden am Holz (post- } \\
\text { depositional), durch das } \\
\text { Wurzelwachstum von } \\
\text { Pflanzen in der } \\
\text { Ablagerungsumgebung. }\end{array}$ & $\begin{array}{l}\text { Taylor et al. 2018; } \\
\text { Dillehay 1997, pp. 136, } \\
140\end{array}$ \\
\hline
\end{tabular}




\begin{tabular}{|c|c|c|c|c|c|}
\hline SE & Sediment Erosion & $\begin{array}{l}\text { The eroding of the surface } \\
\text { due to sediment movement. }\end{array}$ & Sedimentschliff & $\begin{array}{l}\text { Die Erosion der } \\
\text { Oberfläche durch } \\
\text { Sedimentbewegung. }\end{array}$ & $\begin{array}{l}\text { Vidal-Matutano et al. } \\
\text { 2021a }\end{array}$ \\
\hline SeM & Sediment Mark & $\begin{array}{l}\text { Pitting* in the surface } \\
\text { caused by compression* of } \\
\text { sediment and/or small } \\
\text { pebbles into the surface. }\end{array}$ & Sedimenteindruck & $\begin{array}{l}\text { Druckstelle* in der } \\
\text { Oberfläche, verursacht } \\
\text { durch eine Kompression } \\
\text { von Sediment und/oder } \\
\text { kleinen Kieselsteinen in } \\
\text { die Oberfläche (siehe } \\
\text { Kompressionsspur*). }\end{array}$ & \\
\hline Co & $\begin{array}{l}\text { Taphonomic } \\
\text { Compression }\end{array}$ & $\begin{array}{l}\text { Post-depositional } \\
\text { compaction that occurs } \\
\text { when the wood has } \\
\text { become soft from } \\
\text { degradation. The } \\
\text { compression can affect the } \\
\text { entire wood or occur } \\
\text { locally. Compression can } \\
\text { affect wood in multiple } \\
\text { directions leading to } \\
\text { distorted transversal cross- } \\
\text { section, and/or distortion of } \\
\text { the original longitudinal } \\
\text { shape. }\end{array}$ & $\begin{array}{l}\text { Taphonomische } \\
\text { Kompression }\end{array}$ & $\begin{array}{l}\text { Post-Depositionale } \\
\text { Quetschung, die während } \\
\text { der Lagerung auftritt, } \\
\text { wenn das Holz durch } \\
\text { Abbauprozesse weich } \\
\text { geworden ist. Die } \\
\text { Kompression kann das } \\
\text { gesamte Holz betreffen } \\
\text { oder lokal auftreten. } \\
\text { Kompression kann das } \\
\text { Holz in mehreren } \\
\text { Richtungen beeinflussen, } \\
\text { was zu einem verzerrten } \\
\text { Querquerschnitt und/oder } \\
\text { einer Verzerrung der } \\
\text { ursprünglichen Längsform } \\
\text { führt. }\end{array}$ & $\begin{array}{l}\text { Taylor et al. 2018; } \\
\text { Bamforth et al. 2018; } \\
\text { Dillehay 1997, p. 140; } \\
\text { Belitzky et al. } 1991\end{array}$ \\
\hline TaF & Taphonomic Fracture & $\begin{array}{l}\text { A fracture that occurred } \\
\text { post-depositionally, } \\
\text { characterised by shorter } \\
\text { fibres due because of } \\
\text { decomposition of the wood. }\end{array}$ & Taphonomischer Bruch & $\begin{array}{l}\text { Ein post-depositionaler } \\
\text { Bruch, der aufgrund einer } \\
\text { fortgeschrittenen } \\
\text { Zersetzung des Holzes } \\
\text { durch kürzere oder nicht } \\
\text { vorhandene Fasern } \\
\text { gekennzeichnet wird. }\end{array}$ & Aranguren et al 2018 \\
\hline
\end{tabular}




\begin{tabular}{|c|c|c|c|c|c|}
\hline TapS & $\begin{array}{l}\text { Taphonomically } \\
\text { Smoothed }\end{array}$ & $\begin{array}{l}\text { Damage to wood that has } \\
\text { been present in moving } \\
\text { water, resulting in rounded } \\
\text { and smoothed surfaces } \\
\text { (e.g. driftwood). See also } \\
\text { rounded*, which can be } \\
\text { taphonomic or } \\
\text { anthropogenic. }\end{array}$ & $\begin{array}{l}\text { Taphonomische } \\
\text { Verrundung }\end{array}$ & $\begin{array}{l}\text { Schäden am Holz, das } \\
\text { sich in bewegtem Wasser } \\
\text { befunden hat, was zu } \\
\text { stark verrundeten und } \\
\text { geglätteten Oberflächen } \\
\text { führt (z. B. Treibholz). } \\
\text { Siehe auch Verrundung } \\
\text { die auch taphonomisch } \\
\text { oder anthropogen } \\
\text { entstanden sein kann. }\end{array}$ & $\begin{array}{l}\text { Dillehay 1997, p. } 128 \\
\text { (taphonomically } \\
\text { 'smoothed'); Clark } \\
2001, \text { p.484 } \\
\text { ('smoothed') }\end{array}$ \\
\hline TrM & Trampling Mark & $\begin{array}{l}\text { Damage caused by animals } \\
\text { or humans walking on the } \\
\text { wood. }\end{array}$ & Trittspur & $\begin{array}{l}\text { Schäden, die durch } \\
\text { tierische oder } \\
\text { menschliche Tritte } \\
\text { verursacht wurden. }\end{array}$ & $\begin{array}{l}\text { Vidal-Matutano et al. } \\
\text { 2021a }\end{array}$ \\
\hline We & Weathered & $\begin{array}{l}\text { Wood degradation (mostly } \\
\text { the surface) after outdoor } \\
\text { exposure (e.g. UV light, } \\
\text { rain, wind, freeze-thaw). } \\
\text { Weathered wood is grey } \\
\text { and its surface is often } \\
\text { cracked }^{*} \text {, flaked }{ }^{*} \text {, and } \\
\text { rough. Not generally } \\
\text { colonized by fungi. } \\
\text { Weathering can be } \\
\text { classified by stage (see } \\
\text { Dillehay } 1997) \text {. Weathered } \\
\text { wood can be eroded, } \\
\text { usually by rain, and the } \\
\text { erosion rate }(\mu m / h) \text { varies } \\
\text { by wood species (see Feist } \\
1990) .\end{array}$ & Verwittert & $\begin{array}{l}\text { Holzabbau (zumeist an } \\
\text { der Oberfläche) nach } \\
\text { Exposition im Freien (z.B. } \\
\text { UV-Licht, Regen, Wind, } \\
\text { gefrieren und auftauen). } \\
\text { Verwittertes Holz ist grau } \\
\text { und seine Oberfläche ist } \\
\text { oft rissig*, abgeplatzt* und } \\
\text { rau. Im Allgemeinen nicht } \\
\text { von Pilzen befallen. } \\
\text { Kann in Phasen eingeteilt } \\
\text { werden (siehe Dillehay } \\
\text { 1997). Verwittertes Holz } \\
\text { kann erodiert sein, } \\
\text { normalerweise durch } \\
\text { Regen, und die } \\
\text { Erosionsrate }(\mu \mathrm{m} / \mathrm{h}) \\
\text { variiert je nach Holzart } \\
\text { (siehe Feist } 1990) \text {. }\end{array}$ & $\begin{array}{l}\text { Lohmann (2010), p. } \\
\text { 1326; Feist 1990, } \\
\text { pp.278-282 } \\
\text { Dillehay 1997, pp.123, } \\
\text { 138.; Conard et al. } \\
2020\end{array}$ \\
\hline
\end{tabular}




\begin{tabular}{|c|c|c|c|c|c|}
\hline \multicolumn{6}{|c|}{$\begin{array}{c}\text { PHASE } 4 \\
\text { EXCAVATION AND POST-EXCAVATION }\end{array}$} \\
\hline Code & English Term & English Description & German Term & German Description & $\begin{array}{l}\text { References and } \\
\text { further reading }\end{array}$ \\
\hline ED & Excavation Damage & $\begin{array}{l}\text { Damage that occurred } \\
\text { during excavation from } \\
\text { tools cutting or pressing } \\
\text { into the object or scraping } \\
\text { across the surface. }\end{array}$ & Grabungsbeschädigung & $\begin{array}{l}\text { Schäden, die während der } \\
\text { Ausgrabung durch } \\
\text { Werkzeuge entstanden } \\
\text { sind, die in das Objekt } \\
\text { geschnitten oder gedrückt } \\
\text { wurden, oder durch } \\
\text { Schaben über die } \\
\text { Oberfläche. }\end{array}$ & $\begin{array}{l}\text { Rios-Garaizar et al. } \\
\text { 2018; Schoch et al. } \\
\text { 2015; Clark 2001, } \\
\text { p.488, } 490 .\end{array}$ \\
\hline Mi & $\begin{array}{l}\text { Mineralisation } \\
\text { (Efflorescence) }\end{array}$ & $\begin{array}{l}\text { Various minerals (dissolved } \\
\text { metal salts) which have } \\
\text { penetrated the wood, and } \\
\text { which change over time } \\
\text { through oxidation and other } \\
\text { chemical reactions } \\
\text { (exposure to air, drying } \\
\text { out). Can be characterised } \\
\text { by different colours on the } \\
\text { wood material (e.g. blue, } \\
\text { red, white, yellow). }\end{array}$ & $\begin{array}{l}\text { Mineralisation } \\
\text { (Ausblühungen) }\end{array}$ & $\begin{array}{l}\text { Verschiedene Mineralien } \\
\text { (gelöste Metallsalze), die } \\
\text { in das Holz eingedrungen } \\
\text { sind und sich im Laufe der } \\
\text { Zeit durch Oxidation und } \\
\text { andere chemische } \\
\text { Reaktionen } \\
\text { (Lufteinwirkung, } \\
\text { Austrocknung) verändern. } \\
\text { Durch verschiedene } \\
\text { Färbungen erkennbar } \\
\text { (z.B. blau, rot, weiß, gelb). }\end{array}$ & $\begin{array}{l}\text { Caruso Fermé et al. } \\
\text { 2014; Florian } 1990\end{array}$ \\
\hline
\end{tabular}




\section{Acknowledgments}

Version 7 of this preprint has been peer-reviewed and recommended by Peer Community In Archaeology (https://doi.org/10.24072/pci.archaeo.100015). The authors are very grateful to five open peer reviewers with expertise in the analysis of archaeological wood who helped to substantially improve this work: Paloma Vidal-Matutano, Oriol López-Bultó, Eva Martellotta, Laura Caruso Fermé and Michael Bamforth. We are indebted to the significant time and expertise of their contributions, as well as generous sharing of further resources and thoughts. We are grateful to Olga Lozovskaya who generously her thoughts, as well as experimental photographs included in the Appendix of images.

\section{Funding}

The project for which this work was developed, Schöningen Spears - humankind's earliest wooden weapons, is funded by the German Science Foundation (TE 259/18-1). Annemieke Milks is further funded by a British Academy Postdoctoral Fellowship (PF21 l210027).

\section{Conflict of interest disclosure}

The authors of this preprint declare that they have no financial conflict of interest with the content of this article.

\section{References}

Abdel-Azeem, A. M., Held, B. W., Richards, J. E., Davis, S. L., \& Blanchette, R. A. (2019).

Assessment of biodegradation in ancient archaeological wood from the Middle Cemetery at Abydos, Egypt. PLOS ONE, 14(3), e0213753. https://doi.org/10.1371/journal.pone.0213753

Alix, C., Hare, P. G., Andrews, T. D., \& MacKay, G. (2012). A Thousand Years of Lost Hunting Arrows: Wood Analysis of Ice Patch Remains in Northwestern Canada. ARCTIC, 65(5), 95-117. https://doi.org/10.14430/arctic4187

Allington-Jones, L. (2015). The Clacton Spear: The Last One Hundred Years. Archaeological Journal, 172(2), 273-296. https://doi.org/10.1080/00665983.2015.1008839

Aranguren, B., Revedin, A., Amico, N., Cavulli, F., Giachi, G., Grimaldi, S., Macchioni, N., \& Santaniello, F. (2018). Wooden tools and fire technology in the early Neanderthal site of Poggetti Vecchi (Italy). Proceedings of the National Academy of Sciences, 88, 201716068.

https://doi.org/10.1073/pnas.1716068115

Bailey, G., Galanidou, N., Peeters, H., Jöns, H., \& Mennenga, M. (Eds.). (2020). The Archaeology of Europe's Drowned Landscapes (Vol. 35). Springer International Publishing. https://doi.org/10.1007/978-3-030-37367-2

Bamford, M. K., \& Henderson, Z. L. (2003). A reassessment of the wooden fragment from Florisbad, South Africa. Journal of Archaeological Science, 30(6), 637-650. https://doi.org/10.1016/S03054403(02)00245-5

Bamforth, M. G. (2017). Woodworking technology and the utilisation of wood resources at Star Carr [MA by Research Thesis].

http://etheses.whiterose.ac.uk/20569/1/Bamforth\%20MA\%20by\%20research.pdf

Bamforth, M., Taylor, M., Little, A., \& Radini, A. (2018). Woodworking Technology. In N. Milner, C. Conneller, \& M. Taylor (Eds.), Star Carr Volume 2: Studies in technology, subsistence and environment (pp. 347-366). White Rose University Press. 
Barnett, G., \& Saranpää, (2014). Chapter 1 Introduction, In Gardiner, B., Barnett, J., Saranpää, P., Gril, J. (Eds.), 2014. The Biology of Reaction Wood, Springer Series in Wood Science. SpringerVerlag, Berlin Heidelberg. pp. 1-11. https://www.springer.com/de/book/9783642108136.

Belitzky, S., Goren-Inbar, N., \& Werker, E. (1991). A Middle Pleistocene wooden plank with manmade polish. 20(4), 349-353. https://doi.org/10.1016/0047-2484(91)90015-n

Bello, S. M., Parfitt, S. A., \& Stringer, C. B. (2009). Quantitative micromorphological analyses of cut marks produced by ancient and modern handaxes. Journal of Archaeological Science, 36(9), 18691880. https://doi.org/10.1016/j.jas.2009.04.014

Bello, S. M. \& Galway-Witham, J. (2019). Bone taphonomy inside and out_Application of 3dimensional microscopy, scanning electron microscopy and micro-computed tomography to the study of humanly modified faunal assemblages. Quaternary International, 17.

Bencomo Viala, M., Jardón Giner, P., Sirvent Cañada, L. M., \& Hortelano Piqueras, L. (2020). Understanding woodworking in Paleolithic times by means of use-wear analysis. Journal of Archaeological Science: Reports, 29, 102119. https://doi.org/10.1016/j.jasrep.2019.102119

Bigga, G., Schoch, W. H., \& Urban, B. (2015). Paleoenvironment and possibilities of plant exploitation in the Middle Pleistocene of Schöningen (Germany). Insights from botanical macro-remains and pollen. Journal of Human Evolution, 89, 92-104. https://doi.org/10.1016/j.jhevol.2015.10.005

Blanchette, R. A. (2000). A review of microbial deterioration found in archaeological wood from different environments. International Biodeterioration, Volume 46(3), 189-204.

https://doi.org/10.1016/S0964-8305(00)00077-9

Blanchette, R.A., Nilsson, T., Daniel, G., and Abad, A. (1990). Biological Degradation of Wood. In R. Rowell and R. Barbour (Eds.), Archaeological Wood Properties, Chemistry, and Preservation. Advances in Chemistry Series. Washington, D.C.: American Chemical Society. pp.141-174.

Boesch, C., Head, J., \& Robbins, M. M. (2009). Complex tool sets for honey extraction among chimpanzees in Loango National Park, Gabon. Journal of Human Evolution, 56(6), 560-569. https://doi.org/10.1016/j.jhevol.2009.04.001

Bosch, A., Chinchilla, J., Tarrús, J., Piqué, R. (2006). Els objectes de fusta i fibres vegetals. In: Bosch, A., Chinchilla, J., Tarrús, J. (Eds.), Els Objectes de Fusta Del Poblat Neolític de La Draga, Excavacions 1995-2005. Museu d'Arqueologia de Catalunya -_CASC, Girona, pp. 27-126.

Callahan, E. (1995). Functional Motions; Working Wood with Stone Tools. Bulletin of Primitive Technology, 9, 116-118.

Carbonell, E., \& Castro-Curel, Z. (1992). Palaeolithic wooden artefacts from the Abric Romani (Capellades, Barcelona, Spain). Journal of Archaeological Science, 19(6), 707-719. https://doi.org/10.1016/0305-4403(92)90040-A

Caruso Fermé, L., \& Aschero, C. (2020). Manufacturing and use of the wooden artifacts. A use-wear analysis of wood technology in hunter-gatherer groups (Cerro Casa de Piedra 7 site, Argentina). Journal of Archaeological Science: Reports, 31, 102291. https://doi.org/10.1016/j.jasrep.2020.102291

Caruso Fermé, L., \& Civalero, M. T. (2014). Holocene landscape changes and wood use in Patagonia: Plant macroremains from Cerro Casa de Piedra 7. The Holocene, 24(2), 188-197. https://doi.org/10.1177/0959683613516816

Caruso Fermé, L., Clemente, I., Beyries, S., \& T, C. M. (2014). Wood technology of Patagonian Hunter-Gatherers: A use-wear analysis study from the site of Cerro Casa de Piedra 7 (Patagonia, Argentina). In J. Marreiros, N. Bicho, \& J. Gibaja Bao (Eds.), International Conference on use-wear analysis Use-Wear 2012 (pp. 342-351). Cambridge Scholars Publishing.

https://pod51036.outlook.com/owal 
Caruso Fermé, L., Clemente, I., \& Civalero, M. T. (2015). A use-wear analysis of wood technology of patagonian hunter-gatherers. The case of Cerro Casa de Piedra 7, Argentina. Journal of Archaeological Science, 57, 315-321. https://doi.org/10.1016/j.jas.2015.03.015

Caruso Fermé, L., Civalero, M. T., \& Aschero, C. A. (2021a). Wood Technology: Production Sequences and Use of Woody Raw Materials among Hunter-Gatherer Patagonian Groups (Argentina). Environmental Archaeology, 1-14. https://doi.org/10.1080/14614103.2021.1911769

Caruso Fermé, L., Mineo, M., Ntinou, M., Remolins, G., Mazzucco, N., Gibaja, J.F. (2021b). Woodworking technology during the early Neolithic: First results at the site of La Marmotta (Italy). Quaternary International 593-594, pp.399-406.

Clark, J. D. (2001). Kalambo Falls Prehistoric Site Volume III: the earlier cultures: Middle and earlier Stone Age: Vol. III. Cambridge University Press.

Claud, É., Deschamps, M., Colonge, D., Mourre, V., \& Thiébaut, C. (2015). Experimental and functional analysis of late Middle Paleolithic flake cleavers from southwestern Europe (France and Spain). Journal of Archaeological Science, 62, 105-127. https://doi.org/10.1016/j.jas.2015.05.013

Clausen, C. (2010). Biodeterioration of Wood. In Forest Products Laboratory. Wood handbookWood as an engineering material. General Technical Report FPL-GTR-190. (Chapter 14). Madison, WI: U.S. Department of Agriculture, Forest Service, Forest Products Laboratory.

Coles, J. M., Heal, S. V. E., \& Orme, B. J. (1978). The Use and Character of Wood in Prehistoric Britain and Ireland. Proceedings of the Prehistoric Society, 44, 1-45. https://doi.org/10.1017/S0079497X00009968

Coles, B. (2003). An archaeological approach to the study of European beaver and their significance in past wetland ecosystems. In A. Bauerochse \& H. Haßmann (Eds.), Peatlands: Archaeological sites-Archives of nature-Nature conservation-Wise use (pp. 25-35). Verlag Marie Leidorf GmbH.

Conard, N. J., Serangeli, J., Bigga, G., \& Rots, V. (2020). A 300,000-year-old throwing stick from Schöningen, northern Germany, documents the evolution of human hunting. Nature Ecology \& Evolution, 1-6. https://doi.org/10.1038/s41559-020-1139-0

Dillehay, T. D. (1997). Monte Verde: A Late Pleistocene settlement in Chile Volume 2, The archaeological context and interpretation. Smithsonian Institution Press.

Domínguez-Rodrigo, M., Serrallonga, J., Juan-Tresserras, J., Alcalá, L., \& Luque, L. (2001). Woodworking activities by early humans: A plant residue analysis on Acheulian stone tools from Peninj (Tanzania). Journal of Human Evolution, 40(4), 289-299.

https://doi.org/10.1006/jhev.2000.0466

Domínguez-Rodrigo, M., de Juana, S., Galán, A.B., Rodríguez, M. (2009). A new protocol to differentiate trampling marks from butchery cut marks, Journal of Archaeological Science 36(12), 2643-2654. https://doi.org/10.1016/i.jas.2009.07.017.

Donaldson, L., \& Singh, A., (2016). Reaction Wood. Secondary Xylem Biology, pp. 93-110. https://doi.org/10.1016/B978-0-12-802185-9.00006-1

d'Errico, F., Backwell, L., Villa, P., Degano, I., Lucejko, J. J., Bamford, M. K., Higham, T. F. G., Colombini, M. P., \& Beaumont, P. B. (2012). Early evidence of San material culture represented by organic artifacts from Border Cave, South Africa. Proceedings of the National Academy of Sciences, 109(33), 13214-13219. https://doi.org/10.1073/pnas.1204213109

Duches, R., Nannini, N., Romandini, M., Boschin, F., Crezzini, J., \& Peresani, M. (2016). Identification of Late Epigravettian hunting injuries: Descriptive and 3D analysis of experimental projectile impact marks on bone. Journal of Archaeological Science, 66(C), 88-102.

https://doi.org/10.1016/j.jas.2016.01.005 
Eaton, R. A., \& Hale, M. D. C. (1993). Wood: Decay, pests and protection. London; New York: Chapman and Hall.

Facorellis, Y., Sofronidou, M., \& Hourmouziadis, G. (2014). Radiocarbon Dating of the Neolithic Lakeside Settlement of Dispilio, Kastoria, Northern Greece. Radiocarbon, 56(2), 511-528.

https://doi.org/10.2458/56.17456

Fagan, B. M., \& van Noten, F. L. (1971). The hunter-gatherers of Gwisho (Vol. 74). Musée royal de l'Afrique centrale.

Fagan, B. M., van Noten, F. L., \& Vynckier, J. R. (1966). Wooden Implements from Late Stone Age Sites at Gwisho Hot-springs, Lochinvar, Zambia. Proceedings of the Prehistoric Society, 32, 246-261. https://doi.org/10.1017/S0079497X00014407

Feist, W.C. (1990). Outdoor Wood Weathering and Protection. In R. Rowell and R. Barbour (Eds.), Archaeological Wood Properties, Chemistry, and Preservation. Advances in Chemistry Series. Washington, D.C.: American Chemical Society. pp.263-298.

Fernandez-Jalvo,Y. \& Andrews, P. (2016). Atlas of Taphonomic Identifications : 1001+ Images of Fossil and Recent Mammal Bone Modification. Springer.

Fletcher, L. Milner, N., Taylor, M., Bamforth, M., Croft, S., Little, A., Pomstra, D., Robson, H., \& Knight, B. (2018). The Use of Birch Bark. In N. Milner, C. Conneller, \& M. Taylor (Eds.), Star Carr Volume 2: Studies in technology, subsistence and environment (pp. 419-435). White Rose University Press.

Florian, M-L. (1990). Scope and Hostory of Archaeological Wood. In R. Rowell and R. Barbour (Eds.), Archaeological Wood Properties, Chemistry, and Preservation. Advances in Chemistry Series. Washington, D.C.: American Chemical Society. pp.3-32.

Fluck, H. (2015). Initial observations from experiments into the possible use of fire with stone tools in the manufacture of the Clacton point. Lithics-The Journal of the Lithic Studies Society, 28, 15-19.

Forest Products Laboratory. (2010). Wood handbook-Wood as an engineering material. General Technical Report FPL-GTR-190. Madison, WI: U.S. Department of Agriculture, Forest Service, Forest Products Laboratory.

Friedman, J. (1975). The Prehistoric Uses Of Wood at the Ozette Archaeological Site [PhD Thesis, Washington State University].

Gardiner, B., Barnett, J., Saranpää, P., Gril, J. (Eds.) (2014). The Biology of Reaction Wood, Springer Series in Wood Science. Springer-Verlag, Berlin Heidelberg. https://www.springer.com/de/book/9783642108136.

Gaspari, A., Eric, M., \& Odar, B. (2011). A Palaeolithic Wooden Point from Ljubljansko Barje, Slovenia. In J. Benjamin, C. Bonsall, C. Pickard, \& A. Fischer (Eds.), Submerged Prehistory (pp. 186192). Oxbow Books.

Gaudzinski-Windheuser, S. (2016). Hunting Lesions in Pleistocene and Early Holocene European Bone Assemblages and Their Implications for Our Knowledge on the Use and Timing of Lithic Projectile Technology. In Multidisciplinary Approaches to the Study of Stone Age Weaponry (pp. 77100). Springer Netherlands. https://doi.org/10.1007/978-94-017-7602-8 6

Geneste, J.-M. (2010). Systèmes techniques de production lithique: Variations techno-économiques dans les processus de réalisation des outillages paléolithiques. Techniques \& culture, 54-55, 419449. https://doi.org/10.4000/tc.5013

Gilbert, T. P., Jenkins, D. L., Gotherstrom, A., Naveran, N., Sanchez, J. J., Hofreiter, M., Francis Thomsen, P., Binladen, J., Higham, T. F. G., Yoke II, R. M., Parr, R., Scott Cummings, L., \& 
Willerslev, E. (2008). DNA from Pre-Clovis Human coprolites in Oregon, North America. American Association for the Advancement of Science, 320(5877), 786-789.

https://doi.org/10.1126/science.II56533

Gürbüz, R. B., \& Lycett, S. J. (2021). Could woodworking have driven lithic tool selection? Journal of Human Evolution, 156, 102999. https://doi.org/10.1016/j.jhevol.2021.102999

Hayden, B. (1979a). Palaeolithic reflections: Lithic technology and ethnographic excavation among Australian Aborigines. Australian Institute of Aboriginal Studies.

Hayden, B. (1979b). The Ho Ho classification and nomenclature committee report. Lithic Usewear Analysis. Academic Press, New York, pp. 133-135.

Hoadley, R. B. (1990). Identifying Wood: Accurate results with simple tools. The Taunton Press.

Jakob-Friesen, K. H. (1956). Eiszeitliche Elefantenjäger in der Lüneburger Heide. In Jahrb. Röm Germ. Zentralmus. 3, pp. 1-22.

Jolie, E. A., Lynch, T. F., Geib, P. R., \& Adovasio, J. M. (2011). Cordage, Textiles, and the Late Pleistocene Peopling of the Andes. Current Anthropology, 52(2), 285-296.

https://doi.org/10.1086/659336

Latorre, C., Santoro, C. M., Ugalde, P. C., Gayo, E. M., Osorio, D., Salas-Egaña, C., De Pol-Holz, R., Joly, D., \& Rech, J. A. (2013). Late Pleistocene human occupation of the hyperarid core in the Atacama Desert, northern Chile. Quaternary Science Reviews, 77(C), 19-30.

https://doi.org/10.1016/j.quascirev.2013.06.008

Lohmann, U. (2010). Holzlexikon: 1.448 Seiten, 15.700 Stichwörter, 2.050 Abbildungen. 4. Aufl. Hamburg: Nikol.

López-Bultó, O., \& Piqué, R. (2018). Wood Procurement at the Early Neolithic site of La Draga (Banyoles, Barcelona). Journal of Wetland Archaeology, 18(1), 56-76. https://doi.org/10.1080/14732971.2018.1466415

López-Bultó, O., Palomo, A., \& Clemente, I. (2020). Tool mark analysis of Neolithic wooden digging sticks from La Draga (Banyoles, Spain). Quaternary International, 569-570, 39-50.

https://doi.org/10.1016/j.quaint.2020.06.045

López-Bultó, O., Piqué, R., \& Palomo, A. (2012). Woodworking technology and functional experimentation in the Neolithic site of La Draga (Banyoles, Spain). Experimentelle Archäologie in Europa - Bilanz, 56-65.

Lozovskaya, O. V., \& Lozovski, V. M. (2013). Mode de fabrication des outils en bois dans le Mésolithique d'Europe Orientale: Approche expérimentale-tracéologique. In A. Palomo, R. Piqué y X. Terradas (ed.) Experimentación en arqueología. Estudio y difusión del pasado, Sèrie Monogràfica del MAC-Girona 25.1, pp. 73-83.

Luebbers, R. A. (1978). Meals and Menus: A study of change in prehistoric coastal settlements in South Australia [PhD Thesis]. https://www.google.com.aul

Luncz, L. V., Mundry, R., \& Boesch, C. (2012). Evidence for Cultural Differences between Neighboring Chimpanzee Communities. Current Biology, 22(10), 922-926. https://doi.org/10.1016/j.cub.2012.03.031

Macchioni N, Capretti C, Sozzi L, Pizzo B (2013) Grading the decay of waterlogged archaeological wood according to anatomical characterisation. The case of the Fiavé site (N-E Italy). Int Biodeterior Biodegradation 84:54-64. https://doi.org/10.1016/j.ibiod.2013.05.028 
Marguerie, D., \& Hunot, J.-Y. (2007). Charcoal analysis and dendrology: Data from archaeological sites in north-western France. Journal of Archaeological Science, 34(9), 1417-1433.

https://doi.org/10.1016/j.jas.2006.10.032

Martellotta, E. F., Wilkins, J., Brumm, A., \& Langley, M. C. (2021). New data from old collections: Retouch-induced marks on Australian hardwood boomerangs. Journal of Archaeological Science: Reports, 37, 102967. https://doi.org/10.1016/j.jasrep.2021.102967

Martín-Seijo, M. (2020). The presence of decayed wood in Iron Age contexts of northwest lberia: wood-borer galleries and fungal hyphae. Environmental Archaeology.

https://doi.org/10.1080/14614103.2020.1829294

Milks, A. (2018). Lethal Threshold: The Evolutionary Implications of Middle Pleistocene Wooden Spears [PhD Thesis, UCL] https://discovery.ucl.ac.uk/id/eprint/10045809

Milks, A., Parker, D., \& Pope, M. (2019). External ballistics of Pleistocene hand-thrown spears: Experimental performance data and implications for human evolution. Scientific Reports, 9(1), 820. https://doi.org/10.1038/s41598-018-37904-w

Milks, A. (2021). Yew wood, would you? An exploration of the selection of wood for Pleistocene spears. In The missing woodland resources: archaeobotanical studies of the use of plant raw materials. In Berituete-Azorin, M., Martín Seijo, M., López-Bultó, O., Piqué, R. (Eds.), The missing woodland resources: Archaeobotanical studies of the use of plant raw materials. 6: 5.

Moskal-del Hoyo, M., Wachowiak, M., \& Blanchette, R. A. (2010). Preservation of fungi in archaeological charcoal. Journal of Archaeological Science, 37(9), 2106-2116.

https://doi.org/10.1016/j.jas.2010.02.007

Nadel, D., Grinberg, U., Boaretto, E., \& Werker, E. (2006). Wooden objects from Ohalo II (23,000 cal BP), Jordan Valley, Israel. Journal of Human Evolution, 50(6), 644-662.

https://doi.org/10.1016/j.jhevol.2005.12.010

Nugent, S. J. (2006). Applying use-wear and residue analysis to digging sticks. Memoirs of the Queensland Museum, Cultural Heritage Series, 4(1), 89-105.

Oakley, K. P., Andrews, P., Keeley, L. H., \& Clark, J. D. (1977). A Reappraisal of the Clacton Spearpoint. Proceedings of the Prehistoric Society, 43, 13-30.

https://doi.org/10.1017/S0079497X00010343

O'Sullivan, A. (2007). Exploring past people's interactions with wetland environments in Ireland. Proceedings of the Royal Irish Academy, Section C, 107(1), 147-203.

https://doi.org/10.3318/PRIC.2007.107.147

Panagopoulou, E., Tourloukis, V., Thompson, N., Konidaris, G., Athanassiou, A., Giusti, D., Tsartsidou, G., Karkanas, P., \& Harvati, K. (2018). The Lower Palaeolithic site of Marathousa 1, Megalopolis, Greece_Overview of the evidence. Quaternary International, 497, 33-46.

https://doi.org/10.1016/i.quaint.2018.06.031

Pétillon, J. M., Plisson, H., \& Cattelain, P. (2016). Thirty Years of Experimental Research on the Breakage Patterns of Stone Age Osseous Points. Overview, Methodological Problems and Current Perspectives. In R. Iovita \& K. Sano (Eds.), Multidisciplinary Approaches to the Study of Stone Age Weaponry (pp. 47-63). Springer. https://doi.org/10.1007/978-94-017-7602-8 4

Piqué, R., Palomo, A., Terradas, X., Tarrús, J., Buxó, R., Bosch, À., Chinchilla, J., Bodganovic, I., López, O., \& Saña, M. (2015). Characterizing prehistoric archery: Technical and functional analyses of the Neolithic bows from La Draga (NE Iberian Peninsula). Journal of Archaeological Science, 55(C), 166-173. https://doi.org/10.1016/j.jas.2015.01.005 
Pournou, A. (2020). Biodeterioration of Wooden Cultural Heritage: Organisms and Decay Mechanisms in Aquatic and Terrestrial Ecosystems. Springer International Publishing.

https://doi.org/10.1007/978-3-030-46504-9

Pruetz, J. D., Bertolani, P., Ontl, K. B., Lindshield, S., Shelley, M., \& Wessling, E. G. (2015). New evidence on the tool-assisted hunting exhibited by chimpanzees (Pan troglodytes verus) in a savannah habitat at Fongoli, Senegal. Royal Society Open Science, 2(4), 140507-140507. https://doi.org/10.1098/rsos.140507

Puhar, E. G., Erič, M., Kavkler, K., Cramer, A., \& Celec, K. (2018). Comparison and deformation analysis of five 3D models of the Paleolithic wooden point from the Ljubljanica river. Proceedings of the 2018 IEEE International Workshop on Metrology for Archaeology and Cultural Heritage (MetroArchaeo 2018). http://eprints.fri.uni-lj.si/4301/1/Comparison and deformation analysis.pdf

Revedin, A., Grimaldi, S., Florindi, S., Santaniello, F., \& Aranguren, B. (2019). Experimenting the Use of Fire in the Operational Chain of Prehistoric Wooden Tools: The Digging Sticks of Poggetti Vecchi (Italy). Journal of Paleolithic Archaeology, 1-12. https://doi.org/10.1007/s41982-019-00043-3

Rich, S. A., Watts, R., \& Momber, G. (2016). Mesolithic woodworking, experimental archaeology \& underwater heritage in Hampshire and the Isle of Wight (UK). Mesolithic Miscellany, 24(1), 3-12.

Richter, C. (2015). Wood Characteristics. Springer International Publishing.

https://doi.org/10.1007/978-3-319-07422-1

Richter, C. (2019). Holzmerkmale der Bäume. Leinfelden-Echterdingen: DRW-Verlag.

Rios-Garaizar, J., López-Bultó, O., Iriarte, E., Pérez-Garrido, C., Piqué, R., Aranburu, A., IriarteChiapusso, M. J., Ortega-Cordellat, I., Bourguignon, L., Garate, D., \& Libano, I. (2018). A Middle Palaeolithic wooden digging stick from Aranbaltza III, Spain. PLoS ONE, 13(3), e0195044-15. https://doi.org/10.1371/journal.pone.0195044

Ruelle, J. (2014). Morphology, Anatomy and Ultrastructure of Reaction Wood, In Gardiner, B., Barnett, J., Saranpää, P., Gril, J. (Eds.). (2014). The Biology of Reaction Wood, Springer Series in Wood Science. Springer-Verlag, Berlin Heidelberg. pp. 13-35.

https://www.springer.com/de/book/9783642108136

Sands, R. (1997). Prehistoric Woodworking: The analysis and interpretation of Bronze and Iron Age toolmarks. UCL Institute of Archaeology.

Schoch, W. H., Bigga, G., Böhner, U., Richter, P., \& Terberger, T. (2015). New insights on the wooden weapons from the Paleolithic site of Schöningen. Journal of Human Evolution, 89(C), 214225. https://doi.org/10.1016/j.jhevol.2015.08.004

Solé, A., Allué, E., \& Carbonell, E. (2013). Hearth-related wood remains from Abric Romaní layer M (Capellades, Spain). Current Anthropology, 69(4), 535-559. https://www.jstor.org/stable/24393938

Sørensen, M. (2006). The chaîne opératoire applied to Arctic archaeology. In Dynamics of Northern Societies (pp. 31-44). The Danish National Museum. Studies in Archaeology and History.

Soressi, M., \& Geneste, J.-M. (2011). Reduction sequence, chaîne opératoire, and other methods: The epistemologies of different approaches to lithic analysis the history and efficacy of the chaîne opératoire approach to lithic analysis: Studying techniques to reveal past societies in an evolutionary perspective. PaleoAnthropology, 2011, 334-350. doi:10.4207/PA.2011.ART63

Stamm, A.J., (1935). Shrinking and swelling of wood. Industrial \& Engineering Chemistry 27, 401406. 
Stanzl-Tschegg, S. E., Keunecke, D., \& Tschegg, E. K. (2011). Fracture tolerance of reaction wood (yew and spruce wood in the TR crack propagation system). Journal of the Mechanical Behavior of Biomedical Materials, 4(5), 688-698. https://doi.org/10.1016/j.jmbbm.2010.11.010

Stodiek, U. (1993). Zur Technologie der jungpaläolithischen Speerschleuder: Eine Studie auf der Basis archäologischer, ethnologischer und experimenteller Erkenntnisse. Universität Tübingen.

Tafelmaier, Y., Bataille, G., Schmid, V., Taller, A., \& Will, M. (2020). Methoden zur Analyse von Steinartefakten: Eine Übersicht. Springer-Verlag.

Taylor, M., Bamforth, M., Robson, H., Watson, C., Little, A., Pomstra, D., Milner, N., Carty, J., Colonese, A., Lucquin, A., \& Allen, S. (2018). The Wooden Artefacts. In Star Carr Volume II (pp. 367418). White Rose University Press. https://doi.org/10.22599/book2

Terberger, T., Zhilin, M., \& Savchenko, S. (2021). The Shigir idol in the context of early art in Eurasia. Quaternary International, 573, 14-29. https://doi.org/10.1016/j.quaint.2020.10.025

Thieme, H. (1997). Lower Palaeolithic hunting spears from Germany. Nature, 385, 807-810.

Thieme, H. (2000). Lower Palaeolithic hunting weapons from Schöningen, Germany - The Oldest Spears in the World. In W. Dong (Ed.), Acta Anthropologica Sinica (pp. 140-147).

Thieme, H., \& Veil, S. (1985). Neue Untersuchungen zum eemzeitlichen Elefanten-Jagdplatz Lehringen, Ldkr. Verden. Die Kunde, 36, 11-58.

Toriti, M., Fohrer, F., \& Durand, A. (2014). The condition of timber in antiquity: Archaeological, entomologica, and anthracological approaches. In Wood Anatomy \& Tree-Ring Ecology-International Course, International Winter School on Wood Anatomy of Tree Rings, 23-29-11-2014.

Toriti, M., Durand, A., Excoffon, P., \& Fohrer, F. (2021). Xylophagous insects of the wooden floor of Camelin block (Fréjus, France): An interdisciplinary approach combining archaeology and anthracoentomology. Quaternary International, 593-594, 60-70. https://doi.org/10.1016/j.quaint.2020.09.034

Uzquiano, P., Allué, E., Antolín, F., Burjachs, F., Picornel, L., Piqué, R., \& Zapata, L. (2015). All about yew: On the trail of Taxus baccata in southwest Europe by means of integrated palaeobotanical and archaeobotanical studies. Vegetation History and Archaeobotany, 24(1), 229-247.

https://doi.org/10.1007/s00334-014-0475-x

Vidal-Matutano, P., Rodríguez-Rodríguez, A., González-Marrero, M. del C., Morales, J., HenríquezValido, P., \& Moreno-Benítez, M. A. (2021a). Woodworking in the cliffs? Xylological and morphotechnological analyses of wood remains in the Prehispanic granaries of Gran Canaria (Canary Islands, Spain). Quaternary International, 593-594, 407-423.

https://doi.org/10.1016/i.quaint.2020.09.055

Vidal-Matutano, P.; Delgado-Darias, T.; López-Dos Santos, N.; Henríquez-Valido, P.; VelascoVázquez, J.; Alberto-Barroso, V. (2021b). Use of decayed wood for funerary practices:

archaeobotanical analysis of funerary wooden artefacts from Prehispanic (ca. $400-1500$ CE) Gran Canaria (Canary Islands, Spain). Quaternary International, 593-594: 384-398.

https://doi.org/10.1016/j.quaint.2020.10.003

Vidal-Matutano, P., Livraghi, A., \& Peresani, M. (2022). New charcoal evidence at the onset of MIS 4: First insights into fuel management and the local landscape at De Nadale cave (northeastern Italy). Review of Palaeobotany and Palynology, 298, 104594.

https://doi.org/10.1016/j.revpalbo.2021.104594

Wagenführ, R. (1999). Anatomie des Holzes. Leinenfelden-Echterdingen: DRW-Verlag.

Warren, S. (1911). Proceedings: 'First Published Report and exhibition of the specimen, May 10th, 1911'. Quarterly Journal of the Geological Society, 67(1-4), XCIX.

https://doi.org/10.1144/GSL.JGS.1911.067.01-04.02 
Wilson, K. and White, D.J.B. (1986). The anatomy of wood: its diversity and variability. London: Stobard \& Son Ltd 


\section{Appendix of Figures}

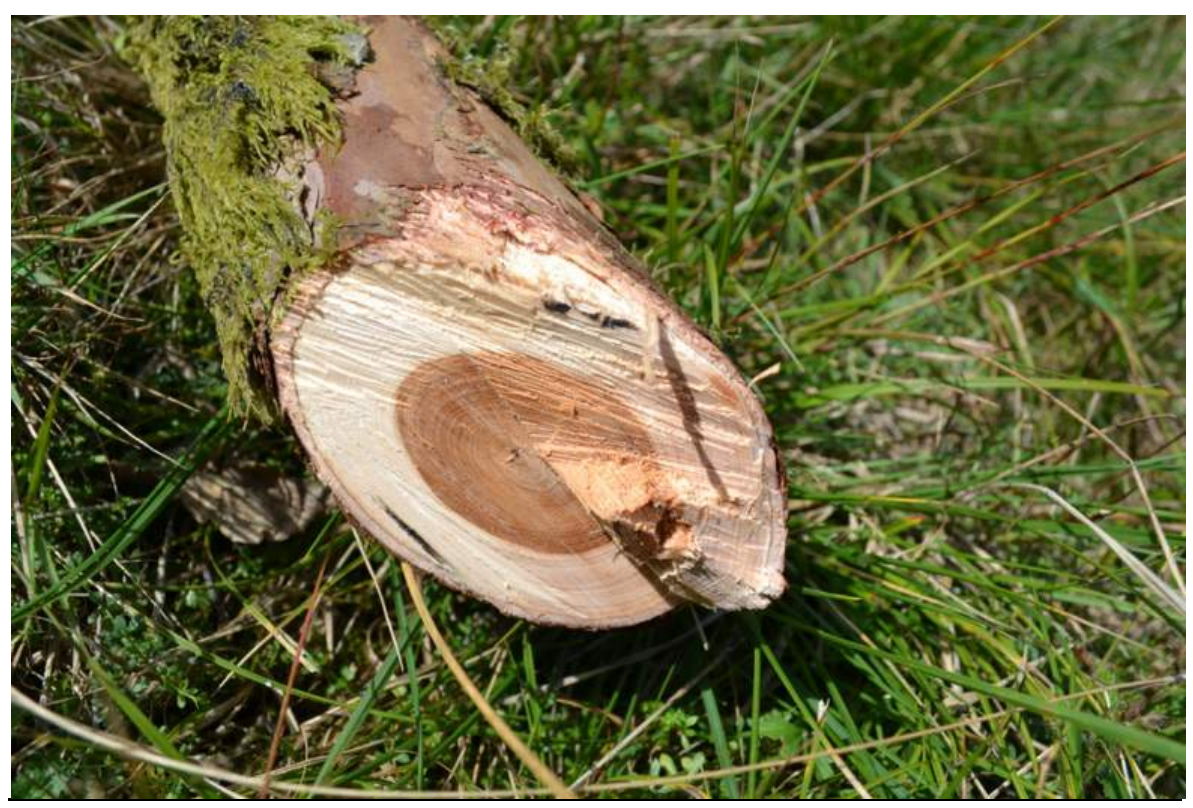

Figure 2. Cross-section* of a yew (Taxus baccata) branch showing the darker heartwood* and lighter sapwood*. Photo A. Milks

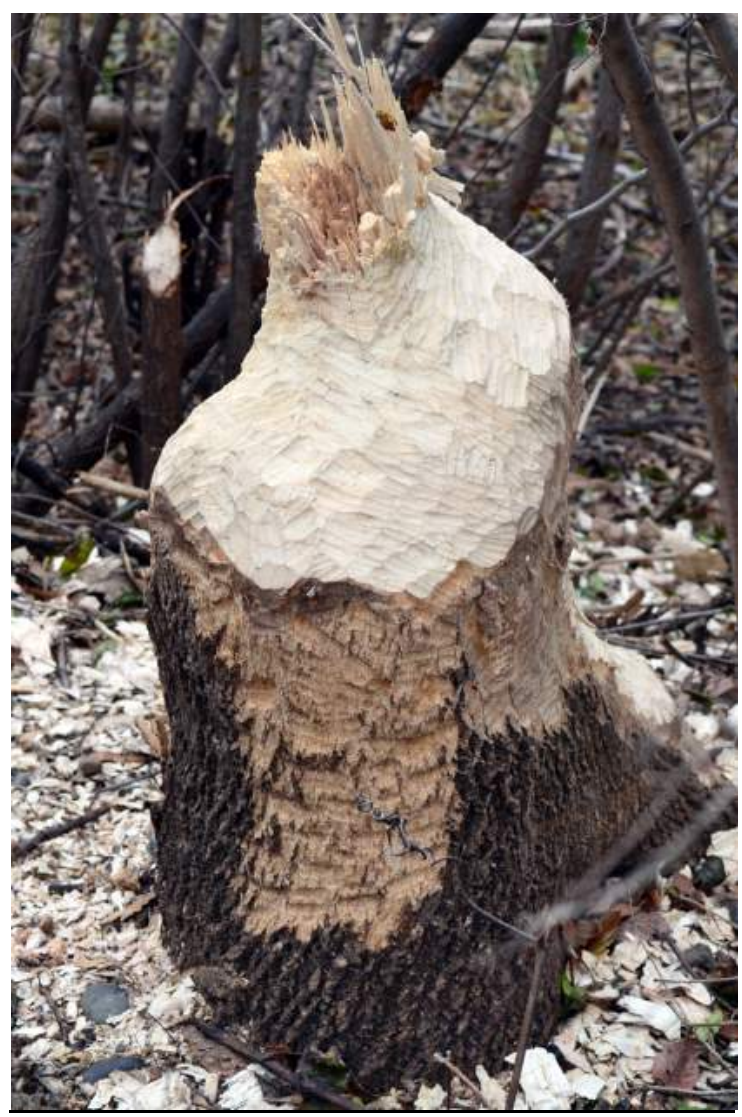

Figure 3. Beaver traces*. Image by USFWSmidwest - Beaver Log, Public Domain, https://commons. wikimedia.org/w/index. php?curid=69206105 


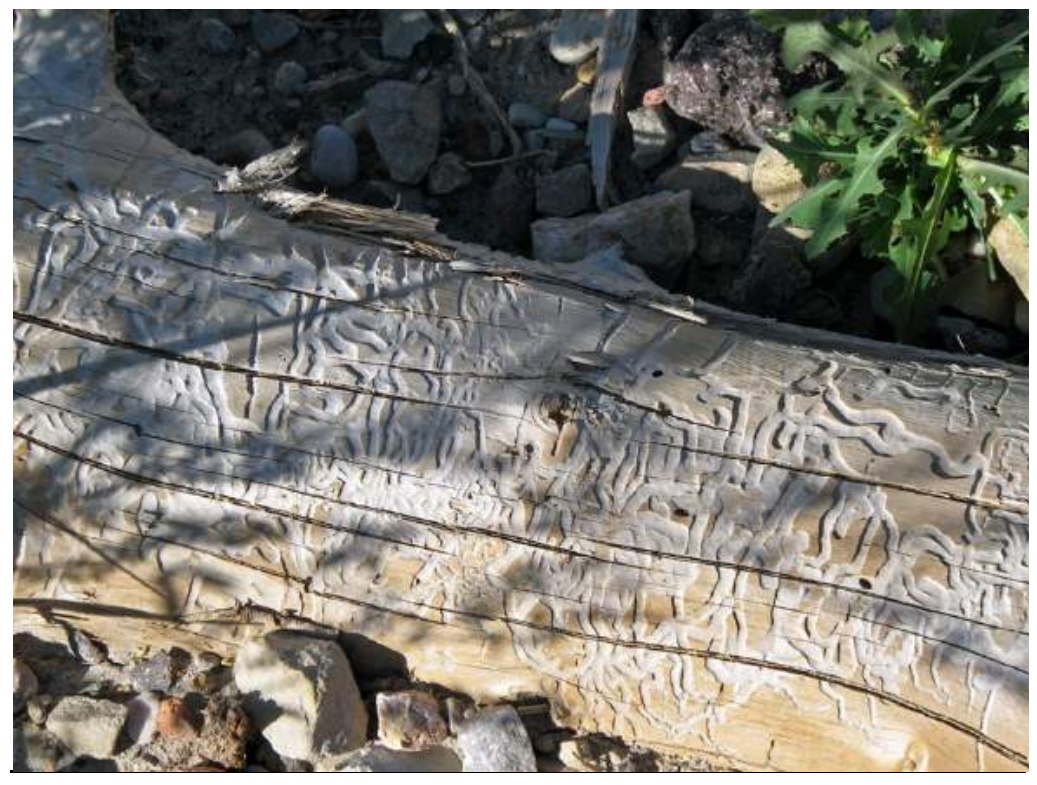

Figure 4. Feeding Traces, Insects*. Image by James St. John - Insect borings in wood (Cedar Canyon, Utah, USA), CC BY 2.0,

https://commons. wikimedia.org/w/index.php?curid=74796298

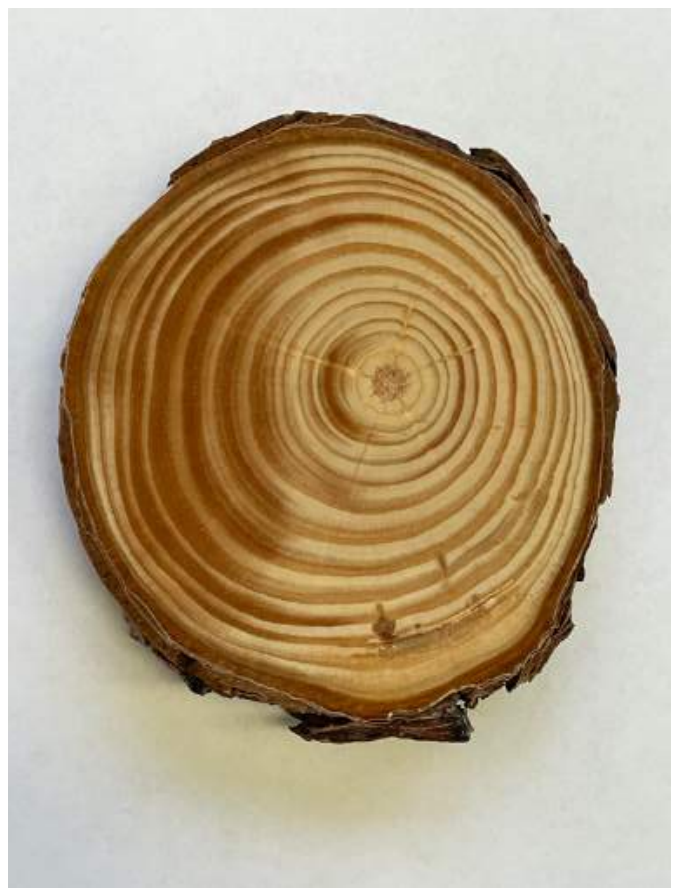

Figure 5. Reaction wood* (Compression wood ${ }^{*}$ ) visible as the darker discolouration in the cross-section of a pine (Pinus sp.) branch. Photo by and (c) Tim Koddenberg. 


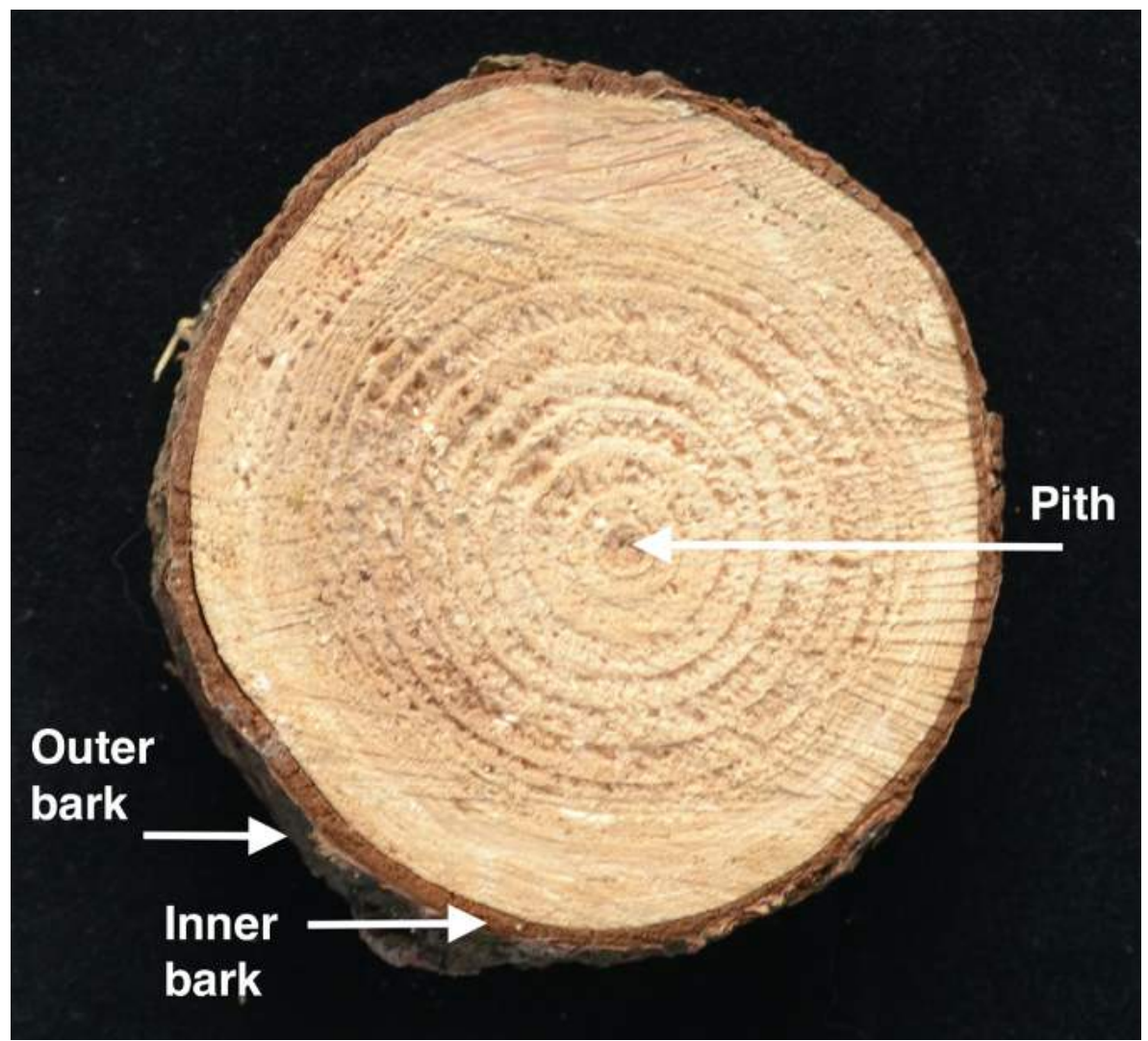

Figure 6. Cross-section* of a spruce (Picea abies) trunk showing the outer bark*, inner bark* and pith*. Photo A. Milks

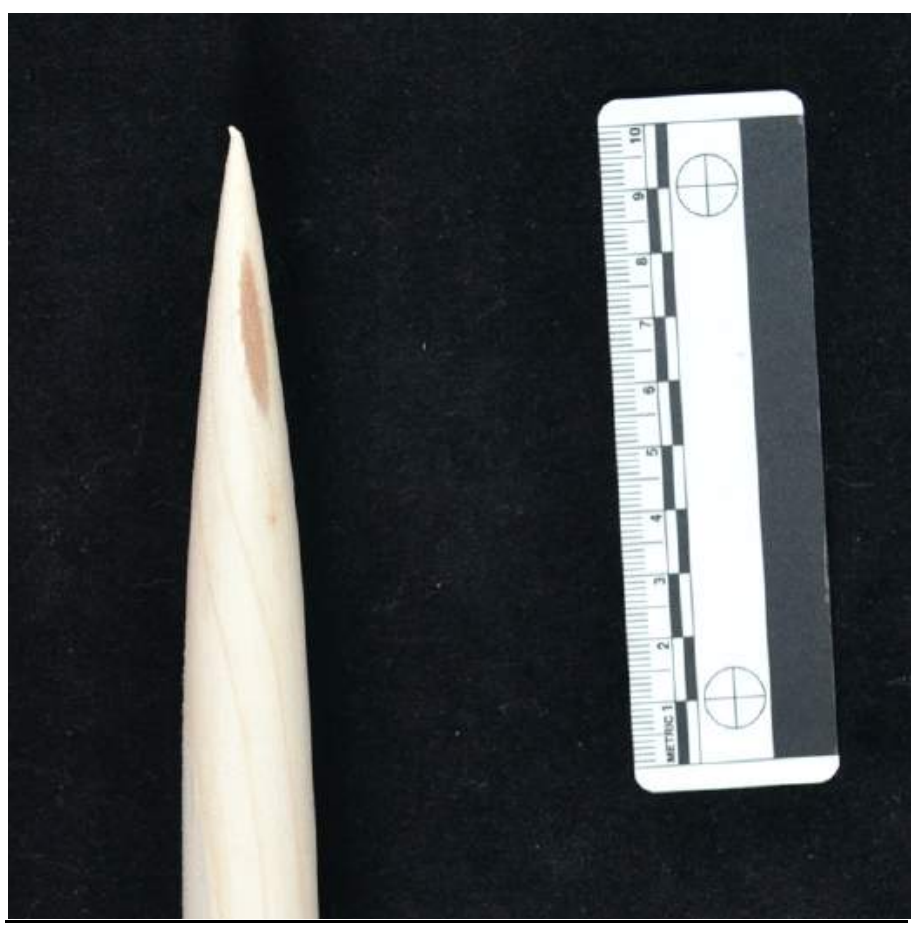

Figure 7. An Offset Point * (pith is the darker patch) on a spruce spear replica. Photo A. Milks. 


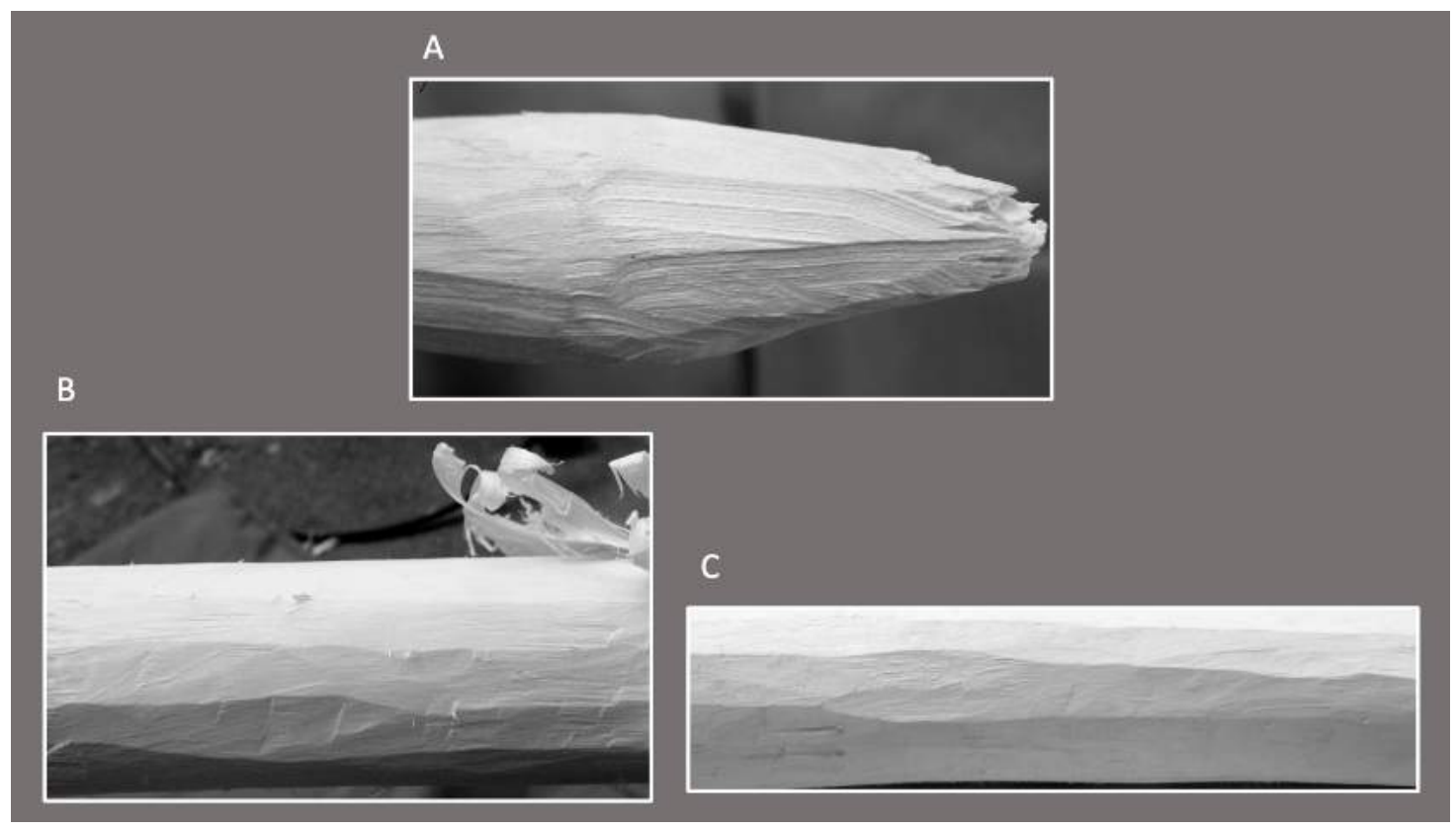

Figure 8. Experimental planing marks, from Lozovskaya \& Lozovski 2013. Photos courtesy of and (c) Olga Lozovskaya.

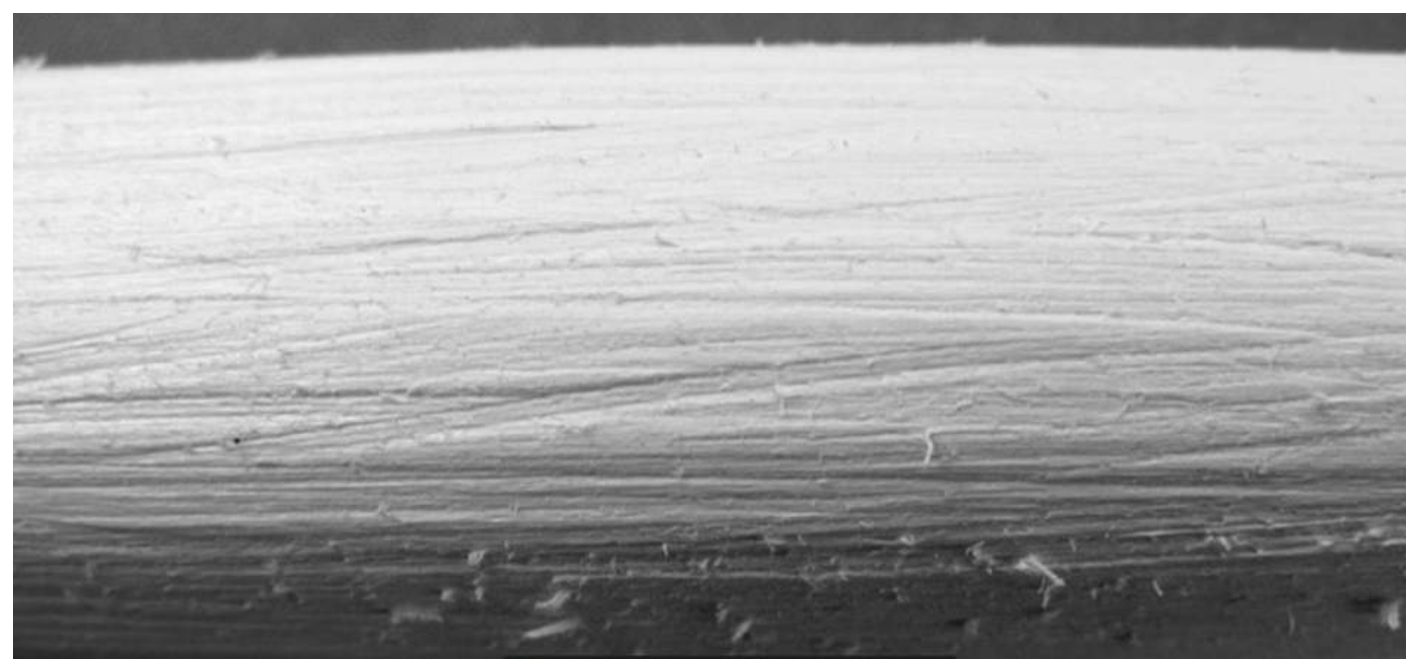

Figure 9. Experimental scraping marks, from Lozovskaya \& Lozovski 2013. Photo courtesy of and @ Olga Lozovskaya. 


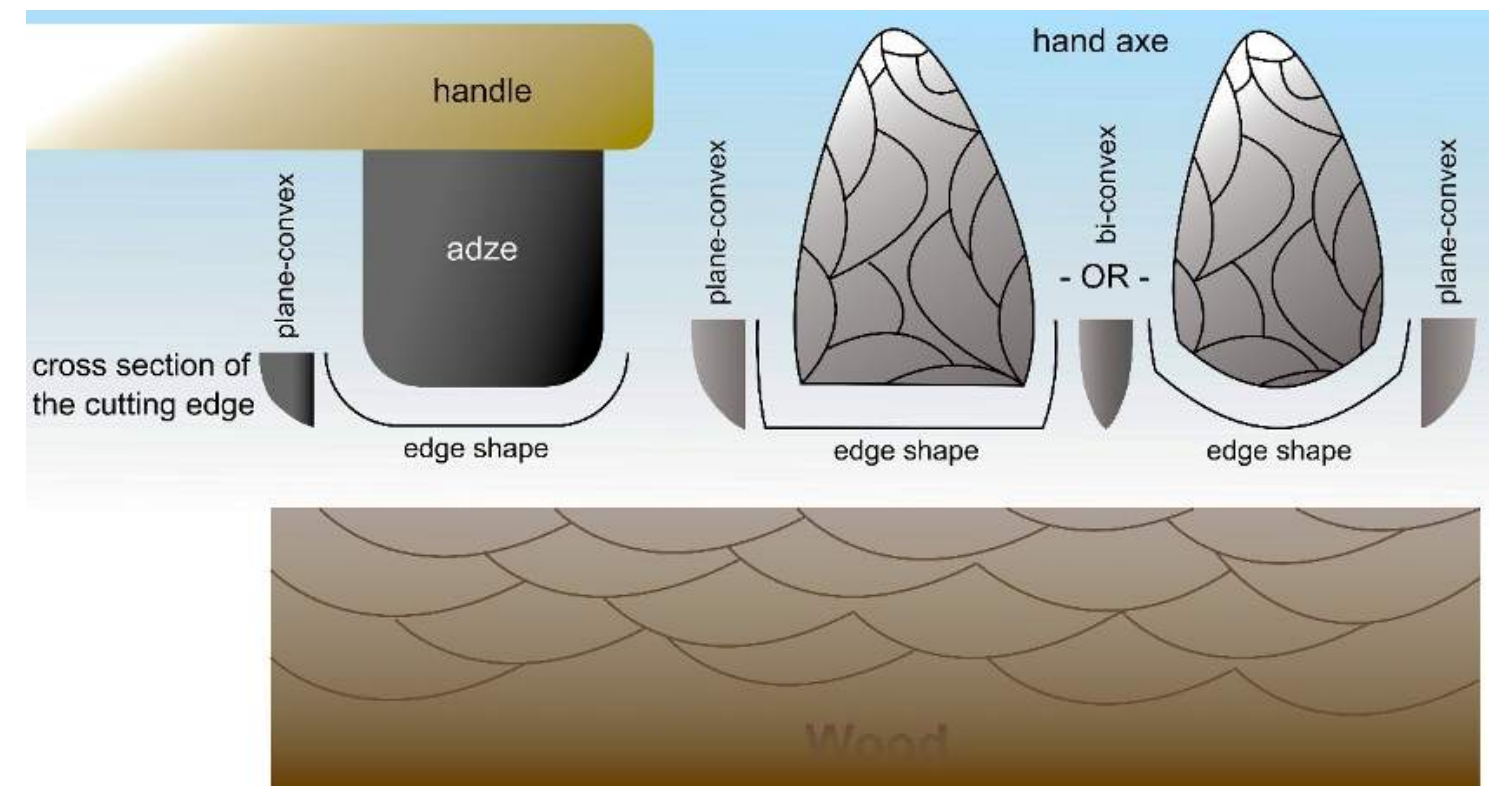

Figure 10. Schematic drawing of shaping facets. Whilst shaping facets have been described in connection with the use of an adze to shape a tool, theoretically other heavy-duty tools could also be used for shaping, and thus leave shaping facets. Drawing by and (C) Dirk Leder.

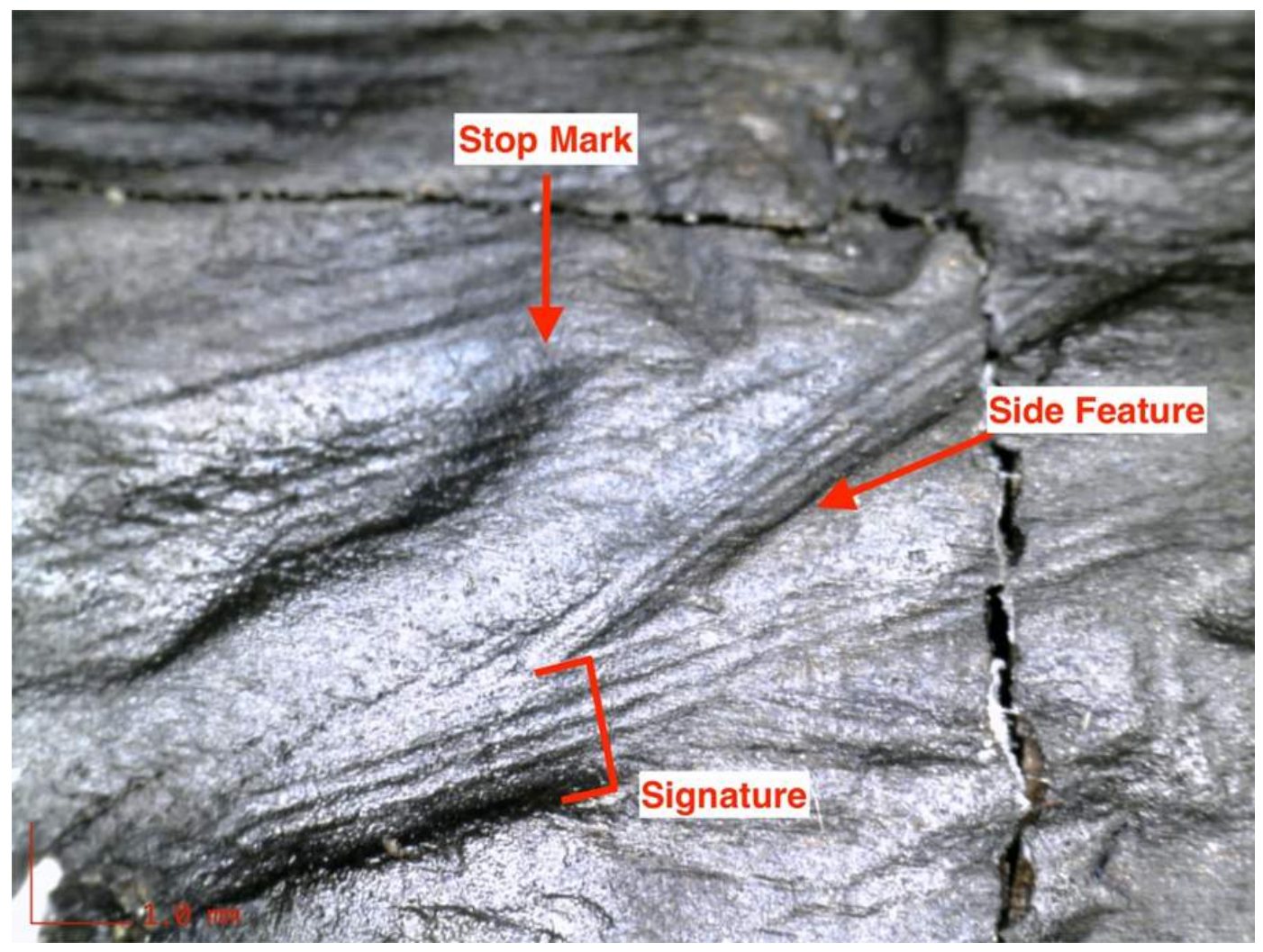

Figure 11. A series of Tool Facets* on the Lehringen spear, showing a stop mark, side features and signatures. Photo A. Milks 


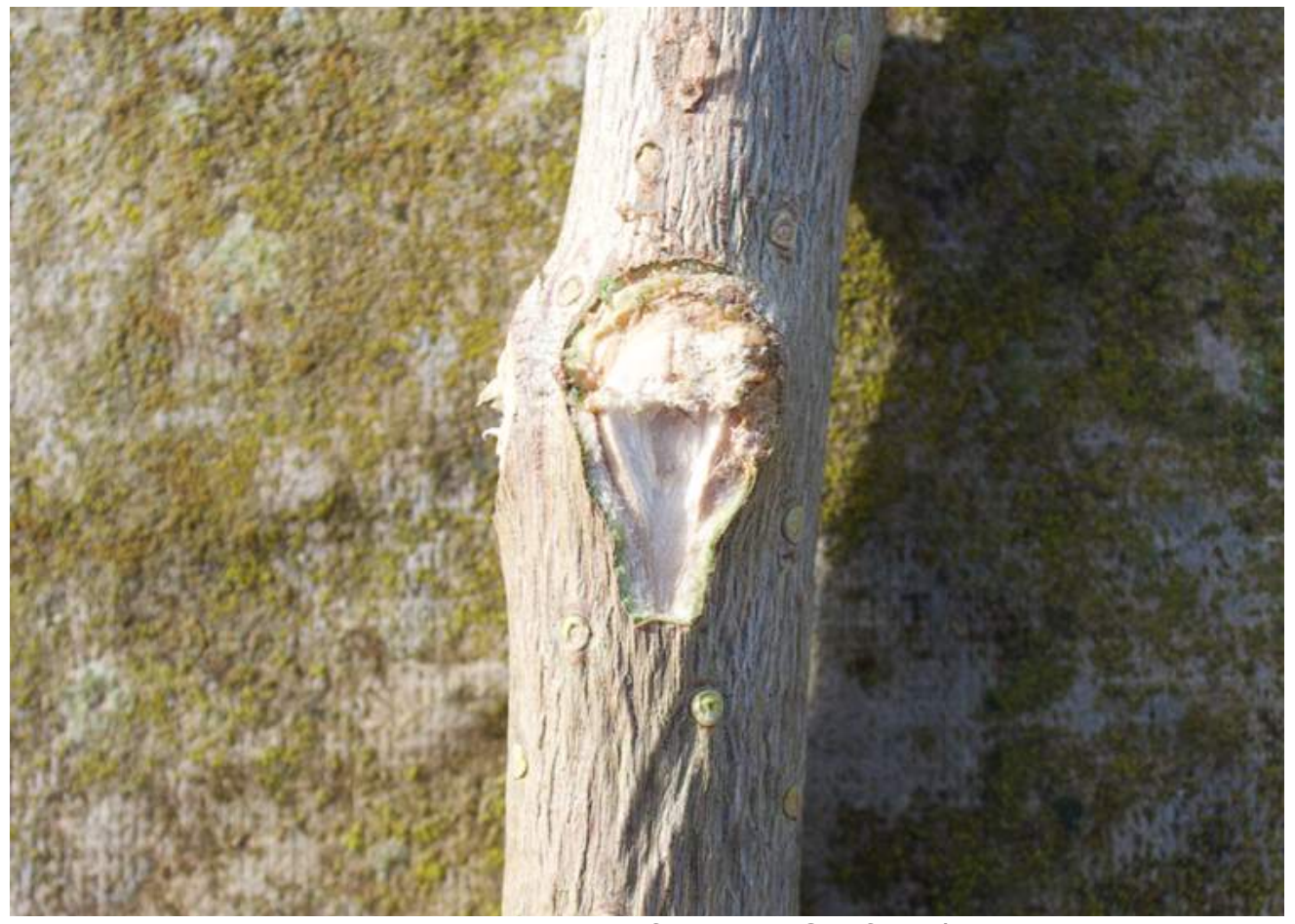

Figure 12. Experimental example of a Torn Surface* created by working the branch with a stone tool, followed by tearing off by hand. Photo A. Milks.

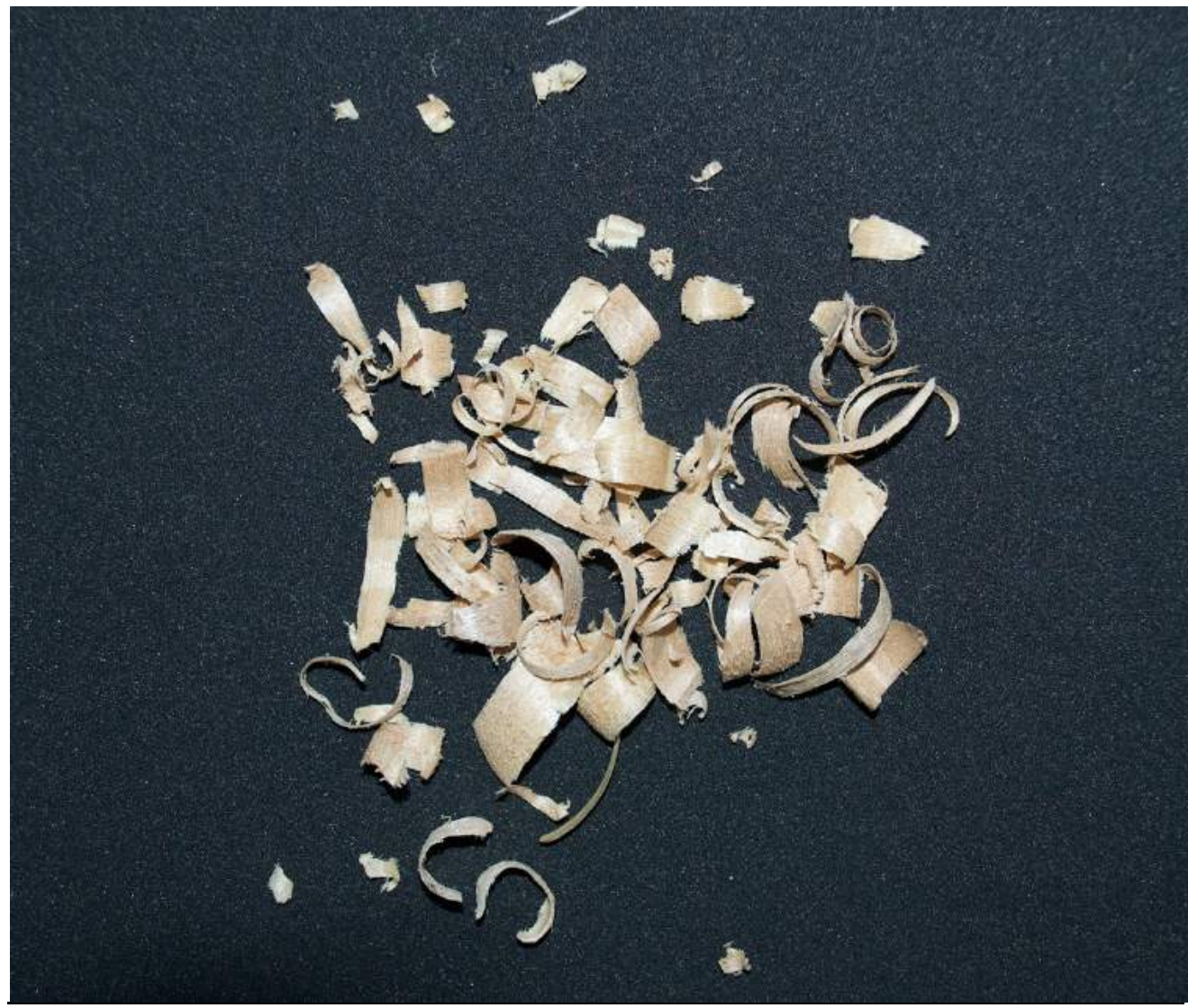

Figure 13. Experimental wood shavings*. Photo by A. Milks 


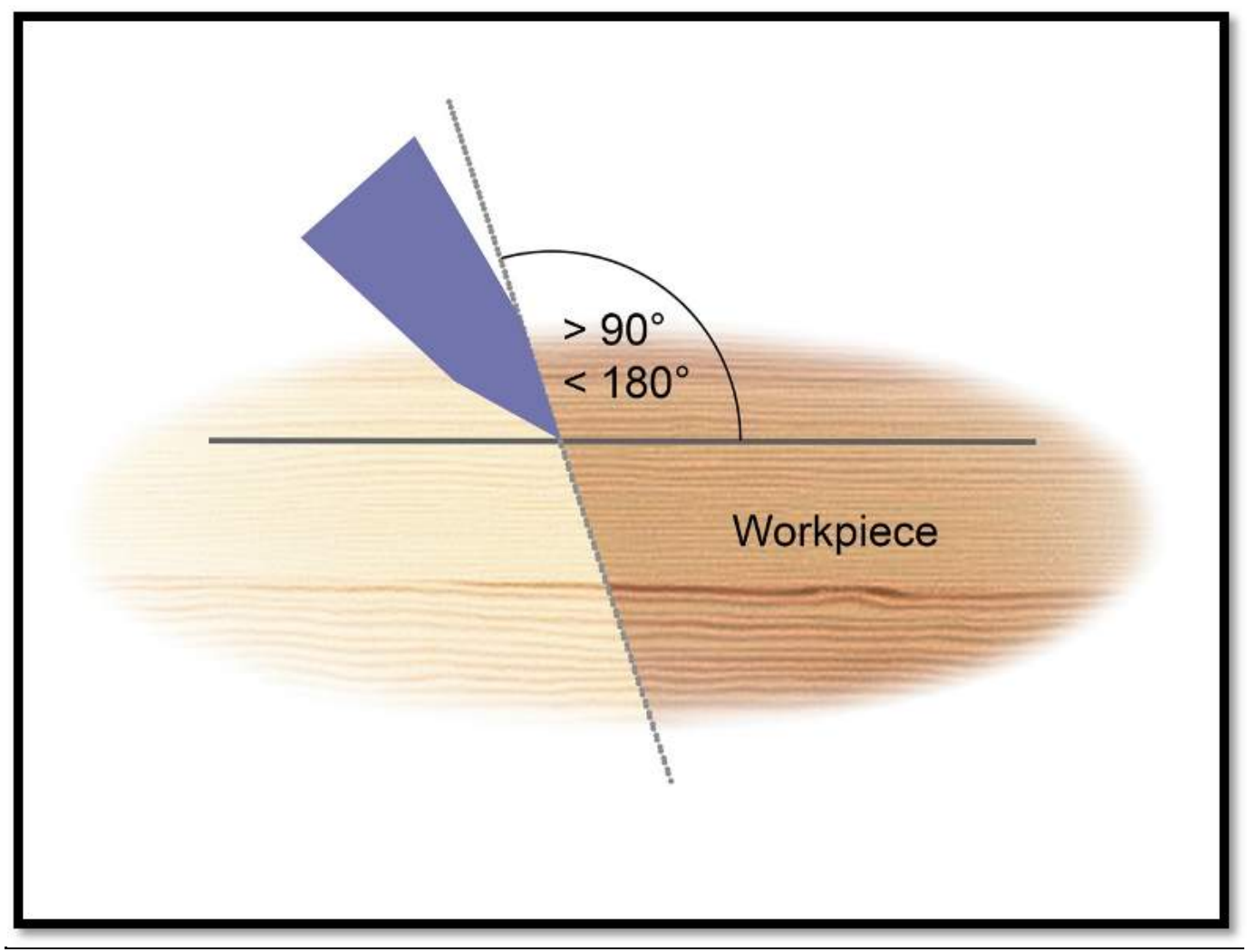

Figure 14. Schematic Illustration of working against the grain*. Drawing by and $\odot \mathrm{M}$. Sietz.

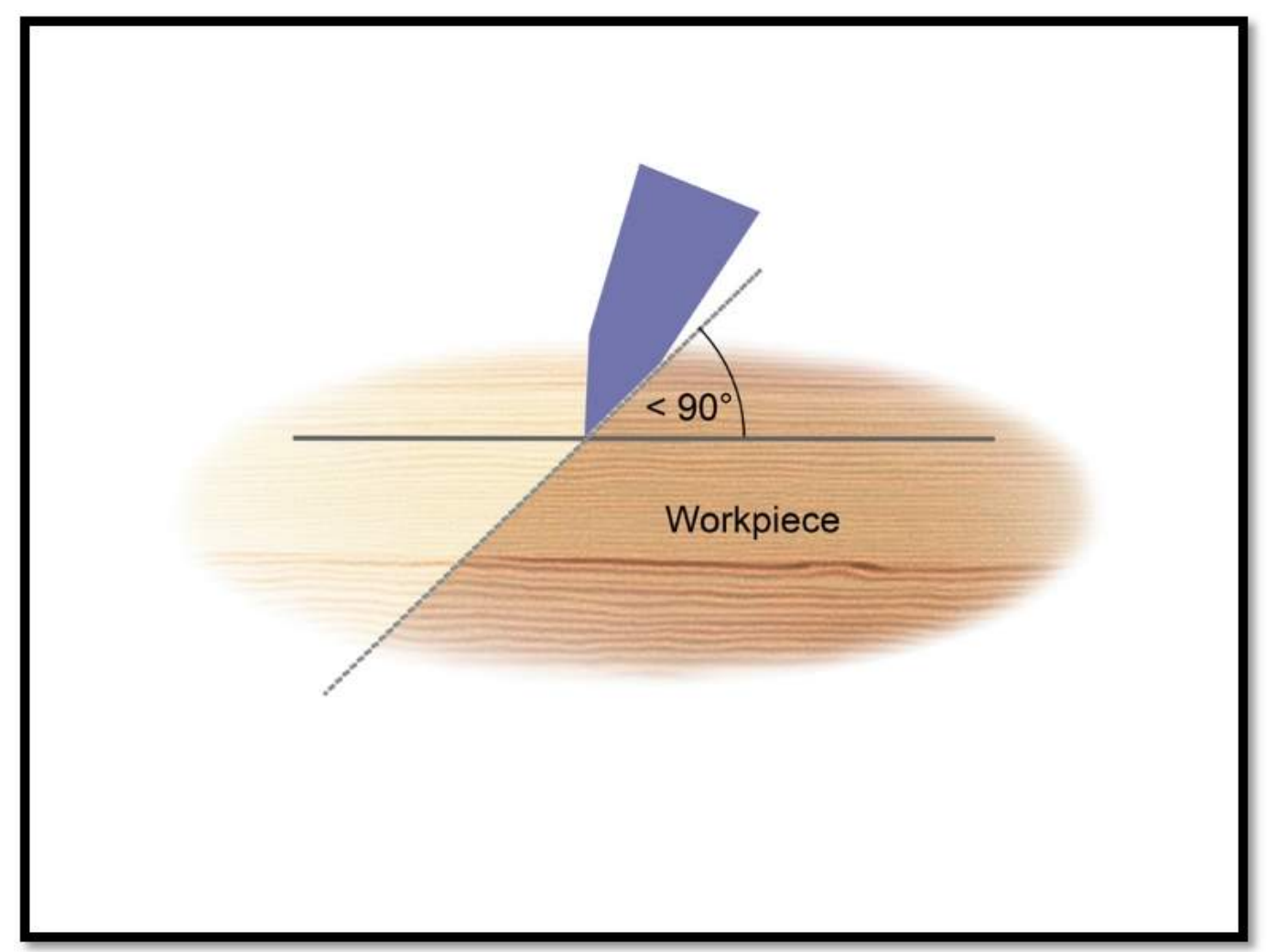

Figure 15. Schematic illustration of working with the grain*. Drawing by and $\odot \mathrm{M}$. Sietz 


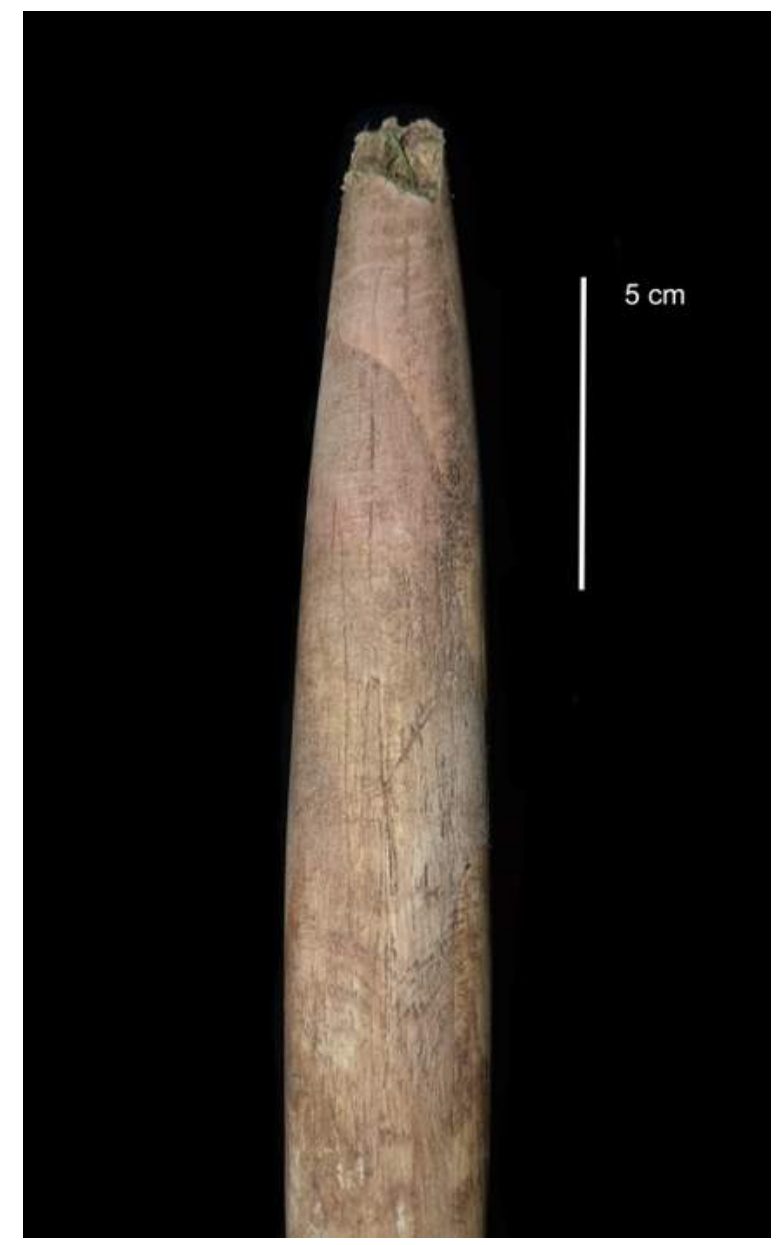

Figure 16. An example of a Bevelled Fracture* on an experimentally used spear replica. Photo A. Milks.

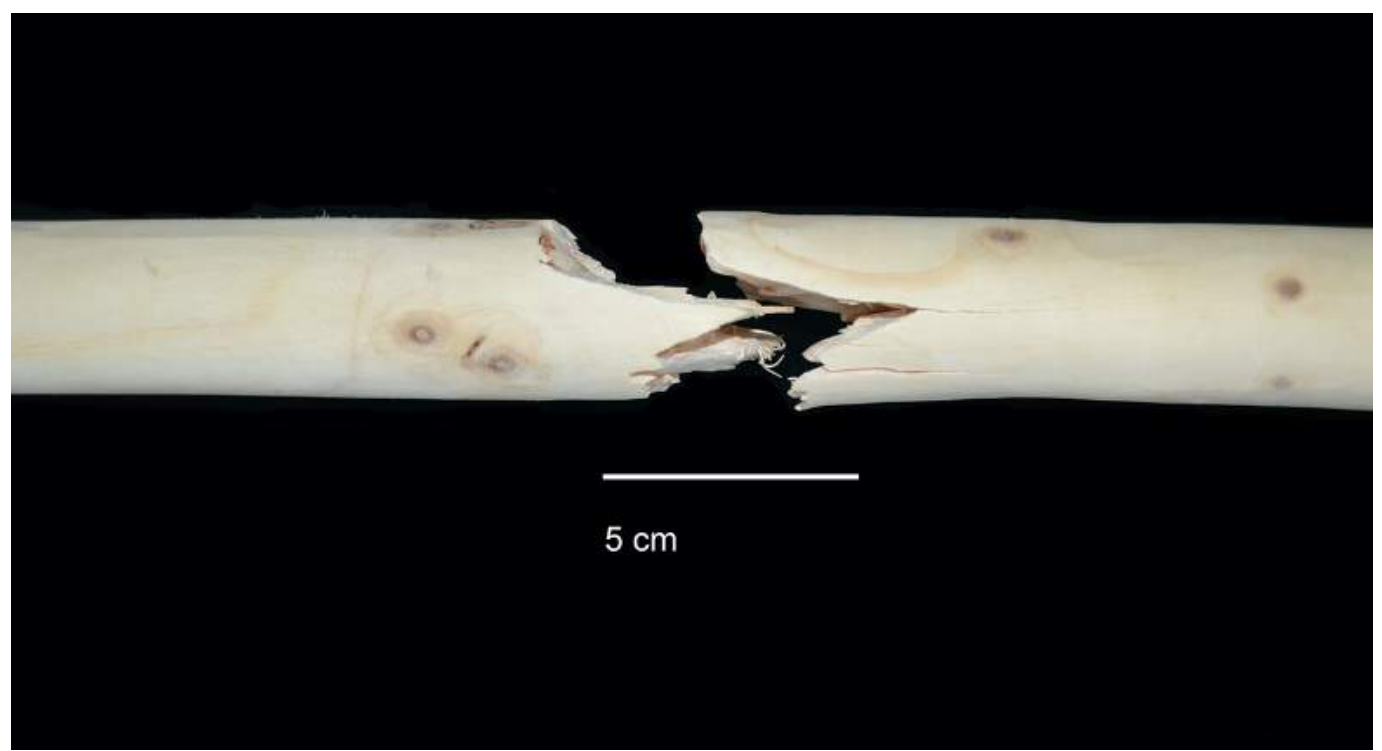

Figure 17. An example of a Shaft Break* on an experimentally used spear replica. Photo A. Milks. 


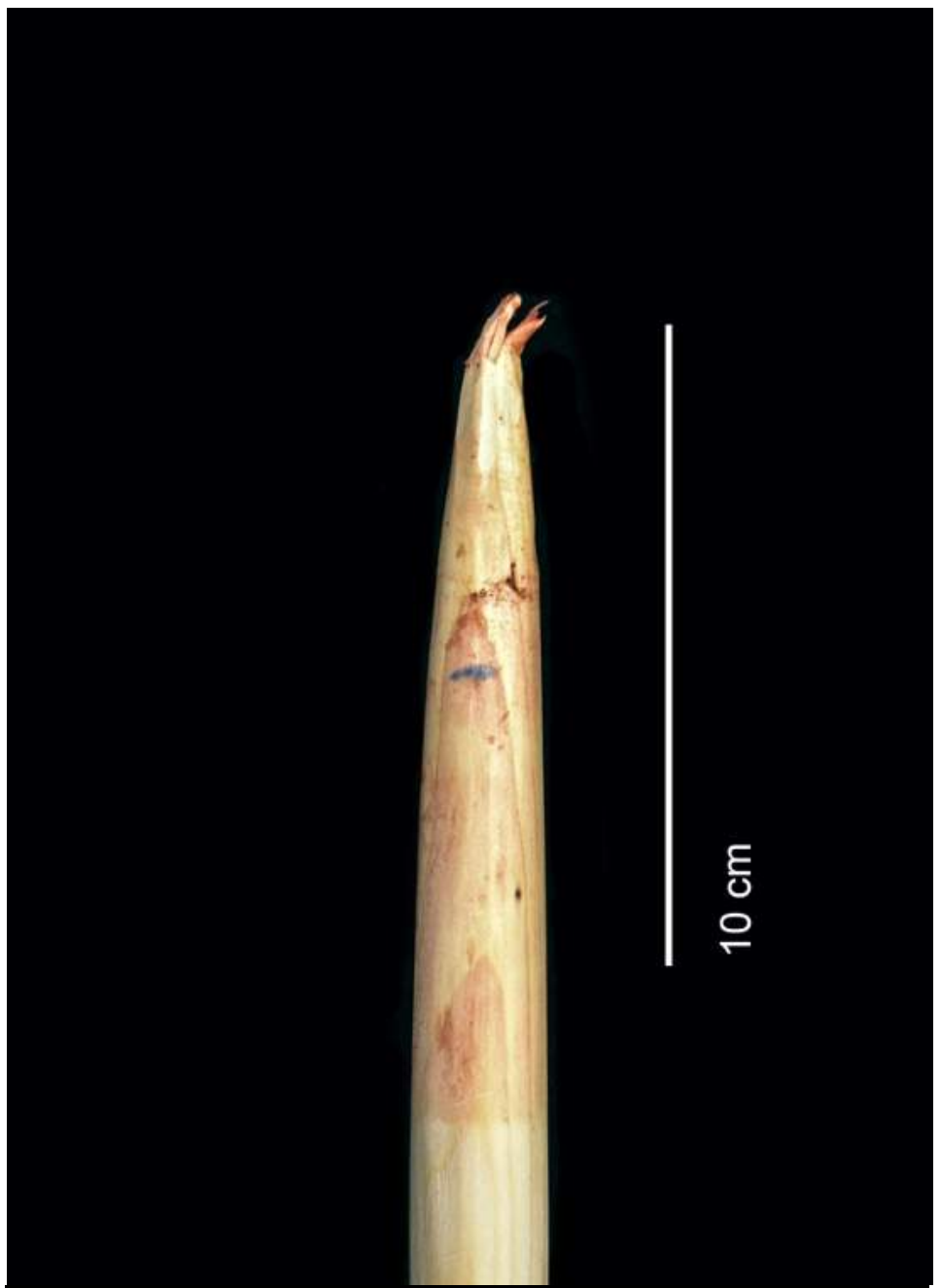

Figure 18. An example of Tip Split* from use of a spear to penetrate a carcass. Photo A. Milks. 